\title{
UNA REVISIÓN SOBRE LAS TIERRAS ABANDONADAS EN ESPAÑA: DE LOS PAISAJES LOCALES A LAS ESTRATEGIAS GLOBALES DE GESTIÓN
}

\author{
TEODORO LASANTA ${ }^{1 *}$, ESTELA NADAL-ROMERO ${ }^{1}$, \\ MAKKI KHORCHANI ${ }^{1}$, ASUNCIÓN ROMERO-DÍAZ ${ }^{2}$
}

\author{
${ }^{1}$ Instituto Pirenaico de Ecología (CSIC), Campus de Aula Dei, \\ Avda. Montañana, 1005, 50080 Zaragoza, España. \\ ${ }^{2}$ Departamento de Geografía, Facultad de Letras, Universidad de Murcia, \\ Campus de la Merced, 30001 Murcia, España.
}

\begin{abstract}
RESUMEN. Las tierras abandonadas ocupan espacios muy extensos en algunos territorios españoles, especialmente en las áreas de montaña y ambientes semiáridos. Originan paisajes muy diversos en función de las condiciones climáticas, el lugar y la edad de abandono, la gestión previa y posterior, y las perturbaciones que sufren durante el proceso post-abandono. Estos factores condicionan la sucesión vegetal y las propiedades edáficas, dando lugar a ecosistemas y paisajes tan contrastados como bosques, matorrales, pastizales y suelos casi desnudos. En este trabajo se revisan los conocimientos actuales sobre el abandono de tierras en España a partir de la bibliografía, con especial referencia al proceso espacio-temporal del abandono, los factores que originan diferentes ecosistemas y paisajes en las tierras abandonadas y las implicaciones de éstos en el suministro de servicios ecosistémicos a la sociedad. En función del paisaje generado y de su gestión dependen la cantidad y calidad de los recursos hídricos, la protección del suelo, el secuestro y stock de carbono, los niveles de biodiversidad, la prevención y control de incendios forestales, los recursos pastorales, la estética del paisaje e incluso las posibilidades de fijar población en el medio rural a partir de aprovechamientos extensivos.
\end{abstract}

\section{A review of abandoned lands in Spain: from local landscapes to global management strategies}

\begin{abstract}
Abandoned lands occupy extensive territories in some Spanish regions, particularly in mountain areas and semiarid environments. These lands originate very diverse landscapes depending on the climatic conditions, the age of abandonment, the management before and after abandonment, and the disturbances that they suffer during the post-abandoned process. These factors condition the plant succession and soil properties, producing contrasted ecosystems and landscapes, like forests, shrublands, grasslands and almost bare soils. This study reviews the current knowledge about land abandonment in Spain, with special reference to the spatial and temporal process of abandonment, the factors that originate different ecosystems, and landscapes in abandoned lands, and the implications of these factors in the provision of ecosystem services to society. Depending on the landscape generated and its management, different services would be provided, such as the quality and quantity of water resources, soil protection, carbon sequestration, levels of biodiversity, prevention and control of forest fires, pastoral resources, landscape aesthetics, and even the possibilities of securing population in the rural environment through extensive land uses.
\end{abstract}


Palabras clave: Sucesión vegetal, degradación del suelo, paisaje cultural, servicios ecosistémicos, montaña mediterránea, zonas semiáridas.

Key words: Plant succession, soil degradation, cultural landscape, ecosystem services, Mediterranean mountains, semiarid areas.

Recibido: 26 Junio 2020

Aceptado: 26 Agosto 2020

*Correspondencia: Teodoro Lasanta, Instituto Pirenaico de Ecología (IPE-CSIC), Campus de Aula Dei, Avda. Montañana, 1005, 50080 Zaragoza, España. E-mail: fm@ipe.csic.es

\section{Introducción}

El abandono de tierras es un fenómeno global, con especial incidencia en los países desarrollados (Strijker, 2005). Ramankutty y Foley (1999) calcularon que se han abandonado aproximadamente 1,5 millones de $\mathrm{Km}^{2}$ en el mundo entre 1700 y 1992, superficie que se ha incrementado considerablemente después y que continuará incrementándose en las próximas décadas (Pointereau et al., 2008), entre otras razones porque hay alrededor de 280 Mha destinadas a agricultura nómada o itinerante (shifting agriculture) que tarde o temprano serán progresivamente abandonadas (Heinimann et al., 2017). En Europa, según Feranec (2010) entre 1990 y 2000 se abandonaron $88.000 \mathrm{~km}^{2}$ y entre los años 2000 y 2012, Kuemmerle (2016) indica que el abandono fue de $20.500 \mathrm{~km}^{2}$. En España, en el año 2019, según el Fondo Español de Garantía Agraria (FEGA), las superficies abandonadas y sin aprovechamiento agrario se estiman en más de 2,32 Mha, lo que representa el 20\% de las superficies de cultivo o el $4,5 \%$ de la superficie agraria total.

$\mathrm{El}$ abandono de tierras constituye un proceso por el que los ecosistemas y paisajes modifican su capacidad para proporcionar bienes y servicios a la sociedad (Pereira et al., 2005; Kozak et al., 2017; García-Llamas et al., 2019). Sus causas son muy diversas y sus implicaciones ambientales, paisajísticas y socioeconómicas son múltiples (Keenleyside y Tucker, 2010; Lasanta-Martínez, 2014; Alonso-Sarria et al., 2016). Es, además, un proceso en el que interactúan simultáneamente factores biofísicos, socioeconómicos, tecnológicos, demográficos, políticos y culturales (Terres et al., 2015; Lasanta et al., 2017a; Huang et al., 2020). Por otro lado, es un tema que requiere cierta perspectiva temporal, ya que la evolución de las tierras abandonadas y su diversidad de respuestas dependen en buena parte del tiempo transcurrido desde el abandono, de las características biofísicas del lugar donde ocurre el abandono de tierras y de las perturbaciones sufridas (García-Ruiz y López Bermúdez, 2009). De ahí, que sea un tema complejo de estudiar, lo que ha impulsado su interés científico. En este sentido, basta señalar que una consulta a la base de datos Scopus el 2 de febrero de 2016, introduciendo las palabras clave más utilizadas por los autores: "land abandonment" y "abandoned agricultural", y tras cruzar los resultados y eliminar los documentos repetidos quedaron 1194 referencias bibliográficas sobre tierras abandonadas en el mundo (Romero Díaz, 2016). Y tres años después, el 1 de marzo de 2019, consultada la misma base de datos con las mismas palabras clave, el número de referencias había ascendido a 1638 (Lasanta et al., 2019a), de las que 309 (18,9\%) tenían como área de estudio España, siendo el segundo país con más referencias, sólo superado ligeramente por Estados Unidos, y muy por encima de los países que le siguen: Italia, Alemania y Francia (Lasanta et al., 2019a).

En España, al igual que en los países europeos de la cuenca mediterránea, las tierras abandonadas ocupan una extensa superficie, siendo uno de los grandes cambios de uso del suelo registrados desde las primeras décadas del siglo XX (García-Ruiz y Lana-Renault, 2011; García-Ruiz et al., 2011). Las áreas de montaña y los secanos semiáridos son los territorios con mayor abandono; se 
consideran tierras marginales, espacios de escasa relevancia económica, con poca capacidad para competir en mercados muy dinámicos y competitivos. Muchos gestores del territorio y científicos consideran que deben abandonarse $\mathrm{o}$, como mucho, explotarse de manera muy extensiva para favorecer la revegetación (Lasanta y García-Ruiz, 1996; Perino et al., 2019).

Las causas que dirigen el abandono de tierras son muy diversas y varios de los autores, que han tratado de estudiarlas, consideran que deben ser tratadas de forma integrada y a diferentes escalas (Alonso Sarria et al., 2016a). Lasanta et al. (2017a) señalan que las causas globales o externas actúan como desencadenantes del proceso de abandono, mientras que las causas locales o internas condicionan la superficie abandonada y las áreas donde se localiza el abandono. Haciendo un esfuerzo de síntesis se puede resumir que el abandono de tierras en España es debido a: (i) la migración de la población rural hacia las ciudades y el envejecimiento de la que permanece (Ruiz-Sinoga et al., 2011; Kosmas et al., 2002; Meléndez-Pastor et al., 2014); (ii) las innovaciones tecnológicas y la mecanización de las tareas agrícolas, lo que ha impulsado el abandono de muchas laderas muy pendientes, los campos de pequeño tamaño y aquellas áreas poco accesibles a la maquinaria agrícola (Lasanta Martínez, 1988a; Nagendra et al., 2003; Onega-López et al., 2010); (iii) la baja productividad de algunos campos, por escasa fertilidad o suelos con horizontes poco desarrollados o muy pedregosos (Duarte et al., 2008); (iv) la elevada competitividad de los mercados, lo que hace poco rentables algunos cultivos y algunas zonas rurales (García-Ruiz et al., 2015; Van Leeuwen et al., 2019); (v) los efectos de la Política Agrícola Común (PAC), que entre 1989 y 2008 incentivó el abandono de tierras agrícolas de forma permanente (land retirement) o temporal (set-aside) (Boellstorff y Benito, 2005; Corbelle-Rico et al., 2012; Lasanta Martínez, 2014); (vi) el clima en ambientes semiáridos (Gisbert et al., 2005; Alonso Sarria et al., 2016b), que reduce la productividad y aumenta la incertidumbre frente a la irregularidad de las lluvias; (vii) la existencia de ocupaciones alternativas (Kozak et al., 2004; Rey Benayas et al., 2007); y (viii) factores vinculados a la gestión, relacionados con un inadecuado manejo de las explotaciones agrarias, como la sobreexplotación y salinización del suelo y/o de los acuíferos (Vera y Romero, 1994; Tobarra González, 2002; Chocano Vañó et al., 2007; Pérez Morales, 2008), la fatiga del suelo debida a la reiteración de determinados cultivos hortícolas intensivos (Vera y Romero, 1994; Guerrero et al., 2014), la proliferación de problemas fitopatológicos específicos (Lucas Espadas, 1996), o el abandono de determinadas prácticas y estructuras tradicionales de conservación de suelos (Vera y Romero, 1994; Franco y Calatrava, 2010). Además, Lasanta et al. (2017a) inciden en que los factores biofísicos (suelo, clima, topografía...) intervienen siempre porque determinan la productividad y, en último término, la rentabilidad y competitividad del producto ofertado. En definitiva, las causas podrían resumirse en socioeconómicas, ambientales y de gestión.

La bibliografía sobre el abandono de tierras en España es muy abundante, debido no sólo a la gran extensión directamente implicada, sino también a su destacado impacto en el territorio y sus múltiples implicaciones socio-ecológicas, hasta tal punto que es uno de los factores más destacados del Cambio Global (Herrando et al., 2014). Por otro lado, hay que tener en cuenta que las tierras abandonadas constituyen una especie de laboratorio natural para los investigadores, por su presencia en un gradiente climático muy amplio, desde ambientes subdesérticos a subalpinos, por la diversidad de sistemas de gestión pre y post-abandono, y por las perturbaciones que sufren las tierras abandonadas, como pueden ser los incendios (Azevedo et al., 2011) o los procesos de erosión (García Ruíz y Lana Renault, 2011; Romero Díaz et al., 2016). Todo ello hace que la evolución de las tierras abandonadas sea muy heterogénea, con consecuencias muy variadas a escala local y en los servicios ecosistémicos que prestan a la sociedad.

Los estudios sobre el abandono de tierras en España se iniciaron, de manera sistemática, en los años ochenta del pasado siglo, centrándose sobre todo en la distribución espacial y temporal del proceso de abandono (Díaz-Muñoz, 1984; Alguacil García, 1985; Lasanta Martínez, 1988a; Arnáez et al., 1990; Lasanta Martínez et al., 1989) y en el comportamiento hidromorfológico de las tierras abandonadas (García-Ruiz et al., 1985 y 1988; García-Ruiz, 1986). Los estudios sobre la erosión del suelo en relación con la sucesión vegetal tuvieron un gran impulso en los años ochenta y noventa, realizándose varias 
tesis doctorales a finales de los años ochenta y en la década de los noventa (Lasanta Martínez, 1988; Ruiz-Flaño, 1993, Padilla-Blanco, 1998) y más recientemente en el siglo XXI (Oserín Elorza, 2007; Cañadas Sánchez, 2008; Martínez Hernández, 2018), así como numerosos artículos y comunicaciones a congresos (ver García-Ruiz y López-Bermúdez, 2009). Posteriormente, los temas de estudio se ampliaron considerablemente, como corresponde a una cuestión con implicaciones ambientales, paisajísticas y socioeconómicas.

En Europa, se han realizado diversas revisiones bibliográficas referentes al abandono de tierras, entre las que caben citarse las relacionadas con la dinámica y restauración de las tierras abandonadas (Bowen et al., 2007; Cramer, 2007) o sobre los impactos ambientales (MacDonald et al., 2000; Haddaway et al., 2014). Y en España también se han realizado excelentes revisiones bibliográficas sobre los impactos hidromorfológicos del abandono de tierras en España (Lasanta, 2006; García-Ruiz y LópezBermúdez, 2009; García-Ruiz, 2010; García-Ruiz y Lana-Renault, 2011; Cantón et al., 2011; Arnáez et al., 2015; van Leeuwen et al., 2019; Moreno-de-las-Heras et al., 2019), pero se echa en falta un estudio que incluya información sobre el proceso espacio-temporal del abandono, sus causas, los ecosistemas y paisajes resultantes y las implicaciones de éstos en el suministro de servicios ecosistémicos a la sociedad. En este trabajo se revisan los conocimientos acumulados sobre el abandono de tierras en España. Se intenta disponer de una perspectiva holística, necesaria para gestionar, con una base científica, un espacio tan extenso como el de las tierras abandonadas en España, por sus elevadas implicaciones en el desarrollo local de muchas áreas marginales y en el suministro de bienes y servicios a otros territorios.

\section{La extensión de las tierras abandonadas}

La bibliografía sobre la extensión de tierras abandonadas en España es relativamente escasa, al igual que en el resto del mundo (Ustaoglu y Collier, 2018), quizás porque cuantificar el proceso espaciotemporal del abandono exige trabajar con documentos gráficos: mapas de usos y cubiertas del suelo, fotografías, fotogramas aéreos, ortoimágenes, imágenes de satélite. Para justificar esta escasez de datos superficiales hay que tener en cuenta cuatro limitaciones importantes: (i) que tras el abandono se inicia un proceso de sucesión vegetal que borra las huellas de la fase de cultivo en un periodo más o menos rápido, lo que exige contar con documentos próximos a la fecha de abandono $\mathrm{o}$, al menos, previos a que la cubierta vegetal haya borrado los márgenes de los campos; (ii) que una secuencia temporal de documentos gráficos es una herramienta reciente; solo a partir de 1956 existen fotogramas aéreos, a los que se añaden más recientemente imágenes de satélite que permiten cartografiar todo el proceso de abandono; (iii) que se requiere un exhaustivo trabajo de fotointerpretación, cartográfico y de campo, que exige dedicar mucho tiempo para completar todo el proceso espacio-temporal de abandono; y (iv) que en el caso del abandono de áreas de pastoreo, como ha sucedido en el piso subalpino tras la crisis de la trashumancia, el proceso de abandono es siempre progresivo y sólo puede cartografiarse en función del avance del bosque, que puede ser en algunos casos muy antiguo. De ahí, que apenas existan estudios que abarquen una superficie superior a la del municipio (Lasanta et al., 2019a), con la excepción de las tesis doctorales de Lasanta-Martínez (1998), en la que estudió el proceso de abandono de siete valles del Pirineo aragonés, Oserín Elorza (2007), que analizó los campos abandonados del sector central de la montaña riojana, y Martínez Hernández (2018), en donde se evaluó el abandono reciente de toda la Región de Murcia (11.313 km² de superficie).

En los años ochenta y noventa se realizaron algunos estudios sobre áreas de montaña, coincidiendo todos ellos en señalar una drástica contracción del espacio cultivado (Lasanta, 1996). Los abandonos se iniciaron en las primeras décadas del siglo XX y experimentaron un repunte importante entre los años cincuenta y setenta, mientras que después de 1980 fueron muy pocos los campos que se abandonaron, porque los que habían resistido hasta ese momento lograron adaptarse al nuevo sistema socioeconómico. Así, por ejemplo, en el Pirineo las parcelas que se podían trabajar con tractor, que tradicionalmente se habían cultivado con cereales, se transformaron en prados de siega para la alimentación invernal de la ganadería (García-Ruiz y Lasanta-Martínez, 1990 y 1993). Algunos datos, 
aportados por la bibliografía, contribuyen a cuantificar la extensión de tierras abandonadas en zonas de montaña. Se abandonó, al menos, el 40\% de la tierra labrada en la Cabrera leonesa (Cabero, 1980), la mitad de los valles asturianos (Rodríguez-Gutiérrez, 1989), el 89\% de la vertiente sur de la Sierra de Ayllón (Bordiú, 1985), las tres cuartas partes del Alto Tormes (Barrientos, 1978), el 36\% de la Sierra de Ronda y el 25\% en la Planicie de Ronda (Gómez Moreno, 1989), el 71\% en los Valles Centrales del Pirineo (Lasanta-Martínez, 1988a), el 99\% en Cameros Viejo (Lasanta-Martínez et al., 1989), el 42\% en el Alto Linares, Sistema Ibérico (Maiso y Lasanta, 1990), el 40\% de la Sierra de Prades (Pérez Albert, 1995) y el 80\% en Valdesamario, montaña media leonesa (Cortizo et al., 1992). El abandono también fue extenso en las montañas del sur de España, sobre todo en las Cordilleras Béticas, pese a que todavía soportaban una presión demográfica relativamente elevada, manteniéndose el cultivo, sobre todo de almendros, en campos localizados en pendientes relativamente empinadas (Faulkner, 1995). Douglas et al. (1994) señalan que los campos abandonados ocupan el 70\% de las tierras de cultivo en las Alpujarras.

El abandono de tierras es, pues, un hecho generalizado en las montañas españolas, si bien a escala temporal y espacial se observan algunas diferencias interesantes. Dado que el primer documento que permite cuantificar la extensión del abandono es la fotografía aérea de 1956 diferenciamos dos etapas: antes y después de 1956, teniendo en cuenta que después de 1980 hubo pocos abandonos en la montaña española, como ya se ha señalado.

i) La primera fase de abandono (antes de 1956) se vincula con los factores físicos locales, abandonándose las parcelas con las peores condiciones: fuertes pendientes, suelos poco fértiles y pedregosos, y mayores limitaciones climáticas. Arnáez et al. (1990) señalan que en el Pirineo aragonés se había abandonado el 63\% del espacio agrícola antes de 1956, localizándose los campos abandonados en laderas con pendientes muy acusadas, importantes limitaciones climáticas y suelos poco fértiles. Así, por ejemplo, los campos de agricultura nómada ("articas") se habían abandonado masivamente (92,7\% de su superficie) antes de 1956 (Errea Abad et al., 2015). Por el contrario, en Cameros Viejo (Sistema Ibérico riojano), sólo se había abandonado el 30\% del área agrícola tradicional al contar con condiciones menos extremas y pendientes más suaves (Ruiz-Flaño et al., 2010).

ii) La segunda fase de abandono (después de 1956) tiene que ver con la capacidad de integración de cada región en la economía nacional. Las parcelas que se pueden mecanizar, ofrecen un producto competitivo y tienen buena accesibilidad al mercado se mantienen en cultivo, mientras que se abandonan las que no admiten la maquinaria agrícola, por excesiva pendiente o mal acceso, y las alejadas de las vías de comunicación. Siguiendo con la comparación entre el Pirineo Aragonés y Cameros Viejo, la primera región mantiene el 29\% de la superficie agrícola histórica, mientras la segunda solamente el $1 \%$. La existencia de valles glaciares, rellanos de obturación glaciar y conos de deyección en el Pirineo permite disponer de campos llanos o de suave pendiente que se cultivan con prados de siega, trabajados con tractor, orientados a la alimentación de la ganadería extensiva durante la estación fría. En Cameros Viejo, la ausencia de valles glaciares limita los espacios llanos y las pocas parcelas que podrían mecanizarse encuentran grandes limitaciones climáticas para el cultivo rentable de prados (Lasanta et al., 1989; Arnáez et al., 1990).

iii) Los bancales se abandonaron lentamente en la primera fase de abandono y masivamente después. En el valle de Aísa (Pirineo aragonés), por ejemplo, el 54,4\% de los campos en pendiente se había abandonado antes de 1956, mientras que la proporción de abandono era menor en los bancales $(39,9 \%)$, en gran parte debido a que los bancales poseían suelos más fértiles y productivos que los campos en pendiente (Errea Abad et al., 2015). Después de 1956, sin embargo, los bancales se han abandonado de forma masiva, por las dificultades que plantean para la mecanización, tendencia que también se ha puesto de manifiesto en otras montañas mediterráneas (Arnáez et al., 2015; Peña-Angulo et al., 2019), mientras que se mantienen los campos de suave pendiente (Errea Abad et al., 2015). 
El abandono de tierras en áreas de montaña fue, pues, muy importante antes de los años 80 . Los espacios llanos, por el contrario, resistieron bien con apenas abandono de tierras hasta los años ochenta, aunque la presión demográfica disminuyó mucho entre 1960 y 1980. La mecanización del campo, la puesta en regadío de muchas áreas y el uso de fertilizantes químicos contribuyó a mantener activas muchas explotaciones que arrendaron las tierras de las cesantes. En otros casos, la agricultura se mantuvo como una actividad complementaria o a tiempo parcial. Sin embargo, la Unión Europea, a través de la PAC, incentivó desde 1988 la extensificación de la producción (Reglamento CEE $\mathrm{n}^{\circ}$ 4115/88, modificado por el n⿳0708/92 y el n ${ }^{\circ} 838 / 93$ ), la retirada de tierras de cultivo (Norma Comunitaria $\mathrm{n}^{\mathrm{o}} 1034 / 88$, Reales Decretos 1435/88 y 1250/90, y Normativa CEE n ${ }^{\mathrm{o}} 1765 / 92$ ), y la jubilación anticipada (Reglamento CEE n ${ }^{\circ}$ 2079/92), entre otras normas y reglamentos que fueron estableciéndose hasta 2008 y que impulsaron el cese de explotaciones y el abandono de tierras. Esta última fase es un abandono inducido por agentes externos al medio rural (García-Ruiz y Lana-Renault, 2011; Lasanta et al., 2017a), que trató de reducir en primer lugar los excedentes agrícolas y, más secundariamente, favorecer la conservación de suelos y mejorar su balance hídrico (García-Ruiz y López Bermúdez, 2009).

Al igual que en las áreas de montaña, tan sólo existe información parcial y no actualizada de la superficie abandonada en tierras llanas. En España se dejaron de cultivar 995.599 ha (el 13,3\% de la superficie cerealista) entre 1989 y 1993, afectando fundamentalmente a las comarcas de secano cerealista y con explotaciones de elevado tamaño (Lasanta, 1996). En Aragón se realizó un estudio muy detallado, con información de todas las explotaciones, sobre la influencia de la PAC en el abandono de tierras (Land retirement y set-aside) comprobándose que entre 1988 y 1994 se vieron afectadas 182.374 ha (el $12,5 \%$ de la superficie cultivada con herbáceas), concentrándose los abandonos en los secanos semiáridos (Lasanta, 1996). El abandono de tierras también ha progresado recientemente en las zonas semiáridas del sureste de España y ambientes semiáridos del centro de la Depresión del Ebro, debido a la baja productividad de las tierras de secano y a problemas ligados con la salinización y degradación de suelos (Lesschen et al., 2007; Romero-Díaz et al., 2007; Fister y Ries, 2009; Alonso-Sarría et al., 2016a, entre otros). Por su parte, Arévalo et al. (2017) señalan que más del $90 \%$ de los campos en terrazas se han abandonado en la isla de Lanzarote en los últimos 40 años. Corbelle-Rico et al. (2012) ponen de relieve que los mayores abandonos en Galicia tienen lugar tras la incorporación de España a la Unión Europea, debido a los avances tecnológicos, que fueron un importante desencadenante para el abandono de pequeñas parcelas y el cese de explotaciones minifundistas, y a la PAC.

\section{Procesos de reconstrucción: edafogénesis y sucesión vegetal}

Cuando un campo se abandona se ponen en marcha de forma simultánea dos procesos interactivos de "reconstrucción" de las condiciones naturales previas a la fase de cultivo. La Figura 1 resume las dinámicas más frecuentes en campos abandonados en función de la situación de partida. Por un lado, se inicia un proceso de edafogénesis, que trata de mejorar las propiedades del suelo. Por otro lado, ocurre un proceso de sucesión secundaria que llevará al establecimiento de un bosque, en su estadio final si se cumplen todas las fases de la sucesión. Numerosos estudios revelan la estrecha relación que se establece entre sucesión vegetal y propiedades del suelo, constituyendo un tema muy complejo: Suelo y planta interactúan condicionando la competencia y/o facilitación entre plantas, así como la heterogeneidad edáfica incluso en terrenos aparentemente homogéneos (Cañadas et al., 2010). Además, la evolución de ambos procesos está muy condicionada por diferentes factores, entre los que destacan: la situación de partida del campo (características del suelo y especies vegetales y/o semillas presentes en el banco del propio campo o en sus proximidades), las condiciones climáticas y litológicas del lugar, la gestión post-abandono y las perturbaciones que puedan surgir a lo largo del tiempo. Por otro lado, del éxito o fracaso en la reconstrucción de las condiciones naturales depende en gran medida el paisaje resultante y los servicios ecosistémicos que las tierras abandonadas proporcionan a la sociedad. 


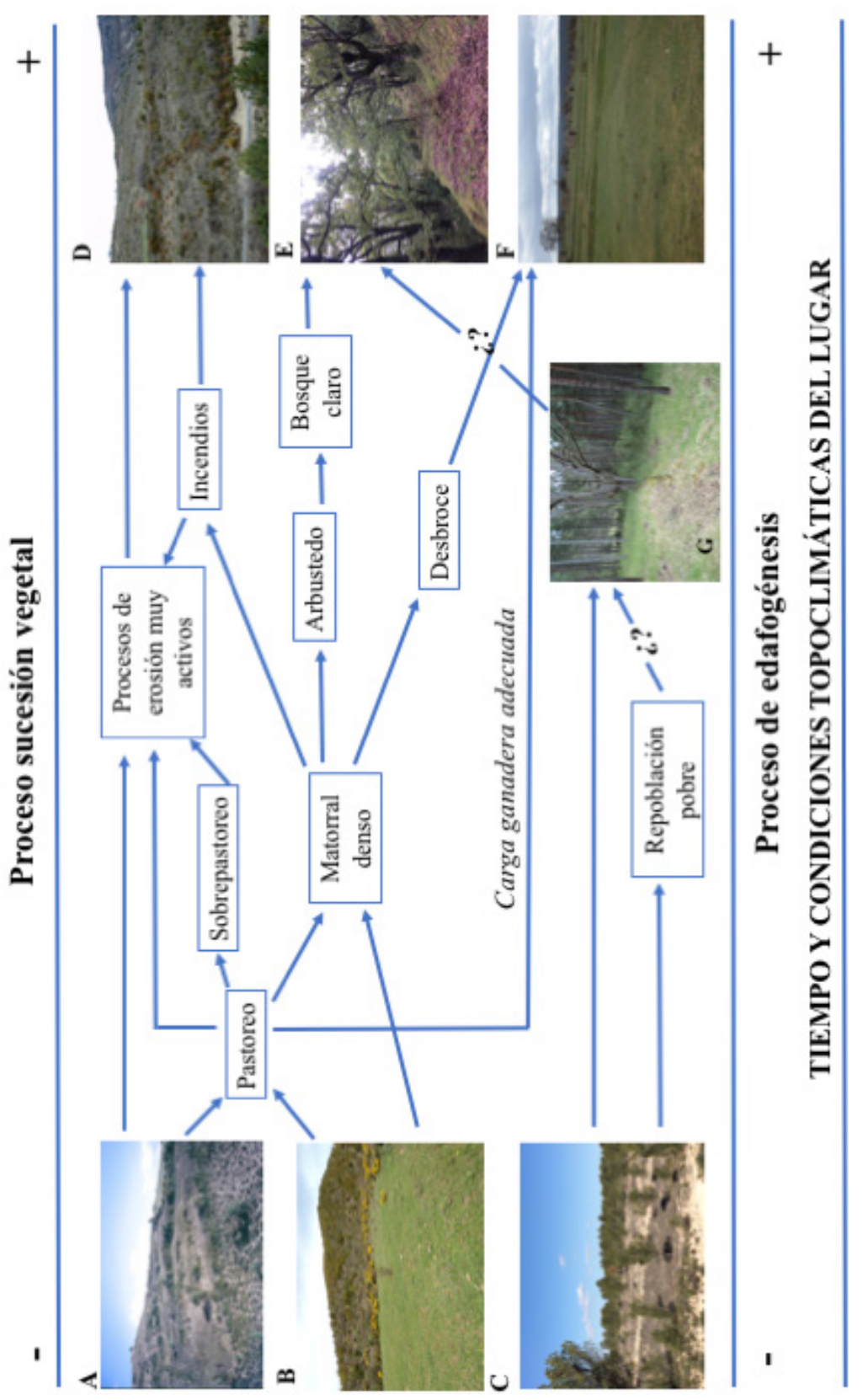

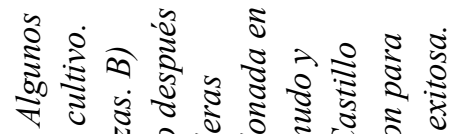

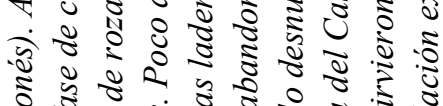

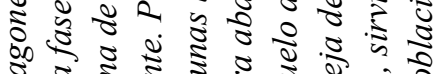

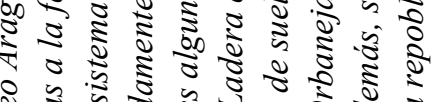

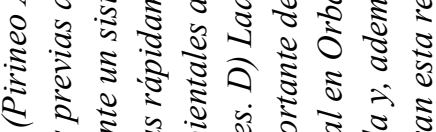

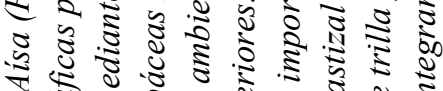

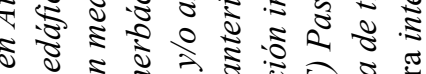

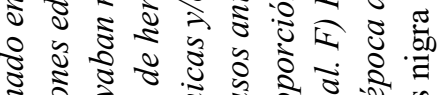

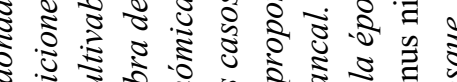

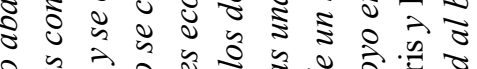

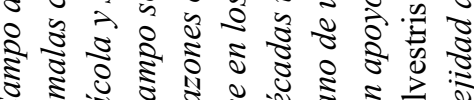

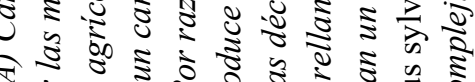

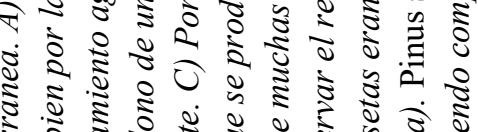

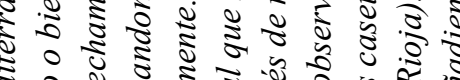

ช.

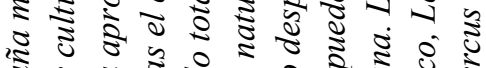

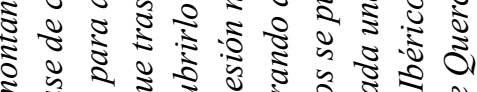

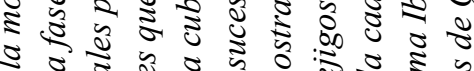

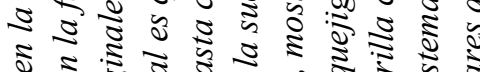

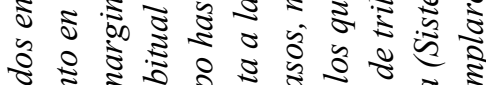

ठ ₹

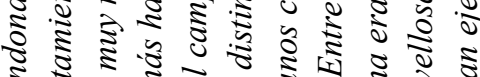

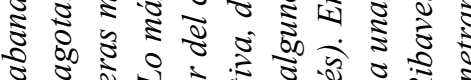

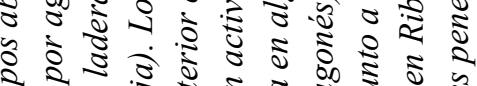

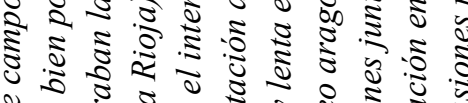

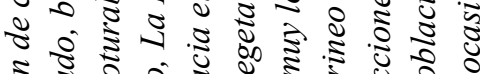

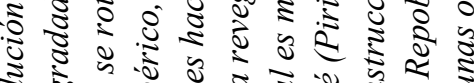

के

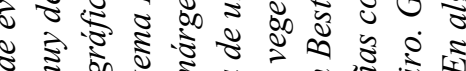

8 इ

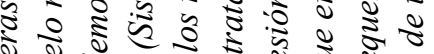

ปิ

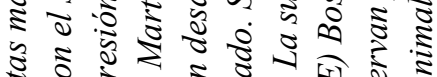

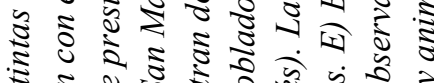

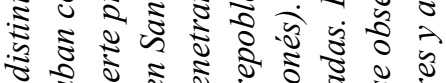

$\approx \approx 8 \%=80 \%$

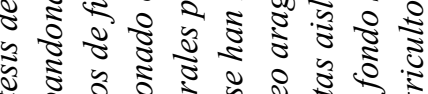

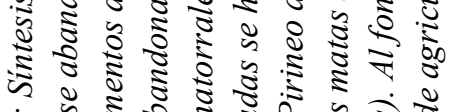

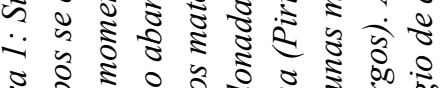

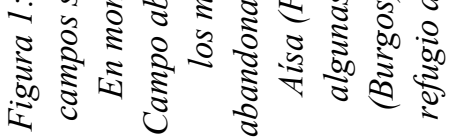


Tras el abandono de un campo agrícola se inicia un rápido proceso de sucesión secundaria o de colonización vegetal (Pugnaire et al., 2016). Inicialmente penetran las herbáceas que estaban presentes en la fase de cultivo como "malas hierbas" (especies arvenses) o bien en las proximidades del campo como ruderales. En muy pocos años (3-5 años), dependiendo de la fertilidad del suelo y de si las condiciones climáticas son favorables (humedad suficiente), el campo puede estar colonizado por una cubierta muy densa de herbáceas, formando pastizales con predominio de gramíneas y leguminosas (Lasanta et al., 2019b). Otro hecho que puede contribuir a una rápida colonización por herbáceas es la presencia de especies ruderales en el margen del campo. Pedroli et al. (2006) han comprobado la rápida colonización de bancales cuando el salto del bancal o lomo está cubierto de vegetación en la fase de cultivo. Contribuye, además, el mayor espesor y fertilidad del suelo en bancales que en campos en pendiente. Arévalo et al. (2017) señalan que los campos en terrazas de la isla de Lanzarote presentan una mejor calidad del suelo que los no aterrazados; además cuentan con suelos más profundos que les permite acumular más agua. Por otro lado, las terrazas favorecen la retención de agua contribuyendo a evitar el estrés hídrico (Bellin et al., 2009). Estudios llevados a cabo en el sureste de España (Zapata et al., 2016) han puesto de manifiesto la importancia que para la colonización vegetal de campos abandonados tiene la presencia cercana de áreas naturales y de especies endozoócoras que dispersen las semillas, y además han corroborado la idea anterior de que elementos internos que sirven de refugio (lindes, terrazas de piedra, setos...) pueden actuar como focos de colonización.

En esta fase inicial de la sucesión vegetal, el pastoreo del ganado es un factor esencial en la composición y ritmo de la sucesión vegetal. Condiciona las relaciones de colonización y extinción de especies a través del consumo, las perturbaciones mecánicas, la dispersión de semillas y la alteración de la fertilidad del suelo con la entrada de nutrientes por el estiércol (Peco et al., 2006). Si la carga ganadera es adecuada e incluso relativamente alta, los campos permanecen como pastizales durante décadas, retrasando el avance de la sucesión vegetal (Molinillo et al., 1997; Lasanta, 2010). Si se produce sobrepastoreo, la sucesión vegetal se interrumpe, el banco de semillas se empobrece, aparecen claros y el suelo se compacta. El pisoteo del ganado apelmaza la tierra y compacta el suelo, modificando algunas de sus propiedades físicas (disminución de la porosidad, ruptura de agregados), lo que implica una menor infiltración, y el incremento de la escorrentía superficial y de las tasas de erosión (Pérez y Díaz Fierros, 1988; Blanco Sepúlveda, 2008). Cuando no hay pastoreo o es muy leve, la sucesión vegetal suele ser muy rápida invadiendo los matorrales y arbustos los campos y pastizales en muy pocos años (Ferrer y Broca, 1999; Komac et al., 2013). García-Ruiz y Lana-Renault (2011) señalan que el pastoreo afecta al proceso de sucesión de distintas maneras. En unos casos retrasa la transición a la fase de matorral, al inhibir el crecimiento de los matorrales, mientras que en otros casos puede facilitar la colonización de los matorrales por el aporte de semillas con el estiércol, o por la competencia entre herbáceas. Lo expuesto aquí es una breve síntesis sobre la enorme complejidad de las interacciones entre pastoreo y sucesión vegetal (ver, por ejemplo, Chauchard et al., 2007 en un estudio en el sur de los Alpes franceses; y Lasanta, 2010 sobre la ganadería extensiva en áreas de montaña).

En un campo abandonado es muy frecuente que los matorrales penetren poco después del abandono, dando lugar a una segunda fase de la sucesión vegetal, caracterizada por el dominio de matorrales. En el proceso de sucesión se observa un patrón de colonización, en el que los matorrales van progresando desde los márgenes del campo, de forma que en la parte externa aparecen sucesivas orlas de matorrales y en el centro queda una cubierta de herbáceas. La penetración y la persistencia de una densa cubierta de matorrales depende de i) las condiciones locales (especies colonizadoras, fuentes de semillas próximas, topoclima); ii) de la actividad humana (frecuencia de incendios, desbroce de matorrales, pastoreo más o menos intenso) y iii) de la calidad del suelo (Dunjó, 2003; Arbelo et al., 2006; Lasanta et al., 2019a).

En suelos con fertilidad escasa penetran especies que tienen la capacidad de mejorar el suelo. En suelos pobres del Pirineo se ha comprobado que se introducen inicialmente especies fijadoras de nitrógeno (Genista scorpius y Echinospartum horridum, principalmente), lo que favorece la expansión de otros matorrales (Buxus sempervirens, Juniperus communis, Crataegus monogyna, Prunus spinosa, 
Rosa sp.), que continúan con el proceso de sucesión (Molinillo et al., 1997). El ritmo temporal de la sucesión puede estar muy influido por la proximidad o lejanía de semillas, así como por los vectores animales que las transportan (Martínez-López et al., 2019). La presencia de especies ruderales próximas al campo abandonado es un factor esencial para que el proceso de sucesión vegetal sea rápido (Pedroli et al., 2006). Para Pugnaire et al. (2006) la colonización vegetal en condiciones ambientales semiáridas es controlada por la dispersión de semillas y la variabilidad climática, que genera eventos de reclutamiento temporalmente separados. Escribano-Ávila et al. (2016) señalan que la dispersión de semillas por diferentes especies animales está modulada por la heterogeneidad ambiental y la estructura del ecosistema. Comprobaron que los zorzales (Turdus spp), el zorro rojo (Vulpes vulpes) y la garduña (Martes foina) dispersan una gran cantidad de semillas, mientras que los conejos (Oryctolagus cuniculus) y las ovejas, muy pocas. López-Bao et al. (2015) comprobaron la efectividad del zorro rojo en la dispersión de semillas a larga distancia, aumentando la conectividad entre las poblaciones de plantas, lo que favorece la colonización e impulsa el proceso de sucesión vegetal. Fedriani et al. (2017) estudiaron cómo la plantación de árboles frutales podría contribuir a estimular la dispersión de semillas por los animales, y con ello acelerar la restauración de tierras abandonadas. Comprobaron que plantar árboles de forma masiva (alta densidad de árboles) es menos eficiente que plantarlos de forma regular o aleatoria. Gómez-Aparicio et al. (2004) comprobaron en el sureste de España que a partir de arbustos pioneros se puede generar un bosque. Por otro lado, la presencia de árboles y arbustos en los campos abandonados puede facilitar la colonización vegetal, tanto indirectamente, actuando como "perchas" donde los pájaros reposan y aportan semillas al suelo (bien por regurgitación, bien por defecación), como directamente, mejorando las condiciones microambientales bajo planta (mayor humedad, menor estrés y mejor regulación hídrica, mayor porosidad del suelo), lo que favorece la germinación de semillas (Verdú y García-Fayos, 1996 y 1998; Puigdefábregas, 2005).

Las condiciones microtopográficas pueden resultar un factor esencial en el ritmo de la sucesión vegetal. Incluso en campos aparentemente homogéneos hay microhábitats relacionados con la topografía, el microclima, las condiciones edáficas y la redistribución de nutrientes por la fauna y flora (Cañadas et al., 2010). Además, la heterogeneidad del suelo es un elemento básico para las interacciones (competencia o facilitación) entre plantas, especialmente en ambientes con estrés hídrico, condicionando los patrones de distribución de plantas y comunidades (Cañadas et al., 2010). Rey-Benayas et al. (2005) comprobaron que el éxito de las plántulas de Quercus requiere un entorno poco competitivo de malas hierbas durante el periodo anterior a la primera estación seca. Una vez que las plántulas se establecen, un ambiente sombreado les resulta muy beneficioso.

Por otro lado, la recuperación edáfica y vegetal tras el abandono conduce a una mayor heterogeneidad a pequeña escala (especialmente en ambientes subhúmedos y semiáridos), ya que no todas las áreas siguen el mismo ritmo, generándose patrones en los que las áreas con vegetación cada vez tienen mejor suelo (Ruiz-Sinoga et al., 2011). En la media montaña mediterránea se ha observado que las laderas solanas presentan mayor estrés hídrico que las umbrías, ralentizando el proceso de colonización (Vicente-Serrano et al., 2005). Por otro lado, los procesos de erosión son más frecuentes e intensos en las laderas solanas, como se comprobó en el Pirineo Central, lo que constituye un factor muy limitante para la recuperación vegetal (Ruiz Flaño, 1993). Shakesby (2011) atribuye la mayor erosión en las laderas solanas a la mayor frecuencia de incendios, a una recuperación de la vegetación más lenta y a una mayor propensión de estas laderas a la erosión por la menor estabilidad de los agregados. Poyatos et al. (2003) comprobaron en el Pirineo catalán que las terrazas localizadas en laderas umbrías y las que tenían más pendiente se forestaban antes.

En la fase de matorrales es frecuente que la sucesión vegetal quede interrumpida, destacando como causas los incendios forestales y la eliminación de matorrales mediante quemas prescritas y desbroce. La acumulación de combustible, como consecuencia de la recolonización vegetal tras el abandono de tierras, favorece la frecuencia de incendios (Pausas, 1999; Duguy et al., 2007; Pausas \& Fernández-Muñoz, 2014; Moreno et al., 2014). Por otro lado, el fuego impulsa la homogeneización del paisaje, creando una retroalimentación positiva en la propagación de nuevos incendios (Loepfe et al., 
2010). Las zonas afectadas ven truncado el proceso de sucesión, retrasando la recuperación de la cubierta vegetal y que ésta presente menos riqueza y cobertura, debido a que las especies germinadoras se adaptan mejor que las rebrotadoras (Gallego Fernández et al., 2004). Los incendios tienen otras consecuencias, como el incremento de las tasas de erosión y la pérdida de fertilidad del suelo (Cerdá y Lasanta, 2005), lo que ralentiza la colonización vegetal y favorece la invasión de especies adaptadas al fuego. Con ello se inducen procesos de retroalimentación que conducen a cambios profundos en los ecosistemas y paisajes (Grigulis et al., 2005). El fuego puede generar distintos microambientes en un mismo campo. En este sentido, Cammeraat et al. (1999) comprobaron que en los lugares donde se produce concentración de cenizas y mantillo la vegetación arbustiva rebrota o germina posteriormente, mientras que en otras zonas se instalan procesos de erosión que degradan el suelo y limitan mucho la colonización vegetal.

En otras ocasiones, las políticas de gestión impulsan la eliminación de matorrales para evitar la acumulación de combustible y favorecer la regeneración de pastos, utilizando métodos como las quemas prescritas o controladas y el desbroce con medios mecánicos (Komac et al., 2013; Lasanta et al., 2015). La combinación de pastoreo y eliminación recurrente de matorrales truncan la sucesión vegetal, de manera que los campos no pasan de la fase inicial de dominio de las herbáceas (García-Ruiz y LanaRenault, 2011; Lasanta et al., 2019b).

La calidad del suelo es un factor esencial en el ritmo temporal de la sucesión vegetal. Esta es rápida en suelos profundos y ricos en materia orgánica. En suelos fértiles, sin estrés hídrico y con un bosque próximo al campo abandonado, se puede alcanzar un bosque joven en 2-3 décadas. Ello ha ocurrido en zonas de clima atlántico y en laderas del Pirineo (García-Ruiz y Lana-Renault, 2011; RubioBalducci, 2019).

Por lo general, la sucesión vegetal en tierras agrícolas abandonadas mejora la calidad del suelo. En campos abandonados del Sureste español, con suelos relativamente buenos de substrato calizo, se comprobó que en un corto periodo de tiempo (4-10 años) se produce un aumento significativo en el contenido de materia orgánica, en la estabilidad de agregados, la permeabilidad y la capacidad de retención de agua (López-Bermúdez et al., 1996). En un estudio comparativo de efectos del abandono en las provincias de Valencia, Murcia y Málaga (Romero Díaz et al., 2017) se puso de manifiesto que la recuperación de la vegetación contribuyó a la mejora en la calidad del suelo desde el punto de vista hidrológico, edafológico y geomorfológico. En el Maestrazgo de Castellón se observó que el abandono de tierras mejoraba el contenido de materia orgánica del suelo y la estabilidad de los agregados, con un notable incremento de su tamaño (Ruecker et al., 1988). Por su parte, Nadal et al. (2009) también observaron el incremento de la fertilidad del suelo a medida que la cubierta vegetal progresaba. Estos autores señalan que no es un proceso lineal, sino que está muy condicionado por la topografía y la fertilidad previa al abandono, así como por la gestión posterior al abandono, sobre todo por perturbaciones como el fuego. No obstante, debe tenerse también en cuenta que si los campos contaban con una adecuada estructura y contenido en nutrientes cuando se dejaron de cultivar, el abandono puede suponer inicialmente una disminución en los niveles de fertilidad, necesitándose más de 50 años para recuperar la correspondiente a la etapa agrícola. Nadal-Romero et al. (2016a) estudiaron en el Pirineo cómo evolucionan las propiedades y calidad del suelo en campos abandonados con gestión pasiva (matorrales de sucesión vegetal) y activa (reforestación con pinos). Sus resultados muestran que las propiedades del suelo evolucionan lentamente en ambos casos, a pesar de ser un clima mediterráneo subhúmedo, y que la reforestación no aceleró la recuperación de las propiedades y calidad del suelo respecto a la sucesión vegetal.

Sin embargo, una cubierta de matorrales puede permanecer durante muchas décadas en campos con suelos mal estructurados o afectados por procesos de erosión severos, aunque la precipitación sea suficiente para el desarrollo forestal y haya árboles próximos. Pueyo y Beguería (2007) comprobaron que en la media montaña mediterránea se produce un decaimiento en las tasas de sucesión vegetal, una vez que los mejores campos han sido colonizados. Lo más habitual es que los campos posean suelos de 
baja calidad cuando se abandonan, como consecuencia del agotamiento de la fertilidad en su fase de cultivo. En el Pirineo central se ha comprobado que los campos cultivados mediante un sistema de rozas (articas) tienen enormes dificultades para que progrese la vegetación, debido al agotamiento del suelo en la fase de cultivo. En estas condiciones los campos se mantienen durante décadas (más de 80 años) con muchas áreas de suelo desnudo, abundante pedregosidad y algunas matas aisladas de matorral (Lasanta et al., 2017b). Casalmiglia et al. (2017) señalan que los suelos de terrazas recientemente abandonadas poseen bajo contenido en materia orgánica y baja masa microbiana como herencia de su pasado agrícola. La calidad del suelo evoluciona en función de la relación que se establece tras el abandono entre sucesión vegetal y degradación del suelo (Lasanta et al., 2019a). Si domina el proceso de sucesión vegetal, la calidad del suelo mejora con el incremento del contenido de materia orgánica y la biomasa microbiana, la disminución de la densidad aparente y una mayor estabilidad de agregados, lo que favorece mayores tasas de infiltración y de humedad del suelo (Bautista Cruz et al., 2007; Lasanta et al., 2005; Lesschen et al., 2008a; Zornoza et al., 2009). Con estas condiciones, los procesos de erosión superficial (erosión laminar y rills) encuentran más dificultades para instalarse (Cerdà, 1996; Lasanta et al., 2001; Cantón et al., 2011), si bien las raíces pueden favorecer la acumulación de agua en el suelo e incrementar los movimientos en masa (Cammeraat et al., 2005). Si, por el contrario, la vegetación no penetra en el campo abandonado o avanza muy lentamente se instalan procesos de erosión muy activos, con la consiguiente pérdida de calidad del suelo (Pardini y Gispert, 2006; Romero Díaz et al., 2007).

La recuperación de la productividad del suelo y el progreso de la sucesión vegetal tienen mucho que ver, además, con las condiciones climáticas (Otto et al., 2006). En un clima húmedo o subhúmedo la sucesión vegetal es rápida, alcanzándose una cubierta de bosque joven en 30-40 años (Pardini et al., 1991; Lasanta et al., 2015; Peña-Angulo et al., 2019), mientras que en ambientes áridos y semiáridos es muy lenta, con un cubrimiento que con frecuencia no alcanza el $60 \%$ en campos de elevada edad de abandono (Ries et al., 2000; Lesschen et al., 2008a; Ruiz-Sinoga y Martínez-Murillo, 2009), y donde difícilmente se alcanza el estadio de bosque joven (Bonet y Pausas, 2004; Rey Benayas et al., 2015). Otra diferencia interesante entre áreas con diferentes condiciones climáticas es que en campos sin estrés hídrico la sucesión vegetal progresa de forma uniforme, mientras que en los que sufren estrés hídrico se desarrollan patrones de vegetación donde alternan manchas con cubierta vegetal y otras de suelo desnudo (Cammeraat y Imeson, 1999; Puigdefábregas, 2005). Allí donde los suelos tienen mayor capacidad de infiltración la vegetación progresa, estableciéndose una retroalimentación positiva entre agua y vegetación, ya que debajo de las plantas se incrementa la materia orgánica, la agregación y porosidad del suelo, lo que favorece mayores tasas de infiltración (Bergkamp et al., 1996; Cammeraat y Imeson, 1999). Por el contrario, en las áreas con suelo desnudo el suelo se compacta, las costras superficiales aumentan y la infiltración disminuye (Lesschen et al., 2007, 2008a; Moret et al., 2011), generándose una retroalimentación negativa entre la ausencia de vegetación, la disminución de la infiltración, el incremento de la escorrentía superficial y la degradación del suelo por erosión (Molinillo et al., 1997; Nadal et al., 2009). En el sureste español se ha comprobado que algunas plantas (Stipa tenacissima y Artemisia herba-alba) favorecen la infiltración del agua a través de sus raíces para reducir la evaporación y asegurar el mantenimiento de la cubierta vegetal, lo que contribuye a mejorar la calidad del suelo (Cammeraat et al., 2010). Otro aspecto a considerar, de gran importancia en medios semiáridos, es el papel que ejerce la litología. En la región de Murcia se ha estudiado el abandono en diferentes litologías y se ha comprobado una ralentización de los procesos de colonización en sustratos poco coherentes (como pueden ser las margas) y en condiciones climáticas más secas (piso Termomediterráneo), aunque es de mencionar que en estos ambientes las comunidades de flora y fauna existentes, por su singularidad, tienen un interés especial (Zapata et al., 2016).

La influencia de la fertilidad del suelo en la colonización vegetal se ha demostrado de manera empírica en ambientes semiáridos. En las proximidades de Zaragoza, tanto el añadido de abono orgánico (estiércol de oveja) como inorgánico (abono químico con $15 \%$ de $\mathrm{N}, 15 \%$ de $\mathrm{P}$ y $15 \%$ de $\mathrm{K}$ ) produjo una colonización vegetal más densa (cobertura entre el 75-80\%) que en las parcelas en las que no se añadió fertilizante (cubertura aproximada del 40\%) (Lasanta et al., 2000). En la Estación Experimental 
del Teuralet (Sierra de Enguera, este de España) el añadido de paja de avena contribuyó a incrementar el carbono orgánico en el suelo, la biomasa microbiana y la actividad y abundancia de hongos, mejorando la estructura del suelo (García-Orenes et al., 2012) y disminuyendo las tasas de erosión (García-Orenes et al., 2013). La importancia de la fertilidad del suelo en el proceso de colonización sugiere que la precipitación media no es el principal limitante para el desarrollo de la cubierta vegetal en medios semiáridos, sino que posiblemente el nivel de nutrientes puede ejercer mayor control en el crecimiento de la cubierta vegetal que la escasez de agua (Lasanta et al., 2000).

\section{El paisaje de campos abandonados y el suministro de servicios ecosistémicos.}

La mayoría de los estudios sobre el paisaje tradicional del medio rural español, aunque especialmente de las áreas de montaña, concluyen que era un paisaje que mostraba cierta complejidad de usos y cubiertas del suelo, con un alto grado de fragmentación y heterogeneidad, que dibujaba un paisaje en mosaico con alternancia de usos en manchas de pequeño tamaño, unidas por corredores ecológicos (Puigdefábregas y Fillat, 1986; Nogués-Bravo, 2006, entre otros). Los cambios de uso del suelo, marcados sobre todo por el abandono de tierras y la sucesión vegetal, muestran una leve simplificación del patrón tradicional, ya que el paisaje conserva un grado de complejidad bastante elevado, como herencia de su pasado con fuerte presencia de actividades humanas. No obstante, tras el abandono agrícola el paisaje pierde coherencia y heterogeneidad, caminando hacia un paisaje más simplificado, desfragmentado y muy homogéneo, donde las manchas son de tamaño mayor que en el paisaje tradicional y menor la diversidad de usos y cubiertas del suelo (Lasanta et al., 2005; Vilà Subirós et al., 2009; Arnáez et al., 2011; Heredia et al., 2013).

Estos cambios de paisaje tienen enormes implicaciones en el suministro de servicios ecosistémicos a la sociedad (Morán-Ordoñez et al., 2013; García-Llamas et al., 2019; van Leeuween et al., 2019). De ahí, que la gestión de las tierras abandonadas sea una cuestión crucial, mucho más en España, por la amplia extensión que ocupan, especialmente en áreas de montaña y ambientes semiáridos. La gestión condiciona la cantidad y calidad de los recursos hídricos, la protección del suelo, el secuestro y stock de carbono, los niveles de biodiversidad, la prevención de riesgos (incendios principalmente), los recursos pastorales y con ello el mantenimiento de la ganadería extensiva, la estética del paisaje y la actividad turística (Conti y Fagarazzi, 2004; Bernués et al., 2014; Lasanta, 2019).

El mundo científico y los gestores del territorio se debaten entre dos posturas: no intervenir en las tierras abandonadas (gestión pasiva o rewilding) o realizar una intervención activa para su restauración ecológica y reincorporación al sistema productivo (Conti y Fagarazzi, 2005; Lasanta et al., 2015). El rewilding es el proceso que permite pasivamente la invasión leñosa (sucesión secundaria) y, según sus partidarios, la reintroducción de grandes mamíferos con el fin de mejorar la biodiversidad y restaurar los paisajes originales después de siglos de actividad humana (Navarro y Pereira, 2012; Pettorelli et al., 2017). Otros científicos, por el contrario, se inclinan por una intervención moderada en el territorio, con el fin de crear un paisaje en mosaico, más parecido al paisaje tradicional o cultural, donde en el territorio se distribuían en alternancia bosques, matorrales y pastos. Se trata de restaurar ecosistemas y paisajes degradados con apoyo del desbroce de matorrales y la ganadería extensiva (Bauer et al., 2009; Regos et al., 2016; García-Ruiz et al., 2020), con el fin de impulsar el desarrollo local y mantener algunos de los muchos servicios ecosistémicos que aportaban los paisajes tradicionales (Kozak et al., 2017). La Figura 2 esquematiza los efectos de los paisajes dominantes en tierras abandonadas en los principales servicios ecosistémicos. 


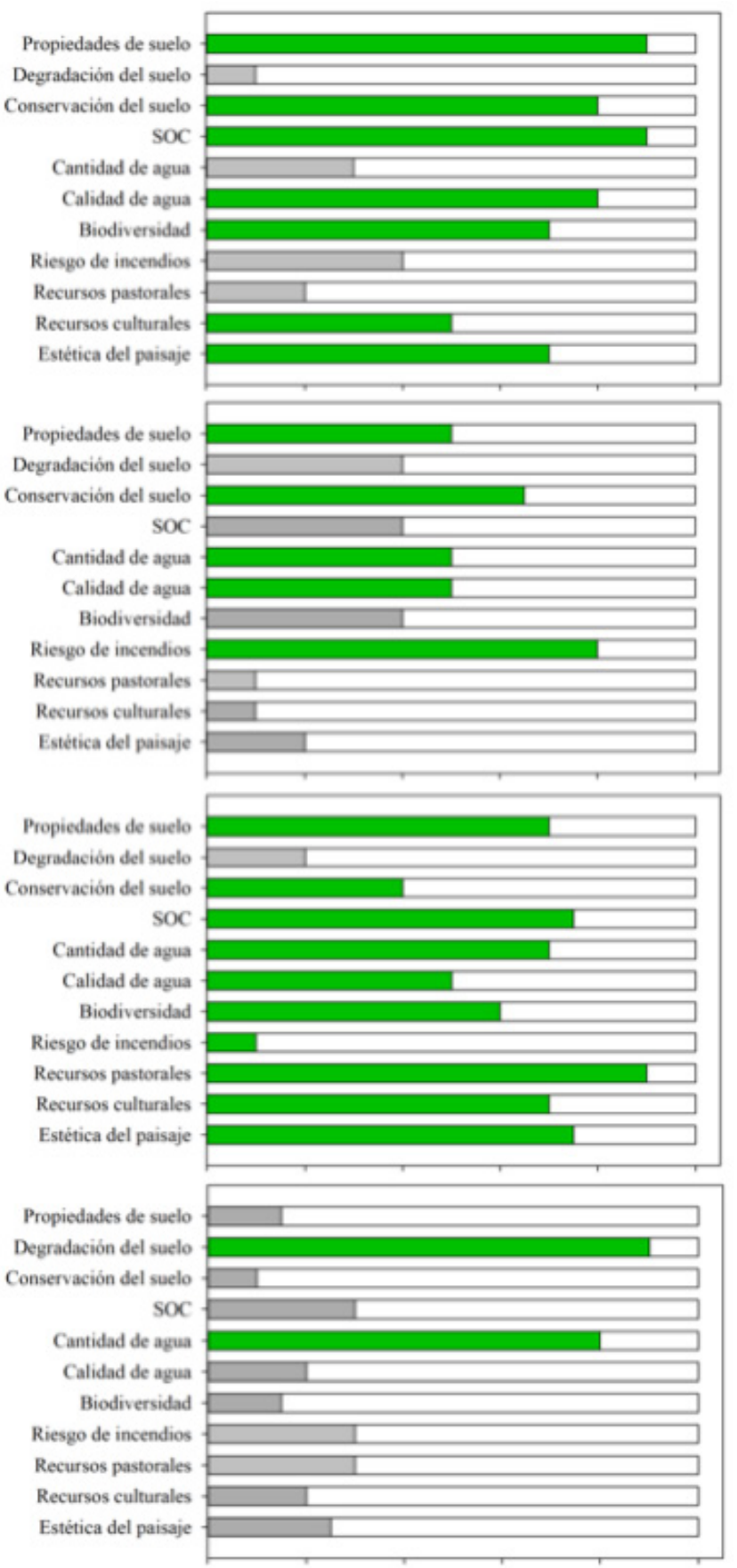

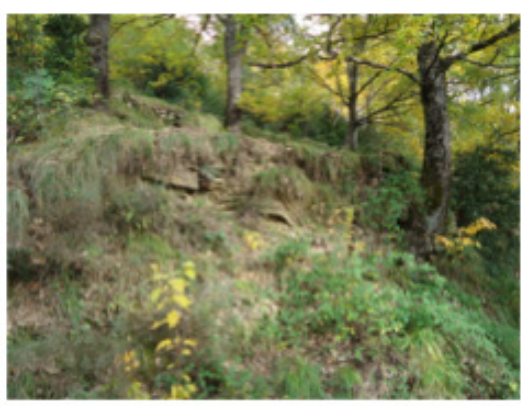

A. BOSQUE

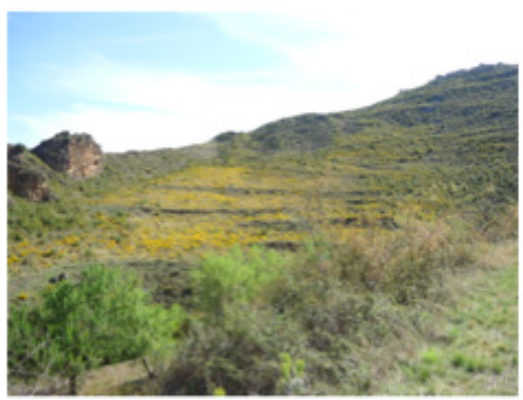

B. MATORRAL

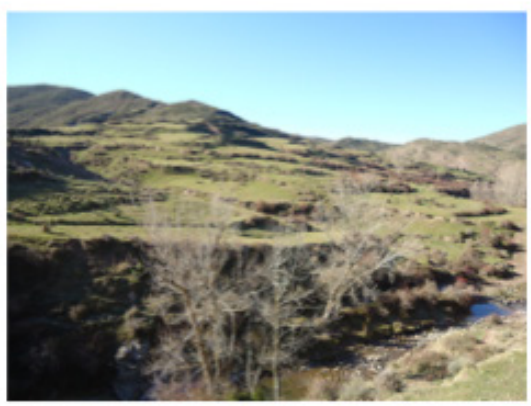

\section{PASTO MADURO}

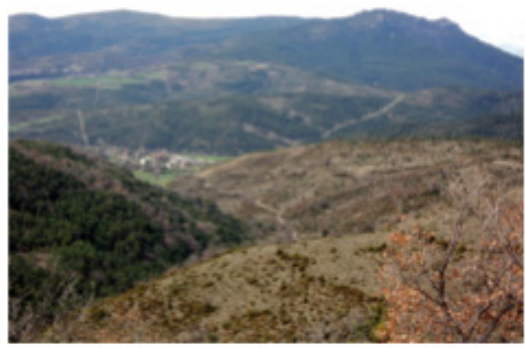

D. SUELO DESNUDO

Figura 2. Servicios ecosistémicos suministrados por los paisajes dominantes de campos abandonados. Foto A. Bosque de quejigos en bancales abandonados en Bestué (Pirineo Central). Los bancales se cultivaron con cereales hasta los años setenta del siglo XX. El proceso de revegetación ha sido muy rápido por la buena fertilidad del suelo y la presencia de ejemplares de Quercus faginea en los lomos del bancal. Foto B. Aliagas en una ladera abandonada en Jubera (Sistema Ibérico, La Rioja). Los campos se cultivaron con cereales hasta los años sesenta del siglo XX. Genista scorpius es el matorral dominante en las primeras fases de la sucesión vegetal en suelos básicos. Entre los 25 y 60 años aproximadamente presenta un cubrimiento muy denso, dejando paso después a otros matorrales y arbustos más exigentes en calidad del suelo. Foto $\boldsymbol{C}$. Ladera de pastos en Vadillos (Sistema Ibérico, La Rioja). La ladera se cultivó hasta los años setenta del siglo XX. El pastoreo continuado con distintas especies ganaderas ha generado un pasto denso, diverso y elevado valor pastoral. Foto D. Ladera de campos abandonados en Aisa (Pirineo Aragonés). Estos campos se cultivaron mediante el sistema de rozas (denominado artigueo en el Pirineo). Desde hace más de 80 años los campos se dejaron de cultivar, pero la sucesión vegetal apenas ha avanzado como consecuencia del agotamiento del suelo en la fase de cultivo y la instalación de procesos de erosión que aún continúan activos. 


\subsection{Servicios de aprovisionamiento}

Los campos abandonados tienen un elevado potencial para suministrar a la sociedad algunos servicios esenciales como agua y pastos.

\subsubsection{El suministro de agua}

La cubierta vegetal es un factor esencial en la regulación de los recursos hídricos (cantidad y calidad), mucho más en un escenario de precipitaciones irregulares e incremento de las temperaturas (García-Ruiz et al., 2011; Otero et al., 2011). En ambientes mediterráneos, donde el agua es más bien escasa, la gestión de las tierras abandonadas es fundamental para asegurar su abastecimiento. Hay que tener en cuenta que es en las montañas donde se generan la mayor parte de los recursos hídricos, actuando como islotes de humedad rodeados de tierras subhúmedas y semiáridas (Viviroli et al., 2003; García-Ruiz et al., 2011). En España existe abundante bibliografía sobre esta cuestión, coincidiendo en que la expansión superficial de la vegetación y el incremento de su densidad disminuyen los recursos hídricos (Gallart y Llorens, 2004; Cantón et al., 2011; García-Ruiz et al., 2011, entre otros). Un estudio de Gallart y Llorens (2002) sobre la evolución de la cubierta vegetal en España en las últimas décadas y sus efectos en los recursos hídricos pone de manifiesto un notable incremento de la primera y una disminución significativa de la aportación anual de los principales ríos. Beguería et al. (2003) analizaron la evolución de los caudales de varios ríos pirenaicos entre los años 1945 y 1995; observaron una disminución de los caudales en ríos no alterados por extracciones de agua, lo que explican por el aumento de la cubierta vegetal debido al abandono de tierras desde mediados del siglo XX. MoránTejeda et al. (2010) estudiaron la evolución hidrológica de las cuencas de cabecera del Duero observando una tendencia negativa generalizada en la escorrentía anual, debido a las pérdidas en el flujo de invierno y primavera. López-Moreno et al. (2011) estudiaron las tendencias climáticas e hidrológicas en 88 subcuencas de la cuenca del Ebro durante el periodo 1950-2006. Los resultados mostraron la disminución de los caudales en la mayoría de las subcuencas, que se atribuye a la combinación entre cambio climático y revegetación por el abandono de tierras, con el consiguiente incremento de la evapotranspiración.

La expansión de la cubierta vegetal, tras el abandono de la tierra, tiene una influencia directa en el ciclo hidrológico, condicionando la interceptación, infiltración, generación de escorrentía y conectividad de las laderas con los arroyos. La cubierta forestal, especialmente la arbórea y, en menor medida, la de matorrales, ejerce un papel amortiguador que, a través de los procesos de partición de la lluvia, reduce de forma considerable la cantidad de precipitación que llega al suelo (Belmonte Serrato y Romero Díaz, 1999). Además, modifica positivamente determinadas propiedades del suelo como la estructura y el contenido de materia orgánica, lo que favorece el incremento de la porosidad del suelo, el desarrollo de macroporos y la infiltración (Martínez-Fernández et al., 1995).

El primer efecto hidrológico de la cubierta vegetal es determinar la cantidad de agua de lluvia que no llega al suelo (interceptación neta). Esta puede ser muy elevada en función de la especie arbórea y de la época del año, con independencia de la intensidad y duración de las precipitaciones (GarcíaOrtiz, 2006). En bosques jóvenes de los Pirineos orientales, surgidos a partir de la colonización en campos abandonados, la interceptación representó aproximadamente el $24 \%$ de la precipitación anual (Llorens et al., 1997a). En áreas cubiertas por Pinus sylvestris, la interceptación puede variar entre el 8 y 48\% de la precipitación registrada, según se ha observado en distintas regiones españolas (Alvera, 1976 y 1977; Santa Regina, 1995; Tarazona et al., 1996; Llorens et al., 1997). En la cuenca de San Salvador (Valle de Aísa, Pirineo aragonés) los valores de interceptación fueron del 22\% para Pinus sylvestris y del $23 \%$ para Quercus faginea, tras un estudio realizado durante dos años (Serrano-Muela et al., 2012). Por otro lado, los mismos autores comprobaron que el agua que llega al suelo se reduce alrededor de un $10 \%$ más si debajo de la cubierta arbórea hay un estrato arbustivo (Serrano-Muela et al., 2012). En un estudio sobre la interceptación de la lluvia por la vegetación en España (Belmonte 
Serrato y Romero Díaz, 2013) en el que se recogen valores de interceptación de 15 áreas de estudio, se da un valor medio de 22,7 para diferentes especies de Pinus, 22,4 para Quercus y 18,3 para Fagus; respecto a especies de matorral, el valor medio de interceptación es de 29,9, lo que demuestra que el matorral, en general, supera al arbolado en pérdidas de agua por interceptación.

Una proporción importante del agua que llega al suelo se infiltra; la infiltración es mayor en suelos bien estructurados, con elevada porosidad y contenido de materia orgánica (Seeger y Beguería, 2003). Especial interés tiene la presencia de macroporos en los suelos, a lo que contribuye tanto una buena estructura como una alta densidad de raíces, especialmente si son de diversos grosores (de árboles, arbustos y plantas herbáceas), y también la actividad de la fauna dentro del suelo. Los macroporos funcionan como vías o caminos para acumular agua en las capas inferiores del suelo y en acuíferos. Bergkamp et al. (1996) comprobaron, en el sureste de España, que las raíces de los matorrales favorecían la infiltración y retención del agua por el suelo, evitando la escorrentía en distancias superiores a $1 \mathrm{~m}$.

Por otro lado, hay que tener en cuenta que parte del agua infiltrada es consumida por la vegetación. Gallart et al. (2002) y Serrano-Muela et al. (2008) demostraron la importancia del consumo de agua por los bosques, especialmente en verano, lo que reduce el contenido de agua en el suelo y la respuesta hidrológica de la cuenca de captación, que incluso puede no responder a lluvias intensas. En este sentido, Gallart et al. (2002) registraron varios casos de falta de respuesta hidrológica en verano después de lluvias de aproximadamente $50 \mathrm{~mm}$. Por su parte, García-Ruiz et al. (2008) compararon la respuesta hidrológica de tres cuencas con distintas cubiertas (bosque de frondosas y pinos; campos abandonados con matorrales y pastos; y cárcavas). La falta de respuesta hidrológica se hizo evidente en la cuenca forestal en verano, pese a la ocurrencia de fuertes tormentas; por el contrario, la cuenca de cárcavas (suelo desnudo) respondió de forma muy rápida, mientras que la de campos abandonados respondió más tardíamente y de manera moderada.

Se han realizado también estudios sobre los efectos hidrológicos de los campos abandonados cuando se encuentran en la fase de cubierta de matorrales. En la Estación Experimental "Valle de Aísa" (Pirineo central) se reprodujeron durante 20 años (1991-2011) usos del suelo que representan los sistemas tradicionales de cultivo (cereal fertilizado con abono químico, barbecho y cereal cultivado con el sistema de rozas o artigueo, es decir con añadido de cenizas como sistema de fertilización) y las diferentes etapas y alternativas del abandono (abandono a partir de cereal fertilizado con abono químico y de cereal cultivado con el sistema de rozas). Los resultados demuestran que el abandono implica una disminución clara de los coeficientes de escorrentía respecto a la fase de cultivo. Dicha disminución es paralela al proceso de sucesión vegetal, de forma que los coeficientes son más elevados cuando domina una cubierta de herbáceas (primeros años de abandono) que cuando el matorral (Genista scorpius, como especie dominante) va cubriendo la parcela, debido a que el estrato de matorral se superpone sobre el de herbáceas, lo que favorece la infiltración del agua y la disminución de la escorrentía. Por el contrario, una cubierta exclusiva de herbáceas incentiva que parte del agua de lluvia resbale sobre la hierba sin llegar al suelo (Nadal-Romero et al., 2013). Se comprobó también que el abandono de la parcela fertilizada producía menos escorrentía que la parcela abandonada tras su cultivo mediante el sistema de rozas, debido a un proceso de sucesión vegetal más rápido en la primera parcela (Lasanta et al., 2006).

En ambientes semiáridos también la gestión de la cubierta vegetal puede ser un factor esencial para los recursos hídricos. Bellot et al. (2001) simularon efectos de algunas políticas de gestión (reforestación de tierras y eliminación de vegetación mediante incendio) sobre el drenaje profundo y la escorrentía. Los resultados pusieron de relieve que la reforestación produciría una reducción tanto de la recarga del acuífero como de la escorrentía, mientras que un incendio forestal produciría los efectos contrarios. 


\subsubsection{El recurso pastoral}

Los campos abandonados forman parte de los itinerarios de pastoreo y, por lo tanto, son un recurso fundamental para alimentar a la ganadería extensiva (Molinillo et al., 1997; Reiné et al., 2014). Son escasos los trabajos que cuantifican el efecto del ganado sobre la vegetación y su dinámica en áreas de campos abandonados; pero todos ellos llegan a la conclusión de que la actual gestión ganadera (escasa diversidad de especies animales, poca carga ganadera y pastoreo muy poco gestionado; ver LasantaMartínez, 2014) es incapaz de detener el proceso de sucesión vegetal, lo que supone la pérdida de producción forrajera (Fernández-Giménez, 2015). Riedel (2007) y Riedel et al. (2013) registraron, en un estudio realizado durante 5 años en pastos arbustivos del Parque de la Sierra y Cañones de Guara (Prepirineo oscense), incrementos significativos en biomasa del estrato sub-arbóreo, tanto en áreas pastadas por ganado ovino (cargas medias de 0,15 Unidades Ganaderas Mayores, UGM/ha/año) como en zonas no pastadas, lo que condujo al embastecimiento del pasto. El pastoreo, en este caso, implicó una reducción en la dinámica de la vegetación, pero no la detuvo; el efecto difería notablemente entre especies vegetales. Casasús et al. (2007), en un estudio realizado en el Valle de la Garcipollera (Pirineo de Huesca), analizaron pastos con arbolado ralo pastoreados por vacas nodrizas y cargas de 2 UGM/ha/año. Comprobaron la eficacia del pastoreo en el control de la vegetación y su efectividad a la hora de conservar espacios forestales abiertos; vieron que el ganado es capaz de mantener estable la biomasa arbustiva, mientras que la ausencia de pastoreo produce una rápida e intensa densificación de la vegetación. Los mismos autores insisten en el papel positivo del ganado para mantener pastos productivos, lo que favorece el control de incendios y facilita el uso recreativo del territorio, una demanda cada vez más presente en la sociedad. En los dos trabajos anteriores se comprobó que el pastoreo evitó la acumulación de biomasa herbácea muerta, disminuyendo la combustibilidad y el riesgo de incendios. También se observó la mejora de la calidad de la hierba, de vital importancia tanto para animales domésticos como silvestres.

En la Cordillera Cantábrica se estudió el efecto del pastoreo con cabras domésticas como factor de control de varias especies de matorral (Cytisus scoparius, Rubus idaeus y Rosa sp.) representativas de áreas abandonadas. A partir de parcelas experimentales se analizó el efecto que ejerce el pastoreo con dos cargas ganaderas (4,5 cabras/ha/año y 9 cabras/ha/año) en el matorral y la obtención de pastos tras la quema, desbroce y poda de la comunidad de matorral. Los resultados ponen de manifiesto que el uso combinado de las cabras con apoyo de otras prácticas (quema, desbroce y poda) puede contribuir tanto a la transformación de áreas de matorral en pastos como al control del avance de los matorrales. El efecto es más positivo con carga doble ( 9 cabras/ha/año) que con carga simple (4,5 cabras/ha/año). El pastoreo de las cabras también cambia la distribución espacial de los matorrales, transformando una cobertura densa y continua en matas individualizadas, lo que permite incrementar la aportación de los matorrales a la dieta alimentaria del ganado y mejorar la accesibilidad del ganado al estrato herbáceo. Ello sugiere que mantener una estructura compleja de matorrales y pastos resulta beneficiosa para la alimentación de la ganadería extensiva y para mejorar la heterogeneidad del paisaje, incrementar la biodiversidad y controlar el riesgo de incendios (Álvarez-Martínez et al., 2013).

Bartolomé et al. (2000) comprobaron que el pastoreo de rebaños de ovino fue incapaz de detener la invasión del estrato arbustivo y mantener un paisaje abierto y diverso en la Reserva de la Biosfera del Montseny (Pirineo Catalán). A la misma conclusión llegan Komac et al. (2013) al comprobar el fuerte avance de Echinospartum horridum en los pastos subalpinos del Pirineo central, reclamando el uso combinado del pastoreo y la eliminación de matorrales por fuego o medios mecánicos. Gómez-García et al. (2011) concluyeron (a partir de parcelas experimentales) que el pastoreo con la actual presión, por sí sólo, no es suficiente para detener el avance de los matorrales en los ambientes atlánticos de Belate y Sierra de Aralar (Navarra). Estos autores aconsejan el uso simultáneo del pastoreo y el desbroce a ras del suelo en zonas de baja pendiente y alta cobertura vegetal, mientras que en áreas con pendientes medias o pronunciadas y baja densidad de cobertura vegetal concluyen que es más efectiva la combinación fuego - ganadería extensiva. Por otro lado, señalan que el equino resulta especialmente interesante para eliminar el matorral y abrir claros para la vegetación herbácea. 
Lo cierto es que los campos abandonados contribuyen muy poco a la alimentación del ganado en las últimas décadas por la presencia masiva de matorrales. García-Ruiz y Lasanta-Martínez (1993) estudiaron las fuentes de alimentación del ganado en tres valles pirenaicos (Aísa, Tena y Hecho), donde los campos abandonados ocupan amplias superficies (el 17,7\%, 4,4\% y 29,8\% del territorio, respectivamente), llegando a la conclusión de que su aportación a la dieta alimentaria del ganado era escasa: del $5 \%$ en Aísa, $1 \%$ en Tena y $2 \%$ en Hecho. Los autores atribuyen la escasa contribución a la existencia de una cubierta de matorral que impide el acceso del ganado al estrato herbáceo inferior, aunque este posee un potencial pastoral alto (Lasanta, 2005). Los campos cubiertos de matorrales dificultan, además, la conectividad entre pastos al interrumpir itinerarios de pastoreo (Valdelvira y Balcells, 1986).

Molinillo et al. (1997) estudiaron la oferta pastoral de los campos abandonados del valle de Aísa (Pirineo aragonés) seleccionando cuarenta campos con distinta edad de abandono (de 1 a 75 años). Comprobaron que el estrato herbáceo estaba compuesto por especies de mediana calidad forrajera (Achillea millefolium, Plantago lanceolata, Plantago media, Primula veris, Daucus carota, Centaurea jacea...) o buena calidad forrajera (Medicago lupulina, Trifolium pratense, Trifolium repens, Brachypodium pinnatum, Carex flacca, Dactylis glomerata, Festuca rubra...), pero que el estrato arbustivo (Genista scorpius, Rosa sp., Prunus spinosa, Crataegus monogyna...) impedía el acceso del ganado a medida que comenzaba a ser dominante.

En el valle del Leza (Sistema Ibérico Noroccidental), Rodríguez-Merino et al. (1998) estudiaron la producción pastoral en campos abandonados con suelos procedentes de litologías calcáreas y silíceas. Observaron que en las primeras dominan comunidades en la que la especie más representativa es $G$. scorpius y en las segundas Cistus laurifolius. Comprobaron también que los campos colonizados por $G$. scorpius ofrecían una productividad ligeramente superior a los de C. laurifolius, lo que vinculan con la mayor densidad del estrato herbáceo en los primeros campos, ya que la composición florística es muy parecida en ambas litologías. Por otro lado, observaron que los campos con mayor intensidad de pastoreo, sin llegar a exceder la capacidad de carga, alcanzaban mayor valor pastoral y lo mantenían durante varios años. En estas circunstancias el ganado detiene el avance de los matorrales y favorece la presencia de especies de mayor calidad forrajera. Además, el pastoreo frecuente del ganado permite aprovechar el pasto en el momento óptimo (cuando se alcanza la mayor calidad forrajera) (Montserrat, 1964). Por último, comprobaron que la productividad fluctúa a lo largo del año, alcanzando el máximo primario en primavera y el secundario en otoño. En verano desciende, especialmente en agosto, al igual que en invierno por parada del ciclo vegetativo.

Ferrer et al. (1995) estudiaron la influencia del pastoreo en bancales del Maestrazgo de la Comunidad Valenciana. Señalan que los bancales llegaron a ocupar un $21 \%$ de la superficie total, alcanzando en algunos municipios hasta el 35\%. A mediados del siglo XX se abandonaron, pastándose el $43 \%$ de ellos mientras que el $57 \%$ no se pastoreaban. Entre los resultados destacan que en los primeros años de abandono el suelo desnudo ocupa hasta el 35\% de la superficie, cubriéndose con mayor rapidez en los bancales no pastados, especialmente entre los 10 y 20 años de abandono. No obstante, comprobaron que al cabo de 40 años ya sólo quedaba un 10\% de suelo desnudo, tanto en bancales pastados como sin pastar. Los bancales pastados ven como su valor pastoral se incrementa de forma paralela a la edad de abandono, de forma que pasan de poder alimentar una carga ganadera inicial de 2,5 ovejas/ha/año a 3,5 ovejas ha/año. Por el contrario, los bancales no pastados experimentan una disminución brusca de su valor pastoral durante los 10 primeros años de abandono, un descenso más ligero entre los 10 y 30 años, para volver a disminuir bruscamente entre los 30 y 40 años, edad en la que se estabilizan admitiendo una carga de 1,2 ovejas/ha/año. Por otro lado, comprobaron que el riesgo de incendio era muy superior en los bancales no pastados. Los resultados obtenidos les llevó a concluir que sería conveniente empradizar (siembra de alfalfa, esparceta, dáctilo, Festuca alta o especies autóctonas de alto valor ganadero) los campos cuando dejan de ser cultivados para evitar problemas de erosión del suelo y favorecer el pastoreo del ganado. Además, señalan la conveniencia de complementar el pastoreo, 
dadas las bajas cargas recientes, con otras actuaciones como desbroces, resiembras con nulo o mínimo laboreo y pequeños abonados.

Errea y Lasanta (1994) estudiaron, en ambientes semiáridos del centro de la Depresión del Ebro, la contribución de campos retirados del cultivo (set-aside) como consecuencia de la PAC. Estimaron que los campos de secano eran capaces de alimentar entre 0,3 ovejas/ha/año y 1,1 ovejas/ha/año, en función de la edad de abandono y de la gestión tras la retirada. Los campos de regadío ofertaban mayor cantidad de pasto, admitiendo cargas ganaderas entre 1,1 ovejas/ha/año y 2 ovejas/ha/año. Los autores calcularon que el $10 \%$ del censo ganadero del área de estudio se alimentaba a partir de los campos abandonados debidos a la PAC. Además, comprobaron que la edad de abandono implicaba la disminución de la oferta forrajera tanto en secano como en regadío, lo que atribuyeron a la pérdida de humedad del suelo, la formación de costras, la menor densidad de la cubierta vegetal y la lignificación de algunas especies. Por otro lado, comprobaron la importancia de la gestión tras el abandono, observando que un laboreo anual con chisel (apero que realiza un laboreo ligero en la capa superior del suelo sin llegar a voltear la tierra) resultaba positivo para mantener la cubierta vegetal, al romper las microcostras superficiales y favorecer la infiltración del agua. También comprobaron que el abonado, tanto orgánico como químico, incrementaba la cubierta vegetal y con ello el potencial pastoral de los campos.

\subsection{Servicios de regulación}

Entre los servicios de regulación dos han ocupado más la atención de los estudiosos sobre campos abandonados: la erosión/conservación del suelo y el secuestro y almacenamiento de carbono por el suelo.

\subsubsection{Erosión/conservación del suelo}

El aumento progresivo de la densidad de la cubierta vegetal tras el abandono de campos de cultivo implica, generalmente, la disminución de la erosión del suelo respecto a la etapa de cultivo (García-Ruiz, 2010; García-Ruiz y López Bermúdez, 2009; García-Ruiz y Lana-Renault, 2011). Es una consecuencia lógica del efecto protector de la vegetación contra el salpicado de la lluvia (splash), el desprendimiento de partículas y la resistencia al avance de los flujos de escorrentía superficiales. Además, como ya se ha señalado, las propiedades del suelo tienden a mejorar algunos años después del abandono favoreciendo la infiltración del agua (Martínez-Fernández et al., 1995; Seeger y Beguería, 2003). En un amplio estudio sobre diferentes litologías en el sureste de España (Belmonte Serrato et al., 2016) se demostró como el abandono mejoró propiedades edáficas como la densidad aparente, estabilidad de agregados, tasa de infiltración, contenido en materia orgánica y, especialmente en margas (una litología muy erosiva) tras el abandono, se observó una tendencia a la mejora de la calidad de sus propiedades edáficas, lo que facilita la dinámica recolonizadora de la vegetación natural.

La erosión del suelo disminuye, generalmente, con la edad de abandono de los campos, a medida que la cubierta vegetal avanza y alcanza mayor densidad y una estructura más compleja. Este hecho parece sugerir que el problema está en los primeros años de abandono, cuando la vegetación no cubre el campo de forma completa (Dunjó et al., 2004). Sin embargo, el tema es mucho más complejo, ya que a veces los campos de mayor edad de abandono son los que tienen suelos más deteriorados y procesos de erosión más severos (rills, descalzamientos, procesos de piping), mientras los campos abandonados más recientemente presentan un mejor grado de conservación, dominando procesos de arroyamiento difuso débil, tanto sobre cubiertas herbáceas como de matorral (García-Ruiz y López-Bermúdez, 2009). Ruiz-Flaño et al. (1992) lo observaron en el Valle de Aísa (Pirineo aragonés), justificándolo por: i) las malas condiciones del suelo en los primeros campos abandonados, debido a que la mayoría de tales campos se cultivaron mediante el sistema de rozas, lo que dificultó el proceso de sucesión vegetal, y ii) 
porque fueron campos sometidos a fuegos recurrentes para regenerar pastos, lo que llevó a una degradación progresiva del suelo. En este sentido, Cerdà y Lasanta (2005) y Lasanta y Cerdà (2005) comprobaron, en el mismo Valle de Aísa, que tras un incendio se incrementan los flujos de escorrentía y las tasas de erosión, a la vez que se pierden cantidades importantes de nutrientes del suelo. Pasados unos años el matorral penetraba de nuevo y se frenaba la erosión, a la vez que se reproducían los problemas para el pastoreo, por lo que el campo se volvía a quemar. La repetición de este fenómeno es, muy probablemente, la causa de que algunos campos alcanzasen una alta degradación del suelo (Ruiz Flaño et al., 1992). En el valle próximo de Borau, Navas et al. (2005) utilizaron medidas de $\mathrm{Cs}^{137}$ para estudiar la redistribución del suelo en campos abandonados; comprobaron que las laderas solanas (las más utilizadas para el cultivo y las que sufrieron más quemas de matorral) tuvieron tasas de erosión más altas y un proceso de sucesión vegetal más lento.

Muchos de los estudios sobre erosión en campos abandonados se han realizado en laderas abancaladas (García-Ruiz et al., 1988; Rodríguez Aizpeolea et al., 1991; Arnáez, 2015, 2017; Gallart y Llorens, 1994; Arnáez y Ortigosa, 1997; Ruecker et al., 1998; Duiker et al., 2001; Lasanta et al., 2001; Cammeraat et al., 2005, Solé-Benet et al., 2010, entre otros). En bancales el proceso de erosión dominante son los desprendimientos en el salto o muro del bancal, formando cicatrices que deterioran la armonía del paisaje de las laderas abancaladas y favorecen la instalación de cárcavas con exportación de elevada cantidad de sedimentos. Además, las zonas internas de los bancales tienden a saturarse y a convertirse en áreas generadoras de escorrentía superficial, mientras que los sistemas de drenaje artificiales producen picos de avenida más rápidos e intensos (Gallart y Llorens, 1994). No obstante, hay que recordar que los deslizamientos también ocurrían durante la fase de cultivo tras lluvias muy intensas o cuando se registraban precipitaciones muy abundantes, pero el agricultor procedía rápidamente a reparar el muro y a rellenar el hueco de tierra desplazado (García-Ruiz et al., 1988). Sin embargo, el cese de las prácticas de conservación de los muros externos tras el abandono es una causa fundamental para el incremento de la erosión (Arnáez et al., 2015).

Lasanta et al. (2001) estudiaron la evolución geomorfológica de 86 bancales en Cameros Viejo (Sistema Ibérico). Confirmaron que el proceso de erosión más importante era el colapso de muros por pequeños deslizamientos (volumen medio: $3,3 \mathrm{~m}^{3}$ ), con un promedio total de $38,8 \mathrm{~m}^{3}$ por cada 100 metros lineales de muro de bancal. La mayor densidad de deslizamientos se observó en laderas cóncavas y parte baja de las laderas, coincidiendo con la mayor acumulación de agua, lo que favorece la saturación del suelo y, consecuentemente, la ocurrencia de movimientos en masa. A partir de la cicatriz del desprendimiento del muro externo el proceso puede avanzar por erosión remontante hasta generar pequeñas cárcavas. Los mismos autores señalan que algunas de las cicatrices de desprendimientos favorecen el paso del ganado de un bancal a otro, dibujando sendas en las que el pisoteo frecuente apelmaza el suelo y hace más efectivo el impacto de las gotas de lluvia y el arroyamiento superficial, lo que lleva a generar cicatrices muy activas en la evacuación de sedimentos. En la misma zona, GarcíaRuiz et al. (1988) mostraron que la densidad de desprendimientos en los muros de los bancales se relacionaba de forma positiva con la pendiente de la ladera y la altura del bancal (mayor en laderas más pendientes), y de forma negativa con la densidad de la cubierta vegetal, que es indicadora de la calidad de la parcela. Lesschen et al. (2008b) llegan a conclusiones parecidas en la Cuenca de Cárcavo (Murcia). Las tasas de erosión que reconstruyen para las terrazas abandonadas son de $87 \mathrm{Mg} \mathrm{ha}^{-1} \mathrm{año}^{-1}$.

En la cuenca del río Bergantes (Castellón), Pallarés Bou (1994) observó también la importancia de los deslizamientos en bancales; además comprobó el papel destacado que juegan la escorrentía subsuperficial y el desarrollo de piping en la aceleración de los movimientos en masa. Este autor señala que los muros no tenían como fin sujetar el terreno, ya que por sus características apenas proporcionaban defensa frente a los deslizamientos, sino que más bien trataban de proteger la superficie del talud frente a la erosión durante lluvias intensas.

Con precipitaciones intensas o muy duraderas, así como en áreas de fuerte acumulación de agua, pueden generarse debris flows, con longitudes de más de $100 \mathrm{~m}$, pudiendo afectar a toda una ladera 
abancalada. Costra et al. (2003) consideran que en estos casos la formación de debris flows se ve favorecida por las propiedades geotécnicas e hidráulicas del terreno, localizándose la línea de rotura en el contacto entre niveles de suelos con distintas características físico - químicas.

La influencia de la edad de abandono en la degradación de laderas abancaladas fue estudiada por Rodríguez Aizpeolea et al. (1991) en la vertiente sur de la Sierra de Mirant (Alicante). Estudiaron campos abandonados de 1, 5, 10 y 20 años mediante simulación de lluvia $\left(55 \mathrm{~mm} \mathrm{hr}^{-1}\right)$. Los resultados ponen de relieve que tanto la escorrentía como la concentración de sedimentos disminuyen con la edad de abandono, a medida que avanza el proceso de sucesión vegetal.

Una parte considerable de los estudios sobre erosión en bancales se ha dedicado a conocer el comportamiento hidromorfológico de la parte interna de bancales abandonados. Llorens et al. (1992) comprobaron en la Cuenca de Cal Parisa (Prepirineo Oriental) que la parte interna se satura con facilidad durante la estación húmeda, convirtiéndose en la principal área de generación de escorrentía. Los suelos son menos profundos y permeables en la parte interna que la externa del bancal. Eso hace que existan notables diferencias en la capacidad de infiltración dentro de cada terraza. Además, parte del agua infiltrada tiende a aflorar al pie del bancal, aumentando la probabilidad de que se sature la parte interna del bancal inferior. Por otro lado, Romero Martín et al. (1994) en el valle de Guiniguada (Gran Canaria), y Lasanta et al. (2001) en Cameros Viejo (Sistema Ibérico) comprobaron que en bancales sin rellano plano era frecuente que apareciesen procesos de arroyamiento laminar e incisiones. Hay que tener en cuenta, que los bancales se construyeron para favorecer la infiltración del agua y disminuir la escorrentía. Por ello, la génesis de un paisaje de terrazas conllevaba el trazado de una red de drenaje con pequeños canales dentro del campo que conducían las aguas sobrantes hacia otros laterales de mayor entidad (Gallart y Llorens, 1994), lo que reducía el riesgo de movimientos en masa. Sin embargo, el abandono de las terrazas implicó el cese de las tareas de mantenimiento de los drenajes, lo que incentiva la saturación del suelo y el incremento de los movimientos en masa en la parte externa del bancal (Gallart y Llorens, 1994; García-Ruiz y López Bermúdez, 2009).

En ambientes semiáridos la mayor o menor erosión del suelo está muy relacionada con las características (rapidez y composición vegetal, sobre todo) del proceso de sucesión vegetal (Cerdà et al., 1994; Ries et al., 1997 y 2000). Belmonte et al. (1999), Romero Díaz (2003) y Romero Díaz et al. (2007) comprobaron en la Región de Murcia que el abandono del cultivo sobre sustrato calizo llevaba a una rápida colonización por parte de las herbáceas y más tarde del matorral, con aumento de la materia orgánica del suelo, lo que resultaba positivo para la conservación del suelo y la diversidad del paisaje; por el contrario, sobre sustrato margoso el abandono implica la génesis de una costra superficial que hace muy lenta la colonización vegetal. Otro proceso de gran importancia que tiene lugar en campos de cultivo aterrazados y abandonados, sobre litología de margas, es el proceso de erosión por piping (López Bermúdez y Torcal, 1986; López Bermúdez y Romero Díaz, 1989). Un amplio estudio de 82 áreas, realizado en la Región de Murcia (Sánchez Soriano, 2012) ha permitido constatar como los procesos de erosión por piping aparecen ligados, predominantemente, a áreas de litología margosa, aterrazadas, de escasa pendiente y con importantes gradientes hidráulicos, generados por la altura existente entre las terrazas de cultivo. La altura entre parcelas condiciona la profundidad que alcanzan los pipes, mientras que la escasa pendiente de las parcelas favorece el estancamiento y la infiltración del agua en lugar de la escorrentía, provocando la formación de los conductos subsuperficiales (Romero Díaz et al., 2016).

Por su parte, Ries et al. (2000) comprobaron en el centro de la Depresión del Ebro que la colonización vegetal es muy lenta, de forma que a los 6-8 años de abandono no suele alcanzar el 50\%, e incluso hay campos con abandono muy antiguo que difícilmente superan el $60 \%$ de cubierta. Estos autores atribuyen las dificultades para el progreso de la vegetación al escaso contenido de agua y a la pobreza de los suelos. Por otro lado, observaron que la infiltración disminuye generalmente con el tiempo de abandono, debido a la reducción de la porosidad por falta de laboreo. A ello se une el pisoteo del ganado, que apelmaza el suelo y favorece la formación de una costra superficial. El incremento de la escorrentía, como consecuencia de la disminución de la infiltración, no acarrea, sin embargo, el 
aumento de las pérdidas de suelo, ya que la costra lo protege de la erosión, al menos hasta un umbral a partir del cual el aumento de la escorrentía implica un incremento de la erosión lineal (Ries et al., 1997). El pastoreo del ganado puede llevar a romper en ocasiones la costra y generar partículas de suelo que son fácilmente transportadas por el viento, incrementando las tasas de erosión eólica (Ries et al., 2000).

En definitiva, los estudios realizados sobre la evolución hidromorfológica de campos abandonados demuestran que se trata de un problema complejo, con resultados muy variables en función de los modelos de campos (abancalados, en pendiente, llanos), de las condiciones climáticas, que regulan el proceso de sucesión vegetal, de la gestión en su fase agrícola, que puede determinar la potencia y fertilidad del suelo en el momento del abandono, y de la gestión posterior al cese del cultivo, que influye a través de posibles perturbaciones (incendios, pastoreo,..). Además, la edad de abandono puede jugar un destacado papel en relación con la evolución de los parámetros edáficos y la colonización vegetal.

\subsubsection{El secuestro de carbono por el suelo}

El suelo constituye un almacén muy importante de carbono orgánico en la mayor parte de los ecosistemas (García-Pausas et al., 2017). En los últimos años, los estudios sobre el secuestro y almacenamiento de carbono en el suelo (SOC) se ha disparado, por sus implicaciones en la mitigación del cambio climático (Emran et al., 2012; Gabarrón-Galeote et al., 2015; García-Pausas et al., 2017). Los campos abandonados tienen un interés especial, al tratarse de áreas degradadas en recuperación, lo que ofrece un potencial significativo de secuestro de SOC (De Baets et al., 2013; Gispert et al., 2018). Así, Rodríguez-Martín et al. (2019) comprobaron en la isla de Mallorca que el SOC se duplicó entre 2006 y 2017 en laderas de bancales abandonados y en pastizales.

La capacidad de SOC guarda una estrecha relación con el ritmo temporal de sucesión secundaria y de mejora de las propiedades del suelo (Gabarrón-Galeote et al., 2015). Emran et al. (2012) comprobaron que la transformación de un espacio cultivado en pastos o en una cubierta forestal implica un incremento del SOC. Trigalet et al. (2016) señalan que la proporción de carbono lábil aumenta a lo largo del proceso de sucesión secundaria. Estruch et al. (2018) estudiaron los cambios en el balance de $\mathrm{C}$ en campos abandonados a lo largo de 100 años en un ambiente semiárido del SE de España. Señalan que fueron necesarios 65 años para que el sistema recuperase la cantidad de $\mathrm{C}$ de la zona no perturbada, lo que explican por la lentitud del proceso de sucesión vegetal. Segura et al. (2006) encontraron que en un clima semiárido los cambios de SOC en el suelo son muy lentos, por las condiciones climáticas y por los bajos aportes de materia orgánica al suelo. Por el contrario, un estudio realizado en la Sierra de los Filabres (sureste de España) concluyó que el C se acumula rápidamente durante los primeros 10-50 años tras el abandono; posteriormente los stocks de C se estabilizan (De Baets et al., 2013). Los mismos autores comprobaron que los stocks de SOC son muy variables (en suelos de $1 \mathrm{~m}$ de profundidad entre 3,16 y 76,44 t/ha), y que las áreas erosionadas que se recuperan tienen mayor capacidad para incrementar las tasas de secuestro, poniendo de relieve la importancia de gestionar campos abandonados.

Lasanta et al. (2020) estudiaron la sucesión secundaria y el SOC en campos abandonados del Sistema Ibérico. Señalan que el proceso de revegetación pasa por cinco etapas: pastos, matorrales $(C$. laurifolius, como especie dominante), arbustedos (J. communis, como especie dominante), bosque joven y bosque viejo, en ambos casos de Quercus pyrenaica). Los autores comprobaron que el contenido de SOC aumentó con la sucesión vegetal, especialmente en los $10 \mathrm{~cm}$ superiores del suelo, hasta la etapa de bosque joven, disminuyendo ligeramente el SOC en la etapa final de bosque maduro. Los autores explican el incremento de SOC por la acumulación de mantillo (hojarasca y necromasa sobre el suelo) conforme la sucesión secundaria avanza, y porque tanto los matorrales como los árboles incrementan la biomasa subterránea. El menor contenido de SOC en los bosques viejos que en los jóvenes lo justifican por el menor cubrimiento de los matorrales en el sotobosque de los primeros (cubrimiento del 14,3\%) que en los segundos (cubrimiento del 40\%). En el Pirineo, Nadal-Romero et al. (2016b) estudiaron qué implica la gestión activa (reforestación de campos abandonados con Pinus sylvestris y Pinus nigra) 
frente a la gestión pasiva (pastos y matorrales de sucesión). Comprobaron que los matorrales acumulan menos SOC que los pastos y pinares. El P. nigra es el uso del suelo con mayor contenido de SOC, seguido por los pastos, $P$. sylvestris y matorrales. Observaron también que las mayores diferencias entre los distintos usos del suelo se establecen en $\operatorname{los} 10 \mathrm{~cm}$ superiores. La evolución del contenido de SOC también se ha estudiado en laderas de pastos subalpinos abandonados en el Pirineo, comprobándose que el paso de pastizal a matorral implica una caída brusca de SOC en el suelo. En las etapas siguientes (bosque joven y maduro de $P$. sylvestris) el contenido de SOC se recupera parcialmente no llegando a alcanzar al del pasto subalpino, posiblemente por la abundancia en este último uso de raíces finas con gran capacidad para fijar $\mathrm{C}$ y por la ausencia de pastoreo en el resto de usos, lo que resta materia orgánica al suelo (Nadal-Romero et al., 2018).

\subsection{Servicios de apoyo}

La mayor parte de los estudios sobre los servicios de apoyo que pueden ofrecer los campos abandonados se han dedicado a cuantificar y valorar la biodiversidad, ya que algunos autores consideran que el abandono de tierras y la revegetación posterior son una oportunidad para la conservación de la biodiversidad (Regos et al., 2016). Por el contrario, otros autores opinan que es una amenaza, debida a la homogeneización del paisaje, la pérdida de prácticas de gestión y la desaparición de especies adaptadas a paisajes en mosaico (Otero et al., 2015). Los últimos señalan, además, que el supuesto carácter restaurador de lo que denominan transición forestal (abandono y revegetación) se basa en la subestimación de la importancia ecológica de los hábitats no forestales. Por el contrario, Regos et al. (2016) consideran que la re-naturalización o rewilding resulta positiva para la biodiversidad. Se basan en un estudio realizado en Galicia, en el que comprobaron que la revegetación de suelos desnudos tuvo como resultado que trece especies de aves de matorrales y bosques aumentaron de forma significativa, mientras que cuatro especies de ecotonos y hábitats abiertos mostraron una tendencia negativa. ReyBenayas et al. (2010) compararon los efectos en la riqueza de aves debidos a la sucesión secundaria (restauración pasiva) y la plantación de árboles (restauración activa). Llegan a la conclusión de que la gestión activa recolecta mayor número de especies (4,2 especies por cada parcela de 0,78 ha), que la restauración pasiva ( 3,5 especies por parcela). Sin embargo, los mismos autores insisten en la necesidad de combinar la restauración pasiva y activa con modelos mixtos con el fin de conciliar la producción agrícola, la restauración de la vegetación y la biodiversidad. Suárez-Seoane et al. (2002) señalan la preferencia de aves eurosiberianas por hábitats boscosos, mientras que las aves mediterráneas prefieren las áreas abiertas y los matorrales. Los mismos autores señalan que en la región mediterránea los mosaicos agrícolas de cultivo de baja intensidad mantienen los niveles más altos de diversidad de especies de aves prioritarias. Concluyen señalando que no debe darse por supuesto que el abandono de tierras agrícolas beneficia a la conservación. No obstante, Tella et al. (1988) señalan que en Monegros tanto la intensificación agrícola como el abandono de tierras son negativos para el cernícalo primilla (Falco naumanni), una especie esteparia amenazada a escala mundial.

Uno de los aspectos más abordados en el estudio de los campos abandonados es el análisis de la riqueza de especies (fauna y flora), porque de ella derivan su mayor o menor productividad, la estabilidad de los ecosistemas y la variedad genética. La diversidad biológica constituye, además, un parámetro valioso para determinar el interés ecológico de un territorio y para orientar la conservación de la naturaleza. Se la considera como un componente sintético de la organización de la estructura y función de los ecosistemas en relación con su origen y evolución (Pineda et al., 1981; Montalvo et al., 1993).

Se estima que aproximadamente el $50 \%$ de las especies de flora y fauna europeas dependen de hábitats agrícolas. De ahí, que el abandono de tierras tenga especial interés de cara a la biodiversidad (Delibes-Mateos et al., 2009a; Cohen et al., 2011). Robledano et al. (2016) en el estudio realizado en la Región de Murcia, consideran que el valor de conservación de los campos abandonados, para la flora leñosa y la avifauna, a menudo supera a superficies equivalentes de hábitat natural y bajo condiciones 
físicas rigurosas (sustratos poco coherentes y escasez de precipitaciones), los cultivos abandonados a menudo dan lugar a hábitats esteparios que albergan especies con alto valor de conservación en Europa.

Los campos abandonados reúnen algunas características que les hacen especialmente sensibles para la biodiversidad: amplia extensión, proceso de sucesión vegetal, que crea heterogeneidades en el territorio en diversidad biológica, suelos pobres y con frecuencia sometidos a dinámicas de degradación/recuperación, ser un espacio abierto rodeado habitualmente por un paisaje forestal y cese de la gestión antropogénica (Bernáldez, 1981; García-Ruiz y Lana-Renault, 2011; Lasanta, 2014).

La diversidad de especies vegetales parece estar condicionada por la edad de abandono, el mosaico vegetal circundante, las perturbaciones humanas tras el abandono, y los factores abióticos, especialmente litología, fertilidad de suelo, topoecología y clima. La edad de abandono condiciona la estructura del paisaje y su biodiversidad; se ha observado que habitualmente en las fases iniciales hay un incremento de la riqueza de especies, mientras que en fases posteriores la riqueza se reduce muchísimo (Suárez-Seoane et al., 2002; Vicente-Serrano et al., 2006). Montalvo et al. (1993) señalan el rápido incremento en la riqueza de especies como consecuencia de la entrada de herbáceas en un campo recién abandonado. Según Gutiérrez-Teira (1997) el abandono de cultivos implica, a corto plazo, un incremento en diversidad alfa (aumento de la diversidad en espacios reducidos) y una disminución en amplitud de nicho de las nuevas especies de plantas. Gómez et al. (2003) han demostrado el incremento en la riqueza de hormigas en una primera fase del abandono. Sin embargo, a medio y largo plazo la biodiversidad disminuye. Así, Suárez-Seoane et al. (2002) indican que el abandono agrícola representa una reducción en los niveles de diversidad paisajística y problemas derivados con la extinción de especies y la reducción de la biodiversidad. Por su parte, Lasanta y Vicente-Serrano (2007) comprobaron, en el Pirineo Central español, que la mayor diversidad vegetal se alcanzó coincidiendo con la penetración de forma dispersa de los primeros pies de matorral y de árboles. En esta etapa el estrato arbustivo convive con el herbáceo, compuesto por especies anuales y plurianuales, lo que se demuestra en una elevada variabilidad espacial en los valores de NDVI respecto a la situación previa. Por el contrario, en los años posteriores se asiste a una etapa de homogeneización con densificación de los matorrales y pérdida de heterogeneidad de la cubierta herbácea.

Entre las perturbaciones derivadas del cese de los cultivos destacan las producidas por la acción del ganado y los incendios forestales. Respecto al pastoreo se ha comprobado que la riqueza específica y la biodiversidad aumentan en áreas gestionadas con ganadería extensiva, que se considera como una perturbación moderada, frente a las áreas no pastoreadas (sin perturbación) o sobrepastoreadas (perturbación alta), que incentivan la degradación del suelo. No obstante, Blanco-Fontao et al. (2012) ponen en duda que haya siempre una relación directa entre ganadería extensiva y biodiversidad. Se basan en su estudio sobre la disminución del urogallo (Tetrao urogallus) en la Cordillera Cantábrica, un ave en peligro de extinción y considerada como una especie paraguas (en Biología de la Conservación, las especies paraguas son aquellas cuya protección implica la protección indirecta de otras con las que comparte hábitat) en los ecosistemas forestales de montaña. La bibliografía previa señalaba el abandono del pastoreo como la causa de la disminución del urogallo, asumiendo que la ausencia del ganado implica la disminución de la biodiversidad a través de la homogeneización de hábitats. Sin embargo, comprobaron que los censos ganaderos se habían incrementado en las últimas décadas, por lo que concluyen que los datos reales no respaldan el supuesto papel de la ganadería extensiva en la conservación de la biodiversidad.

El pastoreo actúa sobre la riqueza específica mediante la selección de especies por el ganado, lo que modifica las relaciones de competencia y cooperación entre las plantas (Ferrer y Broca, 1999). El pastoreo suele ejercer una tarea positiva, sobre todo, en los primeros estadios de sucesión vegetal, controlando por defoliación algunas especies más invasoras y favoreciendo el renuevo de las de mayor interés ganadero (Montserrat, 1964; Fillat et al., 2008); además, favorece la dispersión de semillas mediante endozoocoria (Malo y Suárez, 1996). En este sentido, Reiné et al. (2014) compararon en el Pirineo la diversidad florística entre prados de siega (laboreos de siembra, siega, pastoreo, fertilización 
y riego) y pastos en campos abandonados (tan solo pastoreo). Comprobaron que los prados reunían poca diversidad de especies, y elevada productividad, aunque la calidad del forraje era baja. Por el contrario, los pastos de campos abandonados presentaron alta diversidad de plantas y buena calidad del forraje, aunque la productividad era más baja que la de los prados. Por su parte, Tárrega et al. (2009) compararon en la provincia de León tres tipos de dehesas con diferente gestión: i) dehesas pastadas en la actualidad; ii) dehesas abandonadas (más de 20 años sin pastoreo) y iii) dehesas en las que se eliminaron arbustos tras el abandono. Los resultados señalan que las dehesas pastadas tienen mayor riqueza de especies y cobertura de especies anuales, mientras que las dehesas abandonadas presentan mayor cobertura de matorrales. Señalan, además, que la eliminación de arbustos (no seguida del pastoreo del ganado) puede causar la pérdida de riqueza de especies vegetales.

Los incendios son una perturbación importante en los paisajes de campos abandonados. Implican la eliminación de vegetación y la creación de espacios con hábitats abiertos y arbustivos (Zozaya et al., 2002). Los efectos sobre la biodiversidad parecen contradictorios. Gil-Tena et al. (2009) señalan que la expansión y maduración de los bosques como consecuencia del abandono agrícola anula los efectos negativos de los incendios sobre la distribución de aves forestales. Regos et al. (2016) consideran positivos los fuegos controlados para favorecer la creación de espacios abiertos en paisajes progresivamente cerrados derivados del rewilding, y con ello compaginar la presencia de especies de hábitats abiertos y cerrados. Vallecillo et al. (2008) precisan que los paisajes generados por fuegos controlados pueden mejorar potencialmente la resiliencia de especies amenazadas de hábitats abiertos mediante el aumento de la variedad de hábitats potenciales de ser utilizados.

En procesos de sucesión vegetal más que la cantidad de especies importa la relevancia de algunas especies concretas, por su rareza, función ecológica y significado biogeográfico y evolutivo. Fernández-Alés et al. (1992) y Laiolo et al. (2004) señalan que durante la sucesión secundaria en campos abandonados se pasa por diferentes fases o etapas. En la primera etapa aumenta la diversidad florística. A medio plazo, sin embargo, disminuye la diversidad y la biodiversidad porque las especies invasoras van arrinconando a las de mayor valor ecológico. En esta fase, muchas especies animales corren también peligro por falta de alimento o refugio; otras especies encuentran dificultades para sobrevivir por la desaparición de espacios abiertos que constituyen su hábitat natural. A largo plazo, las especies de alto valor ecológico desaparecen en favor de otras más competitivas, de menor valor. Ello causa una alta reducción de la diversidad de plantas y animales y una pérdida de riqueza. Bonet (2004) ha comprobado en el Sureste español que el pico de riqueza de especies se alcanza en campos abandonados a los 10-20 años, decreciendo posteriormente. También pone de relieve que el uso agrícola previo al abandono influye en la composición de especies y que los pájaros pueden contribuir a la dispersión de semillas incrementando la riqueza específica. Delibes-Mateos et al. (2009b) señalan que el abandono de la gestión tradicional y la revegetación posterior en las montañas de Andalucía han favorecido la expansión de especies de caza mayor y la disminución de las de caza menor. Sugieren que la conservación y regeneración de los paisajes agrícolas tradicionales debería ser una prioridad para la conservación de la biodiversidad de especies de caza menor. La misma propuesta realizan Salaverri et al. (2019) al estudiar en Galicia la disminución de la riqueza y abundancia de aves como consecuencia del abandono de paisajes humanizados. Comprobaron también que la altitud amortigua la pérdida de especies.

\subsection{Servicios culturales}

Todos los paisajes y ecosistemas humanizados guardan una riqueza histórica y cultural, al ser fruto de la simbiosis entre hombre y naturaleza durante siglos de aprovechamiento (Martínez de Pisón, 2009; García-Ruiz y Lasanta, 2018). Por otro lado, el medio rural se ha convertido en lugar de ocio para una parte importante de la población, que valora el paisaje como un servicio, y, por lo tanto, con connotaciones económicas (García-Novo, 2007). Dado que en muchas áreas de montaña la matriz del paisaje son las tierras abandonadas, y que sus cambios presentan un gran dinamismo, se entiende la 
preocupación de la sociedad y los gestores del territorio por los paisajes de espacios marginales (Lasanta et al., 2015).

Sin embargo, en España no se han realizado demasiados estudios sobre los servicios culturales del paisaje de campos abandonados, en contraste con la proliferación de estudios sobre otros servicios ecosistémicos, especialmente los relacionados con el suelo y la hidrología. La percepción y valoración del paisaje de campos abandonados es muy diversa. La sociedad los tiende a considerar en función de su calidad estética, familiaridad o experiencia con un paisaje concreto. También influyen la distancia y el recuerdo, así como la mayor consideración y aprecio que suele suponer la inminencia de la pérdida de un paisaje dado (García-Novo, 2007). El paisaje es contemplado de forma diferente por la población en función de los servicios que recibe o esperar recibir. Las personas vinculadas con el abastecimiento de productos primarios (ganaderos y agricultores) tienden a valorar menos los servicios culturales (paisaje, ocio, turismo) y de regulación (calidad del agua, control de la erosión del suelo, biodiversidad), que ejerce el medio natural, que los grupos cuya economía no depende de los recursos del territorio (Martín-López et al., 2007).

Se establece también una postura muy diferente entre los habitantes rurales y los urbanos. La población local considera que los paisajes deben ser multifuncionales para garantizar su sostenibilidad: deben producir alimentos, contribuir a la estructuración social y mantener valores ambientales; por el contrario, entre los foráneos dominan los que prefieren un paisaje muy natural y escasamente productivo. En este sentido, Rescia et al. (2008) comprobaron en el Parque Nacional de Picos de Europa (Cordillera Cantábrica) que la población local está a favor del turismo, por lo que puede suponer en la mejora de rentas; por el contrario, los representantes del Parque (gestores y trabajadores) consideran que el turismo es una amenaza para la conservación. Lasanta et al. (2016) estudiaron en Cameros Viejo (Sistema Ibérico), a partir de entrevistas a la población vinculada, la percepción sobre el abandono de tierras y el proceso de revegetación. Comprobaron que tanto los habitantes locales como foráneos perciben los cambios de paisaje derivados del abandono. Coinciden, además, en que el proceso de revegetación implica una mejor conservación del suelo frente a la erosión y un mayor riesgo de incendios por la acumulación de biomasa. Difieren, por el contrario, en los cambios hidrológicos que implica el proceso de revegetación. La población local señala que ahora hay menos producción de agua, pero que es un agua de mayor calidad, menos cargada de sedimentos. Entre la población foránea, una mayoría de los entrevistados sostiene que ahora hay más agua que en el pasado porque la mayor cubierta vegetal hace que llueva más. También manifestaron algunas matizaciones respecto a las consecuencias de la revegetación en la fauna, siendo la población local la que observa más claramente la progresión de la fauna silvestre. Respecto a la estética del paisaje, las respuestas son muy coincidentes en que el paisaje actual es más atractivo, si bien entre la población local hay quienes recuerdan el paisaje agrícola tradicional en mosaico, lo que los lleva a restar belleza al paisaje que ahora ven.

En un estudio realizado en la Alta Garrotxa (montaña mediterránea de Cataluña, caracterizada por la despoblación y el abandono durante las últimas décadas), Vila Subirós et al. (2009) concluyen que la valoración y percepción de los cambios de paisaje muestran una doble perspectiva. Una primera interpretación se basa en una visión antropocéntrica, valorando negativamente el avance de la vegetación y el incremento de la superficie forestal, lo que vinculan con un territorio más salvaje y una naturaleza más indómita, fuera del control humano. Una segunda interpretación tiene base ecocéntrica, valorando positivamente esta evolución, al considerar que responde a cánones propios de la dinámica natural.

Los bancales o terrazas agrícolas se construyeron para producir alimentos, favorecer la infiltración del agua y limitar la pérdida de suelo (Violant y Simorra, 1949; Puigdefábregas y Fillat, 1986; García-Ruiz et al., 1988; Arnáez et al., 2015, entre otros muchos). La mayoría de ellos se abandonaron en la segunda mitad del siglo XX, pero mantienen un elevado interés: se incluyen entre los paisajes culturales más valorados del mundo mediterráneo (Lasanta et al., 2013). Su interés cultural deriva de la técnica de construcción empleada, en la medida en que recopila el saber de los agricultores, plasmado en las laderas abancaladas durante siglos (milenios incluso en algunas montañas) y las 
habilidades sociales para organizar simultáneamente unos espacios con fines productivos y de conservación (Asíns, 2007). Frente a la dureza de las condiciones climáticas, la altitud y la pendiente, el agricultor dio acertadas respuestas en el uso de los recursos y materiales disponibles. Los bancales constituyen un notable recurso cultural de los sistemas de cultivo en ladera. Detrás de cada bancal, de cada murete, se esconde el saber hacer y el saber conservar de muchas generaciones de agricultores (Lasanta et al., 2013).

A todo ello se añade la labor de información que aporta un paisaje de bancales, como también ocurre en otros muchos paisajes rurales, con sus setos en los márgenes de los campos, sus caminos, acequias y construcciones (Martínez-Arnáiz, 2018). En un paisaje se encuentran siempre retazos de épocas distintas, superpuestos y entremezclados, a modo de un palimpsesto (García-Ruiz y Lasanta, 2018; García-Ruiz et al., 2017). La fecha en que se abancaló una ladera informa, por ejemplo, de las necesidades de una sociedad en una época de la Historia (Pérez-Carazo, 2008). La localización de los diferentes modelos de bancales (los más perfectos próximos siempre a los pueblos o en lugares propicios para cierta intensificación) manifiesta la discriminación espacial realizada por el hombre en función de la fertilidad del suelo y la accesibilidad. La existencia o ausencia de muretes nos anuncia las condiciones micro climáticas y litológicas de cada enclave (Lasanta et al., 2017c). En los muros y tapiales podemos encontrar piezas de calidad contrastada, llenas de equilibrio en dimensión y proporciones, adaptadas al medio, ajustadas a las necesidades, bien diseñadas y mejor ejecutadas. De gran mérito si tenemos en cuenta los pocos medios y las dificultades de todo tipo inherentes a su época (Lasanta et al., 2013).

Pueden sacarse muchas enseñanzas de un paisaje rural tradicional como el de laderas abancaladas. Con los muretes de piedra se perseguía aumentar la infiltración y disminuir la erosión. Pero los constructores, también usuarios por lo general, aprovecharon las propiedades intrínsecas de la piedra seca: retención de la humedad, aireación moderada pero continua, inercia térmica con mantenimiento de temperatura y avenamiento eficaz de los suelos. Una manera de construir que exigía un profundo conocimiento de las particularidades del terreno y de las posibilidades de la técnica de mampostería en seco o de piedra seca (Lasanta et al., 2013).

Las acequias para regar, unas veces, y para desviar el agua de escorrentía, en la mayor parte de los casos, muestran el interés del agricultor por incrementar la productividad y asegurar la conservación del suelo, pero además nos informan de la técnica y cultura del grupo que las construyó. En Cameros se diferencian las acequias de origen árabe y cristiano (Pérez-Carazo, 2008). En definitiva, en el paisaje y en las infraestructuras asociadas se puede leer a la vez el entramado de hechos y fenómenos visibles y las relaciones funcionales que han existido entre ellos a lo largo del tiempo, por lo que constituyen un patrimonio cultural de un valor irrenunciable.

Además, los paisajes de laderas abancaladas tienen un gran atractivo turístico. Biarge (2009) señala la alta valoración que reciben los paisajes abancalados del entorno del Parque Nacional de Ordesa y Monte Perdido (Pirineo Central), siendo uno de los principales atractivos para los visitantes del Parque. Jiménez Olivenza (1989-90) incluye las laderas de terrazas agrícolas de Sierra Nevada (Sistema Penibético) entre los paisajes más valorados, por su alta diversidad y belleza. Ocaña et al. (2004) indican que en la Axarquía malagueña los paisajes aterrazados con estructura compleja, formada por un mosaico de manchas con vegetación natural alternando con otras manchas de cultivos de cítricos y aguacates, cuentan con la preferencia de los usuarios; los muros de piedra seca de las terrazas están construidos con materiales extraídos del terreno, aportando una perfecta integración visual en el entorno. Sayadi et al. (2009) señalan, al estudiar los paisajes de la Alpujarra granadina, las preferencias de los turistas por las laderas con bancales cultivados frente a las áreas con campos abandonados y vegetación natural. Por otro lado, algunas laderas abancaladas constituyen áreas preferentes para la localización de segundas residencias, especialmente en las proximidades de grandes aglomeraciones urbanas y de espacios turísticos, como en los Montes de Málaga por su cercanía a la Costa del Sol (Ocaña et al., 2004). 


\section{Conclusiones y perspectivas}

Las tierras abandonadas constituyen un uso del suelo con importantes implicaciones ambientales, paisajísticas y socioeconómicas a escala global, por lo que han recibido la atención de científicos de los cinco continentes. España es el segundo país, tras Estados Unidos, con mayor producción bibliográfica, por la amplia superficie que ocupan las tierras abandonadas y por la diversidad de ambientes en que se han abandonado, que van desde las áreas de montaña a las de condiciones semiáridas. Por otro lado, el proceso de abandono se ha dilatado en el tiempo, ya que los principales abandonos se registraron a lo largo del siglo XX, especialmente entre los años cincuenta y ochenta en áreas de montaña, mientras que en los espacios llanos tienen lugar en las últimas décadas, debido tanto a las medidas e incentivos de la PAC para la retirada de tierra como a la degradación de suelos por un uso indebido (intensificación, riego, laboreos inadecuados...).

Las tierras abandonadas tienen una evolución compleja, al interactuar de forma simultánea procesos de sucesión vegetal y edafogénesis, condicionados por el tiempo de abandono, las condiciones climáticas del lugar, la gestión previa y posterior al abandono, la cubierta vegetal próxima al lugar de abandono, y posibles perturbaciones como los incendios forestales. Por ello, surgen ecosistemas y paisajes muy diversos que, además, experimentan cambios a diferente ritmo temporal. La evolución estándar crea en primer lugar ecosistemas, e incluso en ocasiones paisajes, de pastos, seguidos por los de matorrales, arbustedos, bosque claro y bosque denso en la etapa final. Sin embargo, en la realidad cualquiera de las fases anteriores puede ser la última, o al menos la más duradera, en función de los factores que interactúan en cada momento en las tierras abandonadas. Por otro lado, aún se añade más complejidad si tenemos en cuenta que el proceso de abandono ha sido muy dilatado en el tiempo, por lo que en áreas próximas pueden convivir paisajes muy diferentes de tierras abandonadas.

Los paisajes tradicionales en mosaico proporcionaban abundantes bienes y servicios ecosistémicos a la sociedad. Tras su abandono, la oferta se modifica en función del paisaje resultante. Con una perspectiva sintética cuatro son los paisajes dominantes en las tierras abandonadas y sus funcionalidades más destacadas:

i) Si se alcanza la fase de bosque, las propiedades del suelo mejoran y se incrementa el SOC, mientras que disminuyen los recursos hídricos y pastorales; se producen, además, importantes cambios en la biodiversidad (incremento de especies forestales a costa de las adaptadas a paisajes culturales) y en la estética del paisaje; este último es bien valorado por la población urbana y menos por la local.

ii) Si tras el abandono dominan procesos de degradación del suelo, el paisaje resultante se caracteriza por la presencia de laderas con suelo casi desnudo y con abundantes piedras en superficie y manchas aisladas de matorral. En estas condiciones, la biodiversidad se empobrece, las pérdidas de suelo se incrementan mientras el SOC disminuye, los recursos hídricos aumentan, pero con agua de escasa calidad y con efectos negativos en la fauna fluvial y en el aterramiento de embalses; apenas se producen recursos pastorales y el paisaje pierde todo su atractivo, restando alternativas al desarrollo local.

iii) El paisaje dominado por matorrales implica una ligera mejora de las propiedades del suelo y del SOC respecto a la fase de cultivo, pero produce menos agua y limita mucho el pastoreo del ganado; es un paisaje muy homogéneo y de escasa riqueza ecológica, además de tener un elevado riesgo de incendio.

iv) Por último, hay retazos o laderas enteras cubiertas, de forma temporal o permanente, por pastizales. Estos aportan recursos forrajeros a la ganadería extensiva, mejoran las propiedades del suelo y el SOC respecto a los cultivos y matorrales, aunque quizás, aportan valores ligeramente inferiores a los bosques; producen volúmenes de escorrentía superiores a las áreas de matorral y bosque. Si en los márgenes de los campos se mantienen matorrales, arbustos y algunos árboles, se alcanzan altas tasas de biodiversidad, ya que los márgenes 
sirven para alimento y refugio de la fauna, además de como corredores ecológicos. Reducen el combustible y actúan de cortafuegos, por lo que el número de incendios y superficie quemada se reduce.

La amplia extensión que ocupan las tierras abandonadas y la elevada diversidad de paisajes que generan, con impactos ambientales, económicos y sociales, exigen una gestión que tenga en cuenta que los impactos no sólo afectan a los habitantes locales sino también a buena parte de la sociedad. Los científicos están divididos entre los que propugnan una gestión activa (intervenir en el territorio eliminando matorrales o reforestando) y los que apoyan una gestión pasiva (dejar que la naturaleza siga su curso). También los gestores del territorio se debaten entre ambas posturas, tratando en muchos casos de conciliar la no intervención en la mayor parte del territorio, con reforestaciones en algunas laderas, quemas prescritas muy localizadas y desbroces selectivos (cortafuegos y limpieza del sotobosque próximo a vías de comunicación), si bien algunas administraciones utilizan el desbroce de matorrales como una auténtica política de gestión para favorecer la diversidad, fomentar la ganadería extensiva y fijar población, además de reducir los riesgos de grandes incendios.

De los resultados extraídos de la bibliografía se deduce que, para la conservación y el suministro de servicios ecosistémicos, dos paisajes son más positivos (los bosques y los pastos), mientras que las áreas de matorral ofrecen más impactos negativos que positivos, y las de suelo casi desnudo sólo efectos negativos, si bien la presencia de matorrales dispersos puede fomentar la formación de pequeños sectores alrededor de las matas con mayor capacidad de infiltración. Con estos resultados parece lógico compatibilizar ambas posturas, dejando algunas áreas a la evolución natural, si tienen potencial para completar el proceso de reconstrucción y alcanzar la fase de bosque, mientras que en otras es aconsejable intervenir. Así, el desbroce de matorrales en áreas seleccionadas (campos abandonados con buen suelo y accesibles al ganado) parece una buena estrategia para construir un paisaje más heterogéneo y próximo al paisaje cultural tradicional. Con ello, se incrementaría la biodiversidad, los recursos hídricos y pastorales, y se reduciría la probabilidad de grandes incendios forestales. Además, se contribuiría a mantener -e incluso incentivar- sistemas ganaderos extensivos, una actividad clave para mejorar la biodiversidad y el desarrollo socio-económico de muchos territorios rurales. En las áreas de suelo casi desnudo también parece aconsejable intervenir, bien mediante repoblaciones con diversas especies de matorral que acorten el tiempo de revegetación, a ser posible mediante aplicación de enmiendas a los suelos para mejorar sus propiedades e incentivar la sucesión vegetal, o mediante prácticas de conservación de suelos.

Las tierras abandonadas generan paisajes muy diversos, por lo que la gestión también debe ser diversa, adaptada al potencial biótico y abiótico de cada lugar. Pero teniendo siempre presente que de la gestión se derivan impactos con implicaciones ambientales y efectos en la población local y en la sociedad en su conjunto.

\section{Agradecimientos}

Este trabajo se ha realizado con el apoyo de los proyectos LIFE MIDMACC (LIFE18 CCA/ES/001099), financiado por la Comisión Europea, y MANMOUNT (PID2019-105983RB100/AEI/10.13039/501100011033), financiado por el Ministerio de Ciencia e Innovación (Gobierno de España) y FEDER. El grupo de investigación "Procesos Geoambientales y Cambio Global" financiado por el Gobierno de Aragón (E02_17R). M. Khorchani se beneficia de un contrato FPI predoctoral del Gobierno de España (BES-2016-077992) asociado al proyecto ESPAS. José María García Ruiz mejoró el manuscrito original, aportando ideas y referencias bibliográficas. 


\section{Referencias}

Alguacil García, P. 1985. Esquema metodológico para la valoración del cambio de usos del suelo (Sierra de Ayllón). Anales de la Universidad Complutense 5, 143-165.

Alonso Sarría, F., Martínez Hernández, C., Belmonte Serrato, F., Fernández Carrillo, M.A. 2016a. Principales causas del abandono de cultivos en la Región de Murcia. En: A. Romero Díaz (Coord.) Abandono de cultivos en la Región de Murcia. Consecuencias Ecogeomorfológicas. Servicio de Publicaciones de la Universidad de Murcia: 203-226, Murcia.

Alonso-Sarría, F., Martínez-Hernández, C., Romero-Díaz, A., Cánovas-Garcés, F., Gomáriz-Castillo, F. 2016 b. Main environmental features leading to recent abandonment in Murcia Region (Southeast Spain). Land Degradation \& Development 277, 654-670. https://doi.org/10.1002/ldr.2447

Álvarez-Martínez, J., Gómez-Villar, A., Lasanta, T. 2016. The use of goats grazing to restore pastures invaded by shrubs and avoid desertification: a preliminary case study in the Spanish Cantabrian mountains. Land Degradation \& Development 27, 3-13. https://doi.org/10.1002/ldr.2230

Alvera, B. 1976. Contribución al estudio de la intercepción de las precipitaciones atmosféricas en el pinar de San Juan de la Peña. Publicaciones del Centro Pirenaico de Biología Experimental 7 (1), 95-100.

Alvera, B. 1977. Interceptación de las precipitaciones atmosféricas en un pinar altoaragonés. Segundo año de observaciones. Publicaciones del Centro Pirenaico de Biología Experimental 8, 15-22.

Arbelo, C.D., Rodríguez-Rodríguez, A., Guerra, J.A., Mora, J.L., Notario, J.S., Fuentes, F. 2006. Soil degradation processes and plant colonization in abandoned terraced fields overlying pumice tuffs. Land Degradation \& Development 17, 571-588. https://doi.org/10.1002/ldr.735

Arévalo, J.R., Fernández-Lugo, S., Reyes-Betancort, A., Tejeda, M., Jiménez, C., Díaz, F.J. 2017. Relationships between soil parameters and vegetation in abandoned terrace fields vs. non-terraced fields in arid lands (Lanzarote, Spain): An opportunity for restoration. Acta Oecologica 86, 77-84. https://doi.org/10.1016/j.actao.2017.09.014

Arnáez, J., Lasanta, T., Ortigosa, L., Ruiz-Flaño, P. 1990. Le processus d'abandon de l'espace agricole dans la montagne submediterranéenne espagnole : Pyrénées centrales et Système Ibérique. Revue de Géographique des Pyrénées et du Sud-Ouest 6 (2), 237-253. https://doi.org/10.3406/rgpso.1990.3207

Arnáez, J., Lasanta, T., Errea, M.P., Ortigosa, L. 2011. Land abandonment, landscape evolution, and soil erosion in a Spanish Mediterranean mountain region. The case of Camero Viejo. Land Degradation \& Development 22, 537-550. https://doi.org/10.1002/ldr.1032

Arnáez, J., Lana-Renault, N., Lasanta, T., Ruiz-Flaño, P., Castroviejo, J. 2015. Effects of farming terraces on hydrological and geomorphological processes. A review. Catena 128, 122-134. https://doi.org/10.1016/j.catena.2015.01.021

Arnáez, J., Lana-Renault, N., Ruiz-Flaño, P., Pascual, N., Lasanta, T. 2017. Mass soil movement on terraced landscape of the Mediterranean mountain areas: a case study in the Iberian Range, Spain. Cuadernos de Investigación Geográfica 4 (1), 83-100. https://doi.org/10.18172/cig.3211

Arnáez, J., Ortigosa, L. 1997. Abandono, subutilización y erosión en un espacio de montaña: El Sistema Ibérico noroccidental (La Rioja, España). En: J.M. García-Ruiz y P. López García (Eds), Acción humana y desertificación en ambientes mediterráneos. Instituto Pirenaico de Ecología, pp. 205-220, Zaragoza.

Asíns, S. 2007. Los aterrazamientos mediterráneos. Paradigma ambiental-agro-cultural. Cuadernos de la Sostenibilidad y Patrimonio Natural 11, 81-91.

Azevedo, J.C., Moreira, C., Castro, J.P., Loureiro, C. 2011. Agriculture abandonment, land use change and fire hazard in mountain landscapes in Northerastern Portugal. In: C. Li, R. Lafortezza, J. Chen (Eds.), Landscape Ecology in Forest Management and Conservation: Challenges and Solutions for Global Change. Springer, New York, pp. 329-351.

Barrientos, G. 1978. El valle del Alto Tormes (Gredos y Aravalle: estudio geográfico). Caja Central de Ahorros de Ávila, Ávila. 
Bartolomé, J., Franch, J., Plaixats, J, Seligman, N.G. 2000. Grazing alone is not enough to maintain landscape diversity in the Montseny Reserve. Agriculture, Ecosystems \& Environment 77 (3), 267-273. https://doi.org/10.1016/S0167-8809(99)00086-9

Bauer, N., Wallner, A., Hunzinker, M. 2009. The change of European landscapes: Human-nature relationships, public attitudes towards rewilding, and the implications for landscape management in Switzerland. $\begin{array}{llllll}\text { Journal of } & \text { Environmental } & \text { Management } & 90 & \text { (9), }\end{array}$ https://doi.org/10.1016/j.jenvman.2008.01.021

Bautista Cruz A., Etchevers Barra J., del Castillo R.F., Gutiérrez C. 2004. La calidad del suelo y sus indicadores. Ecosistemas 13, 90-97.

Beguería, S., López-Moreno, J.I., Lorente, A., Seeger, M., García-Ruiz, J.M. 2003. Assessing the effect of climate oscillations and land-use changes on streamflow in the Central Spanish Pyrenees. Ambio 32 (4), 283-286. https://doi.org/10.1579/0044-7447-32.4.283

Bellin, N., van Wesemael, B., Meerkert, A., Vanacker, V., Barbera, G.G. 2009. Abandonment of soil water conservation structures in Mediterranean ecosystems. A case study from south east Spain. Catena 76, 114-121. https://doi.org/10.1016/j.catena.2008.10.002

Bellot, J., Bonet, A., Sánchez, J.R., Chirino, E. 2001. Likely effects of land use changes on the runoff and aquifer recharge in a semiarid landscape using a hydrological model. Landscape and Urban Planning 155 (1), 41-53. https://doi.org/10.1016/S0169-2046(01)00118-9

Belmonte Serrato, F., Martínez Hernández, C., Ruíz Sinoga, J.D. 2016. Análisis de las características edáficas más significativas de las áreas abandonadas. En A. Romero Díaz (Coord.) Abandono de cultivos en la Región de Murcia. Consecuencias Ecogeomorfológicas. Servicio de Publicaciones de la Universidad de Murcia, pp. 41-62, Murcia.

Belmonte Serrato, F., Romero Díaz, A. 1999. Interceptación en algunas especies del matorral mediterráneo. Colección Cuadernos de Ecología y Medio Ambiente. Universidad de Murcia, 202 pp.

Belmonte Serrato, F., Romero Díaz, A. (Coord.) 2013. Interceptación de la lluvia por la vegetación en España. Fundación Instituto Euromediterráneo del Agua. Murcia.

Belmonte Serrato, F., Romero Díaz, A., López Bermudez, F. 1999. Efectos sobre la cubierta vegetal, la escorrentía y la erosión del suelo de la alternancia cultivo-abandono en parcelas experimentales. Investigaciones Geográficas 22, 95-107. https://doi.org/10.14198/INGEO1999.22.01

Bergkamp, G., Cammeraat, L.H., Martínez-Fernández, J. 1996. Water movement and vegetation patterns on shrubland and an abandoned field in two desertification -threatened areas in Spain. Earth Surface Processes and Landforms 21, 1073-1090. https://doi.org/10.1002/(SICI)1096-9837(199612)21:12<1073::AIDESP640>3.0.CO;2-8

Bernáldez, F.G. 1991. Ecological consequences of the abandonment of traditional land use systems in Central Spain. Options Méditerranéennes 15, 23-29.

Bernués, A., Rodríguez-Ortega, T., Ripoll-Bosch, R., Alfnes, F. 2014. Socio-cultural and economic valuation of ecosystem services provided by Mediterranean ecosystems. PLoS ONE 9 (7), e102479. https://doi.org/10.1371/journal.pone.0102479

Biarge, F. 2009. Sobrarbe. Letra menuda. Diputación de Huesca, 322 pp., Huesca.

Blanco-Fontao, B., Quevedo, M., Obeso, J.R. 2011. Abandonment of traditional uses in mountain areas: typological thinking versus hard data in the Cantabrian Mountains (NW Spain). Biodiversity Conservation 20, 1133-1140. https://doi.org/10.1007/s10531-011-0016-1

Blanco Sepúlveda, R. 2008. La evaluación de la vulnerabilidad del suelo a la degradación por uso ganadero en espacios montañosos. Análisis metodológico. Estudios Geográficos 264, 51-80.

Boellstorff, D., Benito, G. 2005. Impacts of sed-aside policy on risk of soil erosion in central Spanish. Agriculture, Ecosystems \& Environment 107, 231-243. https://doi.org/10.1016/j.agee.2004.11.002 
Bonet, A. 2004. Secondary succession of semi-arid Mediterranean old-field in South-Easter Spain. Insights for contribution and restoration of degraded lands. Journal of Arid Environment 56 (2), 213-233. https://doi.org/10.1016/S0140-1963(03)00048-X

Bonet, A., Pausas J. 2004. Species richness and cover along a 60-year chronosequence in old-fields of southeastern Spain. Plant Ecology 174, 257-270. https://doi.org/10.1023/B:VEGE.0000049106.96330.9c

Bordiú, E. 1985. Valoración e infrautilización en la Sierra de Ayllón y aportación de un modelo alternativo. Anales de la Universidad Complutense 5, 167-187.

Bowen, M.E., McAlpine, C.A., House, A.P.N., Smith, G.C. 2007. Regrowth forests on abandoned agricultural land: A review of their habitat values for recovering forest fauna. Biological Conservation 140 (3-4), 273 296. https://doi.org/10.1016/j.biocon.2007.08.012

Cabero, V. 1980. Espacio agrario y economía de subsistencia en las montañas galaico-leonesas. Institución "Fray Bernardino de Sahagún" (CSIC) y Ediciones de la Universidad de Salamanca: 134 pp., León.

Calsamiglia, A., Lucas-Borja M.E., Fortesa, J., García-Comendador, J., Estrany, J. 2017. Changes in soil quality and hydrological connectivity caused by the abandonment of terraces in a Mediterranean burned catchment. Forests 8, 333. https://doi.org/10.3390/f8090333

Cammeraat, E.L.H., Cerdà, A., Imeson, A.C. 2010. Ecohydrological adaptation of soils following land abandonment in a semi-arid environment. Ecohydrology 3, 421-430. https://doi.org/10.1002/eco.161

Cammeraat, E., Van Beek, R., Kooijman, A. 2005. Vegetation succession and its consequences for slope stability in SE Spain. Plant and Soil 278 (1-2), 135-147. https://doi.org/10.1007/s11104-005-5893-1

Cammeraat, L. H., Imeson, A.C. 1999. The evolution and significance of soil-vegetation patterns following land abandonment and fire in Spain. Catena 37, 107-127. https://doi.org/10.1016/S0341-8162(98)00072-1

Cantón, Y., Solé-Benet, A., de Vente, J., Boix-Fayos, C., Calvo-Cases, A., Asensio, C., Puigdefábregas, J. 2011. A review of runoff generation arid soil erosion across scales in semiarid south-eastern Spain. Journal of Arid Environments 75, 1254-1261. https://doi.org/10.1016/j.jaridenv.2011.03.004

Cañadas Sánchez, E.M. 2008. Estudio de tierras agrícolas abandonadas en ambiente mediterráneo semiárido: vegetación, suelos y distribución espacial. Bases para la gestión. Tesis Doctoral, Universidad de Granada. Granada.

Cañadas, E.M., Jiménez, M.N., Valle, F., Fernández-Ondoño, E., Martín-Peinado, F., Navarro, F.B. 2010. Soilvegetation relationships in semi-arid Mediterranean old field (SE Spain): implications for management. Journal of Arid Environments 74 (11), 1525-1533. https://doi.org/10.1016/j.jaridenv.2010.06.007

Casasús, I., Bernués, A., Sanz, A., Villalba, D., Riedel, J.L., Revilla, R. 2007. Vegetation dynamics in Mediterranean forest pastures as affected by beef cattle grazing. Agriculture, Ecosystems \& Environment 121 (4), 365-370. https://doi.org/10.1016/j.agee.2006.11.012

Cerdà, A. 1996. Soil erosion after land abandonment in a semiarid environment of southeastern Spain. Arid Soil Research and Rehabilitation 11 (2), 163-176. https://doi.org/10.1080/15324989709381469

Cerdà, A., García-Álvarez., Cammeraat, L.H., Imeson, A.C. 1994. Agregación del suelo en una catena afectada por el abandono del cultivo en la cuenca del Guadalentín (Murcia). I. Estabilidad y distribución de los agregados del suelo. En: J.M. García-Ruiz y T. Lasanta (Eds), Efectos geomorfológicos del abandono de tierras. Sociedad Española de Geomorfología, pp. 9-19, Zaragoza.

Cerdà, A., Lasanta, T. 2005. Long-term erosional responses after fire in the Central Spanish Pyrenees. 1 Water and sediment yield. Catena 60, 59-80. https://doi.org/10.1016/j.catena.2004.09.006

Chauchard, S., Carcaillet, C., Guibal, F. 2007. Patterns of land-use abandonment control tree-recruitment and forest dynamics in Mediterranean mountains. Ecosystems 10, 936-948. https://doi.org/10.1007/s10021007-9065-4

Chocano Vañó, C., Sánchez Fuster, C., López Bermúdez, F. 2007. La agroecología como alternativa a la prevención y lucha contra la desertificación en la Región de Murcia: La Comarca del Noroeste. Agroecología $2,75-84$. 
Conti, G., Fagarazzi, L. 2005. Forest expansion in mountain ecosystems: “environmentalist's dream” or societal nightmare? Planum 11, 1-20.

Cohen, M., Varga, D., Vila, J., Barrassaud, E. 2011. A multi-scale and multi-disciplinary approach to monitor landscape dynamics: a case study in the Catalan pre-Pyrenees (Spain). The Geographical Journal 177 (1), 79-91. https://doi.org/10.1111/j.1475-4959.2010.00368.x

Corbelle-Rico, E., Crecente-Maseda, R., Santé-Riveira, I. 2012. Multi-scale assessment and spatial modelling of agricultural land abandonment in a European peripheral region: Galicia (Spain), 1956-2004. Land Use Policy 29, 493-501. https://doi.org/10.1016/j.landusepol.2011.08.008

Cortizo, J., Maya, A., Redondo, J.M. 1992. Valdesamario. Un enclave de la montaña leonesa. Imprenta Moderna, 109 pp., León.

Costra, G.B., Dal Negro, P. y Frattini, P. 2003. Soil slips and debris flows on terraced slopes. Natural Hazards and Earth System Science 3, 31-42. https://doi.org/10.5194/nhess-3-31-2003

Cramer, V. 2007. Old fields: dynamics and restoration of abandoned farmland. Island Press, 352 pp.

De Baets, S., Meerswaus, J., Vanacker, V., Quine, T. A., Van Oost, K. 2013. Spatial variability and change in soil organic carbon stocks in response to recovery following land abandonment and erosion in mountainous dry lands. Soil Use and Management 29, 65-76. https://doi.org/10.1111/sum.12017

Delibes-Mateos, M., Ferreras, P., Villafuerte, R. 2009a. European rabbit population trends and associated factors: A review of the situation in the Iberian Peninsula. Mammal Review 39 (2), 124-140. https://doi.org/10.1111/j.1365-2907.2009.00140.x

Delibes-Mateos, M., Farfán, M.A., Olivero, J., Márquez, A.L., Vargas, J.M. 2009b. Long-term changes in game species over a long period of transformation in the Iberian Mediterranean landscape. Environmental Management 43, 1256-1268. https://doi.org/10.1007/s00267-009-9297-5

Díaz Muñoz, M.A. 1984. Criterios para el análisis de evolución de usos del suelo en zona de montaña: aplicación a un sector de Somosierra. Anales de Geografia de la Universidad Complutense 4, 131-14.

Douglas, T.D., Kirkby, S.J., Critchley, R.W., Park. G.J. 1994. Agricultural terrace abandonment in the Alpujarra, Andalucía, Spain. Land Degradation and Rehabilitation 5, 281-291. https://doi.org/10.1002/ldr.3400050405

Duarte, F., Jones, N., Fleskens, L. 2008. Traditional olive orchards on sloping land: sustainability or abandonment? Journal of Environmental Management 89, 86-98. https://doi.org/10.1016/j.jenvman.2007.05.024

Duguy, B., Alloza, J.A., Röder, A., Vallejo, R., Pastor, F. 2007. Modelling the effects of landscape fuel treatments on fire growth and behaviour in a Mediterranean landscape (Eastern Spain). International Journal of Wildland Fire 16 (5), 619-632. https://doi.org/10.1071/WF06101

Duiker, S.W., Flanagan, D.C., Lal, R. 2001. Erodibility and infiltration characteristics of five major soils of Southwest Spain. Catena 45, 103-121. https://doi.org/10.1016/S0341-8162(01)00145-X

Dunjó, G., Pardini, G., Gispert, M. 2003. Land use change effects on abandoned terraced soils in a Mediterranean catchment, NE Spain. Catena 52, 23-37. https://doi.org/10.1016/S0341-8162(02)00148-0

Dunjó, G., Pardini, G., Gispert, M. 2004. The role of land use-land cover on runoff generation and sediment yield at a microplot scale, in a small Mediterranean catchment. Journal of Arid Environments 57, 99-116. https://doi.org/10.1016/S0140-1963(03)00097-1

Emran, M., Gispert, M., Pardini, G. 2012. Patterns of soil organic carbon glomalin and structural stability in abandoned Mediterranean terraced lands. European Journal of Soil Science 63, 637-649. https://doi.org/10.1111/j.1365-2389.2012.01493.X

Errea, M.P., Lasanta, T. 1994. Aportación de las tierras retiradas por la PAC a la extensificación del ovino en el “Campo de Zaragoza”. XIV Congreso Nacional de Geografía. Asociación de Geógrafos Españoles Universidad de Salamanca, pp. 217-219, Salamanca.

Errea Abad, M.P., Nadal-Romero, E., Lasanta, T. 2015. La complejidad de la cubierta vegetal en los campos abandonados del valle de Aísa (Pirineo Aragonés). Un análisis del papel de los tipos de campos. En: J. de 
la Riva, P. Ibarra, R. Montorio, M. Rodrigues, (Eds.), Análisis espacial y representación geográfica: innovación y aplicación. Universidad de Zaragoza - AGE, pp. 933-942.

Escribano-Ávila, G., Sanz-Pérez, V., Pías, B., Virgós, E., Escudero, A., Valladares, F. 2012. Colonization of abandoned land Juniperus thurifera is mediated by the interaction of a diverse dispersal assemblage and environmental heterogeneity. Plos One 7 (10), e46993. https://doi.org/10.1371/journal.pone.0046993

Estruch, C., Lozano, Y.M., Armas, C., Pugnaire, F.L. 2018. Plant community changes after land abandonment control $\mathrm{CO}_{2}$ balance in dry environment. Plant and Soil 425, 253-268. https://doi.org/10.1007/s11104018-3581-1

Faulkner, H. 1995. Gully erosion associated with the expansion of unterraced almond cultivation in the coastal Sierra de Lujar, S. Spain. Land Degradation \& Rehabilitation 6, 170-200. https://doi.org/10.1002/ldr.3400060306

Fedriani, J.M., Wiegard, T., Ayllon, D., Palomares, F., Suárez-Esteban, A., Grimm, V. 2017. Assisting seed dispersers to restore oldfields: An individual-based model of the interactions among badgers, foxes and Iberian pear trees. Journal of Applied Ecology 55, 600-611. https://doi.org/10.1111/1365-2664.13000

FEGA 2019. https://www.agronegocios.es/espana-cuenta-con-mas-de-232-mha-de-superficie-agricola-abandonaday-sin-aprovechamiento/

Feranec, J., Jaffrain, G., Soukup, T., Hazeu, G. 2010. Determining changes and flows in European landscapes 1990-2000 using Corine Land Cover data. Applied Geography 30 (1), 19-35. https://doi.org/10.1016/j.apgeog.2009.07.003

Fernández-Alés, R., Martín, A., Ortega, F., Alés, E.E. 1992. Recent changes in landscape structure and function in a Mediterranean region of SW Spain (1950-1984). Landscape Ecology 7, 3-18. https://doi.org/10.1007/BF02573953

Fernández-Giménez, M. 2015. "A shepherd has to invent" Poetic analysis of socio-ecological change in the cultural landscape of the central Spanish Pyrenees. Ecology and Society 20 (4), 29 http://doi.org./10.5751/ES-08054-200429

Ferrer, C., Ascaso, J., Maestro, M., Broca, A. 1995. Evolución de bancales no cultivados en función del grado de pastoreo en el Maestrazgo de la Comunidad Valenciana. XXXV Reunión Científica de la SEEP: pp. $197-$ 201, Tenerife.

Ferrer, C., Broca, A. 1999. El binomio agricultura-ganadería en los ecosistemas mediterráneos. Pastoreo frente a “desierto verde". Actas de la XXXIX Reunión de la S.E.E.P., pp. 309-334, Almería.

Fillat, F., García-González, R., Gómez, D., Reiné, R. 2008. Pastos del Pirineo. Diputación de Huesca, 319 pp., Huesca.

Fister, W., Ries, J.B. 2009. Wind erosion in the central Ebro Basin under changing land use management. Field experiments with a portable wind tunnel. Journal of Arid Environments 73, 996-1004. https://doi.org/10.1016/j.jaridenv.2009.05.006

Franco, J.A., Calatrava, J. 2010. Adopción y difusión de prácticas de no laboreo en el olivar de la provincia de Granada. Economía Agraria y Recursos Naturales 10 (1), 135-154. https://doi.org/10.7201/earn.2010.01.08

Gabarrón-Galeote, M.A., Trigalet, S., van Wesemael, B. 2015. Effect of land abandonment on soil organic carbon fractions along a Mediterranean precipitation gradient. Geoderma 249-250, 69-78. https://doi.org/10.1016/j.geoderma.2015.03.007

Gallart, F., Llorens, P. 1994. Papel de los cultivos de montaña y su abandono en la economía del agua. En: J.M. García-Ruiz, T. Lasanta (Eds.), Efectos geomorfológicos del abandono de tierras. Sociedad Española de Geomorfología: 43-55 pp., Zaragoza.

Gallart, F., Llorens, P. 2002. Water resources and environmental change in Spain. A key issue for sustainable catchment management. En: J.M. García-Ruiz, J.A.A. Jones, J. Arnáez (Eds.), Environmental change and water sustainability. IPE-CSIC, pp. 11-20, Zaragoza. 
Gallart, F., Llorens, P. 2004. Observations on land cover changes and water resources in the headwaters of the Ebro catchment, Iberian Peninsula. Physics and Chemistry of the Earth 29, 769-773. https://doi.org/10.1016/j.pce.2004.05.004

Gallart, F., Llorens, P., Latron, J, Regüés, D. 2002. Hydrological processes and their seasonal controls in a small Mediterranean mountain catchment in the Pyrenees. Hydrology and Earth System Science 6 (3), 527-537. https://doi.org/10.5194/hess-6-527-2002

Gallego Fernández, J.B., García-Mora, M.R., García-Novo, F. 2004. Vegetation dynamics of Mediterranean shrublands in former cultural landscape at Grazalema mountains, South Spain. Plant Ecology 172, 83-94. https://doi.org/10.1023/B:VEGE.0000026039.00969.7a

García-Llamas, P., Geijzendorffer, I.R., García-Nieto, A.P., Calvo, L., Suárez-Seoane, S., Cramer, W. 2019. Impact of land cover change on ecosystem services supply in mountain systems: a case study in the Cantabrian Mountains (NW of Spain). Regional Environmental Change 19, 529-542. https://doi.org/10.1007/s10113-018-1419-2

García-Novo, F. 2007. Los paisajes europeos en una cultura tecnológica. Cuadernos de la Sostenibilidad y Patrimonio Natural 11, 22-39.

García-Orenes, F., Morugán-Coronado, A., Zornoza, R., Scow, K. 2013. Changes in soil microbial community structure influenced by agricultural management practices in a Mediterranean agro-ecosystems. Plos One 8 (11), e80522. https://doi.org/10.1371/journal.pone.0080522

García-Orenes, F., Roldán, A., Mataix-Solera, J., Cerdà, A., Campoy, M., Arcenegui, V., Caravaca, F. 2012. Soil structural stability and erosion rates influenced by agricultural management practices in a semi-arid Mediterranean agro-ecosystem. Soil Use and Management 281, 571-579. https://doi.org/10.1111/j.14752743.2012.00451.x

García-Ortiz, E. 2006. Efecto de la estructura de la copa en la partición de lluvia de tres especies arbustivas en clima semiárido. Tesis Doctoral. Universidad de Almería: 404 pp., Almería.

García-Pausas, J., Casals, P., Camareto, I., Huguet, C., Thompson, R., Sebastià, M.T., Romanyà, J. 2007. Soil organic carbon storage grasslands of the Pyrenees: effects of climate and topography. Biochemistry 82, 279-289. https://doi.org/10.1007/s10533-007-9071-9

García-Ruiz, J.M. 1988. La evolución de la agricultura de montaña y sus efectos sobre la dinámica del paisaje. Revista de Estudios Agro-Sociales 146, 7-37.

García-Ruiz, J.M., Arnáez, J., Lasanta, T. 2017. Complejidad y diversidad en el paisaje de la montaña riojana: Una perspectiva general sobre su proceso de construcción y transformación. Berceo 173, 141-164.

García-Ruiz, J. M., Lana-Renault, N. 2011a. Una revisión de los efectos hidrológicos y erosivos del abandono de tierras en España. Geographicalia 59-60, 125-135. https://doi.org/10.26754/ojs_geoph/geoph.20115960827

García-Ruiz, J.M., Lana-Renault, N. 2011b. Hydrological and erosive consequences of farmland abandonment in Europe, with special reference to the Mediterranean region - A review. Agriculture, Ecosystems \& Environment 140, 317-338. https://doi.org/10.1016/j.agee.2011.01.003

García-Ruiz, J.M., Lana-Renault, N., Beguería, S., Lasanta, T., Regüés, D., Nadal-Romero, E., Serrano-Muela, P., López-Moreno, J.I., Alvera, B., Martí, C., Alatorre, L.C. 2010. From plot to regional scales: interactions of slope and catchment hydrological and geomorphic processes in the Spanish Pyrenees. Geomorphology 120, 248-257. https://doi.org/10.1016/j.geomorph.2010.03.038

García-Ruiz, J.M., Lasanta, T. 2018. El Pirineo aragonés como paisaje cultural. Pirineos 173, e038. https://doi.org/10.3989/pirineos.2018.173005

García-Ruiz, J.M., Lasanta, T., Nadal-Romero, E., Lana-Renault, N., Álvarez-Farizo, B. 2020. Rewilding and restoring cultural landscapes in Mediterranean mountains: Opportunities and challenges. Land Use Policy 99, 104850. https.//doi.org/10.1016/j.landusepol.2020.104850

García-Ruiz, J.M., Lasanta-Martínez, T. 1990. Land use changes in the Spanish Pyrenees. Mountain Research and Development 10 (3), 267-279. https://doi.org/10.2307/3673606 
García-Ruiz, J.M., Lasanta-Martínez, T. 1993. Land-use conflicts as a result of land-use change in the Central Spanish Pyrenees: a review. Mountain Research and Development 13 (3), 295-304. https://doi.org/10.2307/3673658

García-Ruiz, J.M., Lasanta, T., Sobrón, I. 1985. Estudio comparado de la evolución geomorfológica de campos abandonados y áreas repobladas de la Cuenca del Jubera. Comunidad Autónoma de La Rioja, 345 pp., Logroño.

García-Ruiz, J.M., Lasanta, T., Sobrón, I. 1988. Problemas de evolución geomorfológica de campos abandonados: el valle del Jubera (Sistema Ibérico). Zubía 6, 99-111.

García-Ruiz, J.M., López-Bermúdez, F. 2009. La erosión del suelo en España. Sociedad Española de Geomorfología. 441 pp., Zaragoza.

García-Ruiz, J.M., López-Moreno, J.I., Lasanta, T., Vicente-Serrano, S.M., González-Sampériz, P., ValeroGarcés, B.L., Sanjuán, Y., Beguería, S., Nadal-Romero, E., Lana-Renault, N., Gómez-Villar, A. 2015. Los efectos geoecológicos del Cambio Global en el Pirineo Central español. Una revisión a distintas escalas espaciales y temporales. Pirineos 170, e012. http://dx.doi.org/10.3989/Pirineos.2015.170005

García-Ruiz, J.M., López-Moreno, J.I., Vicente-Serrano, S.M., Lasanta, T., Beguería, S. 2011. Mediterranean water resources in a Global Change scenario. Earth Science Reviews 105 (3-4), 121-139. https://doi.org/10.1016/j.earscirev.2011.01.006

García-Ruiz, J.M., Regüés, D., Alvera, B., Lana-Renault, N., Serrano-Muela, P., Nadal-Romero, E., Latrón, J., Martí-Bono, C., Arnáez, J. 2008. Flood generation and sediment transport in experimental catchment affected by land use changes in the Central Pyrenees. Journal of Hydrology 356 (1-2), 245-260. https://doi.org/10.1016/j.jhydrol.2008.04.013

Gil-Tena, A., Brotons, L., Saura, S. 2009. Mediterranean forest dynamics and forest bird distribution changes in the late $20^{\text {th }}$ century. Global Change Biology 15, 474-485. https://doi.org/10.1111/j.13652486.2008.01730.x

Gisbert, J.M., Ibáñez, S., Pérez, M.A. 2005. Terrace Abandonment in the Ceta Valley, Alicante Province, Spain. Adv Geoecol. 36: 329-337.

Gispert, M., Pardini, G., Emran, A., Doni, S., Masciandaro, G. 2018. Seasonal evolution of soil matter, glomalin and enzymes and potential for $\mathrm{C}$ storage after land abandonment and renaturalization processes in soils of NE Spain. Catena 162, 402-413. https://doi.org/10.1016/j.catena.2017.10.019

Gómez-Aparicio, L., Zamora, R., Gómez, J.M., Hódar, J.A., Castro, J., Baraza, E. 2004. Applying plant facilitation to forest restoration: a meta-analysis of the use of shrubs as nurse plant. Ecological Applications 14, 11281138. https://doi.org/10.1890/03-5084

Gómez-García, D., Aguirre, A.J., Lizaur-Sukía, X. 2011. Recuperación del matorral tras el desbroce mecánico y quema en pastos de la Sierra de Aralar y Belate (Navarra). En: C. López-Carrasco, M.P. Rodríguez, A. San Miguel, F. Fernández, S. Roig, Eds.), Pastos, paisajes culturales entre tradición y nuevos paradigmas del siglo XXI SEEP, pp. 133-138, Toledo.

Gómez-Moreno, M.L. 1989. La montaña malagueña: estudio ambiental y evolución del paisaje. Servicio de Publicaciones de la Diputación Provincial de Málaga, 412 pp., Málaga.

Grigulis, K., Lavorel, S., Davies, I.D., Dossantos, A., Lloret, F., Vilà, M. 2005. Landscape - scale positive feedbacks between fire and expansion of the large tussock grass, Ampedelodesmos mauritanica in Catalan shrublands. Global Change Biology 11 (7), 1042-1053. https://doi.org/10.1111/j.13652486.2005.00980.x

Guerrero, M.M., Guirao, P., Martinez-Lluch, M.C., Tello, J.C., Lacasa, A. 2014. Soil fatigue and its specificity towards pepper plants in greenhouses. Spanish Journal of Agricultural Research 12 (3), 644-652. https://doi.org/10.5424/sjar/2014123-5701

Gutiérrez Teira, A. 1997. Cambios de uso del suelo y modelos de organización espacial de un paisaje de montaña mediterránea. El Valle de Lozoya (Sistema Central, Madrid). Tesis Doctoral, Universidad Autónoma de Madrid, 250 pp. + apéndices, Madrid. 
Haddaway, N.R., Styles, D., Pullin, A.S. 2014. Evidence on the environmental impacts of farmland abandonment in high altitude/mountain regions: A systematic map. Environmental Evidence 3 (1), art. no. 17. https://doi.org/10.1186/2047-2382-3-17

Heinimann, A., Mertz, O., Frolking, S., Christensen, A.E., Hurni, K., Sedano, F., Chini, L.P., Sahajpal, R., Hansen, M., Hurtt, G. 2017. A global view of shifting cultivation: Recent, current, and future extent. PLoS One 12. https://doi.org/10.1371/journal.pone.0184479

Heredia, A., Frutos, L.M., González-Hidalgo, J.C. 2013. Diferencias en la evolución del paisaje entre dos municipios prepirenaicos (Alquézar y Valle de Lierp) durante la segunda mitad del siglo XX. Pirineos 168, 77-101. https://doi.org/10.3989/Pirineos.2013.168005

Hernando, S., Anton, M., Sardà-Palomera, F., Bota, G., Gregory, R.D., Brotons, L. 2014. Indicators of the impact of land use changes using large-scale bird surveys: Land abandonment in a Mediterranean region. Ecological indicators 45, 235-344. https://doi.org/10.1016/j.ecolind.2014.04.011

Huang, J., Li, F., Xie, H. 2020. A scientometrics review on farmland abandonment research. Land 9, 263. https://doi.org/10.3390/land9080263

Jiménez-Olivenza, Y. 1989-90. Cambios ambientales que suceden al abandono de los campos de cultivo en terrazas: La acequia de Cachariche. Cuadernos Geográficos de la Universidad de Granada 18-19, 5-45.

Keenleyside, C., Tucker, G.M. 2010. Farmland abandonment in the EU: an assessment of trends and prospects. Report prepared for WWF. Institute for European Environmental Policy: 93 pp., London.

Komac, B., Kofi, S., Nuche, P., Escós, J., Alados, C.L. 2013. Modeling shrub encroachment in subalpine grasslands under different environmental and management scenarios. Journal of Environmental Management 121, 160-169. https://doi.org/10.1016/j.jenvman.2013.01.038

Kosmas, C., Danalatos, N. G., López Bermúdez, F., Romero Díaz, A. 2002. The effect of land use on soil erosion and land degradation under Mediterranean conditions. En: N.A. Geeson, C.J. Brandt, J.B. Thornes (Eds.), Mediterranean Desertification: a mosaic of processes and responses, pp. 58-70. Wiley, London.

Kozak, J., Ostapowicz, K., Szablowska-Midor, A., Widacki, W. 2004. Land abandonment in the Western Beskidy Mts and its environmental background. Ekologia (Bratislava) 23 (1), 116-26.

Kozak, J., Gimmi, U., Houet, T., Bollinger, J. 2017. Current practices and challenges for modelling past and future land use and land cover changes in mountains regions. Regional Environmental Change 17, 2187-2191. https://doi.org/10.1007/s10113-017-1217-2

Kuemmerle, T., Levers, C., Erb, K., Estel, S., Jepsen, M.R., Müller, D., Plutzar, C., Stürck, J., Verkerk, P.J, Verburg, P.H., 2016. Hotspots of land use change in Europe. Environment Research Letter 11, 064020. https://doi.org/10.1088/1748-9326/11/6/064020

Laiolo, P., Dondero, F., Ciliento, E., Rolando, A. 2004. Consequences of pastoral abandonment for the structure and diversity of the Alpine avifauna. Journal of Applied Ecology 41, 294-304. https://doi.org/10.1111/j.0021-8901.2004.00893.x

Lasanta, T. 1996. El proceso de marginación de tierras en España. En: T. Lasanta, J.M. García-Ruiz, J.M. (Eds.), Erosión y recuperación de tierras en áreas marginales. Instituto de Estudios Riojanos - Sociedad Española de Geomorfología, pp. 7-31, Logroño.

Lasanta, T. 2005. Gestion des champs abandonés pour le developpement de l'élevage extensif dans les Pyrénées centrales espagnoles. Sud-Ouest Européen 19, 109-119.

Lasanta, T. 2010. Pastoreo en áreas de montaña: Estrategias e impactos en el territorio. Estudios Geográficos 268, 203-233. https://doi.org/10.3989/estgeogr.0459

Lasanta, T. 2019. Active management against shrubland expansion: seeking a balance between conservation and exploitation in the mountains. Cuadernos de Investigación Geográfica 45 (2), 423-440. https://doi.org/10.18172/cig.3616

Lasanta, T., Arnáez, J., Nadal-Romero, E. 2019a. Soil degradation, restoration and management in abandoned and afforested lands. In: Advances in Chemical Pollution, Environmental Management and Protection. Volume 4, 71-117. https://doi.org/10.1016/bs.apmp.2019.07.002 
Lasanta, T., Arnáez, J., Pascual, N., Ruiz-Flaño, P., Errea, M.P., Lana-Renault, N. 2017a. Space-time process and drivers of land abandonment in Europe. Catena 149, 810-823. https://doi.org/10.1016/j.catena.2016.02.024

Lasanta, T., Arnáez, J., Ruiz-Flaño, P., Lana-Renault, N. 2013. Los bancales en las montañas españolas: un paisaje abandonado y un recurso potencial. Boletín de la Asociación de Geógrafos Españoles 63, 301-322.

Lasanta, T., Beguería, S., García-Ruiz, J.M. 2006. Geomorphic and hydrological effects of traditional shifting agriculture in a Mediterranean mountain, Central Spanish Pyrenees. Mountain Research and Development 26 (2), 146-152. https://doi.org/10.1659/0276-4741(2006)26[146:GAHEOT]2.0.CO;2

Lasanta, T., Cerdà, A. 2005. Long-term erosional responses after fire in the Central Spanish Pyrenees. 2. Solute release. Catena 60, 81-100. https://doi.org/10.1016/j.catena.2004.09.005

Lasanta, T., Errea, M.P., Nadal-Romero, E. 2017c. Traditional agrarian landscape in the Mediterranean mountains. A regional and local factors analysis in the Central Spanish Pyrenees. Land Degradation \& Development 28, 1626-1640. https://doi.org/10.1002/ldr.2695

Lasanta, T., García-Ruiz, J.M. 1996. Erosión y recuperación de tierras en áreas marginales. Instituto de Estudios Riojanos - Sociedad Española de Geomorfología, 211 pp., Logroño.

Lasanta, T., García-Ruiz, J.M., Pérez-Rontomé, M.C., Sancho, C. 2000. Runoff and sediment yield in a semi-arid environment: the effect of land management after farmland abandonment. Catena 38, 265-278. https://doi.org/10.1016/S0341-8162(99)00079-X

Lasanta, T., Nadal-Romero, E., Arnáez J. 2015. Managing abandoned farmland to control the impact of revegetation on the environment. The state of art in Europe. Environmental Science and Policy 52, 99-109 https://doi.org/10.1016/j.envsci.2015.05.012

Lasanta, T., Nadal-Romero, E., Errea, M.P. 2017b. The footprint of marginal agriculture in the Mediterranean mountain landscape: An analysis of the Central Spanish Pyrenees. Science of the Total Environment 599600, 1823-1836. https://doi.org/10.1016/j.scitotenv.2017.05.092

Lasanta, T., Nadal-Romero, E., García-Ruiz, J.M. 2019b. Clearing shrubland as a strategy to encourage extensive livestock farming in the Mediterranean mountains. Cuadernos de Investigación Geográfica 45 (2), 487 513. http://doi.org/10.18172/cig.3616

Lasanta, T., Nadal-Romero, E., Serrano-Muela, P. 2016. Los efectos de la revegetación en el medio natural y su percepción por la población vinculada de Cameros Viejo (Sistema Ibérico). Boletín de la Asociación de Geógrafos Españoles 70, 183-210. https://doi.org/10.21138/bage.2168

Lasanta, T., Sánchez-Navarrete, P., Medrano-Moreno, L.M., Khorchani, M., Nadal-Romero, E. 2020. Soil quality and soil organic carbon storage in agricultural abandoned fields: effects of revegetation processes in a Mediterranean mid-mountain area. Land Degradation \& Development. https://doi.org/10.1002/ldr.3655

Lasanta, T., Vicente-Serrano, S.M. 2007. Cambios en la cubierta vegetal en el Pirineo aragonés en los últimos 50 años. Pirineos 162, 125-154. https://doi.org/10.3989/pirineos.2007.v162.16.

Lasanta, T., Vicente-Serrano, S.M., Cuadrat, J.M. 2005. Mountain Mediterranean landscape evolution caused by the abandonment of traditional primary activities: a study of the Spanish Central Pyrenees. Applied Geography 25, 47-65. https://doi.org/10.1016/j.apgeog.2004.11.001

Lasanta Martínez, T. 1988a. The process of desertification of cultivated areas in the Central Spanish Pyrenees. Pirineos 132, 15-36.

Lasanta Martínez, T., 1988b. La evolución del espacio agrario en áreas de montaña: modelos en el Pirineo aragonés. Tesis Doctoral, Universidad de Zaragoza. Zaragoza.

Lasanta Martínez, T. 1989. Evolución reciente de la agricultura de montaña: el Pirineo Aragonés. Geoforma Ediciones: 220 pp., Logroño.

Lasanta-Martínez, T. 2014. El paisaje de campos abandonados en Camero Viejo (Sistema Ibérico, La Rioja). Instituto de Estudios Riojanos. Colección Ciencias de la Tierra 32, 305 pp., Logroño. 
Lasanta-Martínez, T., Arnáez, J., Ruiz-Flaño, P., Ortigosa, L. 1989. Evolución superficial del espacio cultivado en Camero Viejo (Sistema Ibérico) y su relación con algunos factores geoecológicos. Estudios Geográficos $197,553-572$.

Lesschen, J.P., Cammeraat, L.H., Kooijman, A.M., Wesamael, B. 2008a. Development of spatial heterogeneity in vegetation and soil properties after land abandonment in a semi-arid ecosystem. Journal of Arid Environments 72, 2082-2092. https://doi.org/10.1016/j.jaridenv.2008.06.006

Lesschen, J.P., Cammeraat, L.H., Nieman, T. 2008b: Erosion and terrace failure due to agricultural land abandonment in a semi-arid environment. Earth Surface Processes and Landforms 33, 1574-1584. https://doi.org/10.1002/esp.1676

Lesschen, J.P., Kok, K., Verburg, P.H., Cammeraat, L.H. 2007. Identification of vulnerable areas for gully erosion under different scenarios of land abandonment in Southeast Spain. Catena 71, 110-121. https://doi.org/10.1016/j.catena.2006.05.014

Llorens, P., Latron, J., Gallart, F. 1992. Analysis of the role of agricultural abandoned terraces on the hydrology and sediment dynamics in a small mountainous basin. Pirineos 139, 27-46. https://doi.org/10.3989/pirineos.1992.v139.180

Llorens, P., Poch, R., Latron, J., Gallart, F. 1997. Rainfall interception by a Pinus sylvestris forest patch overgrown in a Mediterranean mountainous abandoned area. I. Monitoring design and results down to the event scale. Journal of Hydrology 199, 331-345. https://doi.org/10.1016/S0022-1694(96)03334-3

Loepfe, L., Martínez-Vilalta, J., Oliveras, J., Piñol, J., Lloret, F. 2010. Feedbacks between fuel reduction and landscape homogenization determine fire regimes in three Mediterranean areas. Forest Ecology Management 259, 2366-2374. https://doi.org/10.1016/j.foreco.2010.03.009

López-Bao, J.V., González-Varo, J.P., Guitián, J. 2015. Mutialistic relationships under landscape change: carnivorous mammals and plants after 30 years of land abandonment. Basic and Applied Ecology 16, 151161. https://doi.org/10.1016/j.baae.2014.12.001

López-Bermúdez, F., Romero-Díaz, M.A. 1989. Piping erosion and badland development in South-east Spain. Catena Suppl. 14, 59-73.

López-Bermúdez, F., Romero-Díaz, M.A., Martínez-Fernández, J., Martínez-Fernández, J. 1996. The Ardal fieldsite: soil and vegetation cover. In: J. Brandt, J.B. Thornes (Eds.), Mediterranean Desertification and Land Use Wiley, 169-188 pp, Chichester.

López-Bermúdez, F., Torcal, L. 1986. Procesos de erosión en túnel (piping) en cuencas sedimentarias de Murcia (España). Estudio preliminar mediante difracción de rayos $\mathrm{X}$ y microscopio electrónico de barrido. Papeles de Geografia Física 11, 7-20.

López-Moreno, J.I., Vicente-Serrano, S.M., Morán-Tejeda, E., Zabalza, J., Lorenzo-Lacruz, J., García-Ruiz, J.M. 2011. Impact of climate evolution and land use changes on water yield in the Ebro basin. Hydrological Earth Systems Science 15, 311-322. https://doi.org/10.5194/hess-15-311-2011.

Lucas Espadas, A. 1996. Sanidad vegetal en Murcia. Agricultura 766, 398-400.

MacDonald, D., Crabtree, J.R., Wiesinger, G., Dax, T., Stamou, N., Fleury, P., Gutierrez Lazpita, J., Gibon, A. 2000. Agricultural abandonment in mountain areas of Europe: Environmental consequences and policy response. Journal of Environmental Management 59 (1), 47-69. https://doi.org/10.1006/jema.1999.0335

Maiso, E., Lasanta, T. 1990. El espacio agrario en el valle del Linares: características y utilización reciente. Berceo 118, 53-62.

Malo, J.E., Suárez, F. 1996. Las boñigas de vaca, el encespedado de Poa bulbosa y la diversidad en un pastizal de dehesa. Pastos 26 (1), 61-75.

Martín-López, B., Montes, C., Benayas, J. 2007. Influence of user characteristics on valuation of ecosystem services in Doñana Natural Protected Area (South-West, Spain). Environmental Conservation 34, $215-$ 224. https://doi.org/10.1017/S0376892907004067

Martínez Arnáiz, M. 2018. Paisaje y patrimonio en las Loras y Paramera de la Lora en Burgos y Palencia. El singular valor de un modelo de poblamiento subordinado al relieve. En: F. Molinero, J. Tort 
(coordinadores), Paisajes patrimoniales de España. Ministerio de Agricultura, Pesca y Alimentación, Ministerio para la Transición Ecológica, UAM ediciones, 1398-1421 pp., Madrid.

Martínez de Pisón, E. 2009. Los paisajes de los geógrafos. Geographicalia 55, 5-25.

Martínez-Fernández, J., López-Bermúdez, F., Martínez-Fernández, J., Romero-Díaz, M.A. 1995. Land use and soil-vegetation relationships in a Mediterranean ecosystem. Catena 25, 153-167. https://doi.org/10.1016/0341-8162(95)00007-F.

Martínez Hernández, C. 2018. El abandono de campos de cultivo en la Región de Murcia. Causas y consecuencias medioambientales y socioeconómicas. Tesis Doctoral Universidad de Murcia, Murcia.

Martínez-López, V., Zapata, V., de la Riva, P., Robledano, F. 2019. Uncovering mechanisms of bird seed dispersal in semiarid environments to helps to restore them. Ecosphere 10 (4), e02673. https://doi.org/10.1002/ecs2.2673

Meléndez-Pastor, I., Hernández, E.I., Navarro-Pedreño, J., Gómez, I. 2014. Socioeconomic factors influencing land cover changes in rural areas: The case of the Sierra de Albarracín (Spain). Applied Geography 52, 34-45. https://doi.org/10.1016/j.apgeog.2014.04.013

Molinillo, M., Lasanta, T., García-Ruiz, J.M. 1997. Managing degraded landscape after farmland abandonment in the Central Spanish Pyrenees. Environmental Management 21, 587-598. https://doi.org/10.1007/s002679900051

Montalvo, J., Casado, M.A., Levassor, C., Pineda, F.D. 1993. Species diversity patterns in Mediterranean grasslands. Journal of Vegetation Science 4, 213-222. https://doi.org/10.2307/3236107

Montserrat, P. 1964. Ecología del pasto (Ecología de los agrobiosistemas pastorales). Publicaciones del Centro Pirenaico de Biología Experimental 1 (2), 1-68.

Montserrat, P. 1976. Aspectos relacionados con la investigación en praticultura y ganadería. Anales del Instituto de Estudios Agropecuarios 2, 63-84.

Morán-Ordoñez. A., Bugter, R., Suárez-Seoane, S., de Luis, E., Calvo, L. 2013. Temporal changes in socioecological systems and their impact on ecosystems services at different governance scales: A case study of heathlands. Ecosystems 16, 765-782. https://doi.org/10.1007/s10021-013-9649-0

Morán-Tejeda, E., Ceballos-Barbancho, A., Llorente-Pinto, J.M. 2010. Hydrological response of Mediterranean headwaters to climate and land-cover changes: The mountains of Duero River basin (Central Spain). Global and Planetary Change 72, 39-49. https://doi.org/10.1016/j.gloplacha.2010.03.003

Moreno, M.V., Conedera, M., Chuvieco, E., Pezzatti, G.B. 2014. Fire regime changes and major driving forces in Spain from 1968 to 2010. Environmental Science Policy 37, 11-22. https://doi.org/10.1016/j.envsci.2013.08.005

Moreno-de-las-Heras, M., Lindenberger, F., Latron, J., Lana-Renault, N., Llorens, P., Arnáez, J., Romero-Díaz, A., Gallart, F. 2019. Hydro-geomorphological consequences of the abandonment of agricultural terraces in the Mediterranean region: Key controlling factors and landscape stability patterns. Geomorphology 333, 73-91. https://doi.org/10.1016/j.geomorph.2019.02.014

Moret, D., Pueyo, Y., Bueno, C.G., Alados, C.L. 2011. Hydro-physical responses of gypseous and non gypseous soils to livestock grazing in a semi-arid region of NE Spain. Agriculture Water Management 98, 1822 1827. https://doi.org/10.1016/j.agwat.2011.07.001

Nadal, J., Pélachs, A., Molina, D., Soriano, J.M. 2009. Soil fertility evolution and landscape dynamics in a Mediterranean area: a case study in the Sant Llorenç Natural Park (Barcelona, Ne Spain). Area 41 (2), 129-138. https://doi.org/10.1111/j.1475-4762.2008.00858.x

Nadal-Romero, E., Cammeraat, E., Pérez-Cardiel, E., Lasanta, T. 2016a. Effects of secondary succession and afforestation practices on soil properties after cropland abandonment in humid Mediterranean mountain areas. Agriculture, Ecosystems \& Environment 228, 91-100. https://doi.org/10.1016/j.agee.2016.05.003

Nadal-Romero, E., Cammeraat, E., Pérez-Cardiel, E., Lasanta, T. 2016b. How do soil organic carbon stocks change after cropland abandonment in Mediterranean humid mountain areas? Science of the Total Environment 566-567, 741-752. https://doi.org/10.1016/j.scitotenv.2016.05.031 
Nadal-Romero, E., Lasanta, T., García-Ruiz, J.M. 2013. Runoff and sediment yield from land under various uses in a Mediterranean mountain area: long term results from experimental station. Earth Surface Processes and Landforms 38 (4), 346-355. https://doi.org/10.1002/esp.3281

Nadal-Romero, E., Otal-Laín, I., Lasanta, T., Sánchez-Navarrete, P., Errea, P., Cammeraat, E. 2018. Woody encroachment and soil stocks in subalpine areas in the Central Spanish Pyrenees. Science of the Total Environment 636, 727-736. https://doi.org/10.1016/j.scitotenv.2018.04.324

Nagendra, H., Southworth, J., Tucker, C. 2003. Accessibility as a determinant of landscape transformation in western Honduras: linking pattern and process. Landscape Ecology 18 (2), 141-58. https://doi.org/10.1023/A:1024430026953

Navarro, L.M., Pereira, H.M. 2012. Rewilding abandoned landscape in Europe. Ecosystems 15 (6), 900-912. https://doi.org/10.1007/s10021-012-9558-7

Navas, A., Machín, J., Soto, J. 2005. Assessing soil erosion in a Pyrenean mountain catchment using GIS and fallout 137Cs. Agriculture, Ecosystems \& Environment 105, 493-506. https://doi.org/10.1016/j.agee.2004.07.005

Nogués-Bravo, D. 2006. Assessing the effects of environmental and anthropogenic factors in land cover diversity in a Mediterranean mountain environment. Area 38 (4), 432-444. https://doi.org/10.1111/j.14754762.2006.00709.x

Ocaña, M.C., Gómez-Moreno, M.L., Blanco-Sepúlveda, R. 2004. Las vistas como recurso territorial. Ensayo de evaluación del paisaje visual mediante un SIG. Imalgraf, 172 pp., Málaga.

Onega-López, F.J., Puppin de Oliveira, J.A., Crecente-Maseda, R. 2010. Planning innovations in land management and governance in fragmented rural areas: two examples from Galicia (Spain). European Planning Studies 18 (5). https://doi.org/10.1080/09654311003594067

Oserín Elorza, M. 2007. Cambios en la gestión del territorio en una montaña media mediterránea y sus impactos mediambientales. Hacia un nuevo paisaje (altos valles del Iregua, Leza, Jubera y Cidacos, Sistema Ibérico Noroccidental). Tesis Doctoral, Universidad de Zaragoza, Zaragoza.

Otero, I., Boada, M., Badía, A., Pla, E., Vayreda, J., Sabaté, S., Gracia, C.A., Peñuelas, J. 2011. Loss of water availability and stream biodiversity under land abandonment and climate change in a Mediterranean catchment (Olzinelles, N.E., Spain). Land Use Policy 28, 207-218. https://doi.org/10.1016/j.landusepol.2010.06.002

Otero, I., Marull, J., Tello, E., Diana, G.L., Pons, M., Coll, F., Boada, M. 2015. Land abandonment, landscape, and biodiversity: questioning the restorative character of the forest transition in the Mediterranean. Ecology and Society 20 (2). https://doi.org/10.5751/ES-07378-200207

Otto, R., Kiüsi, B.O., Burga, C.A., Fernández-Palacios, J.M. 2006. Old-field succession along a precipitation gradient in the semi-arid coastal region of Tenerife. Journal of Arid Environments 65 (1), 156-178. https://doi.org/10.1016/j.jaridenv.2005.07.005

Padilla-Blanco, M.A. 1998. Colonización vegetal en campos abandonados de la provincial de Alicante. Servicio de Publicaciones de la Universidad de Alicante, 365 pp + anexo cartográfico, Murcia.

Pallarés Bou, J. 1994. Procesos que conducen a la rotura de muros en terrazas de cultivo (Norte de Castellón). Cuaternario y Geomorfología 8 (3-4), 23-36.

Pardini, G., Aringheri, R., Plana, F., Gallart, F. 1991. Soil properties relevant to land degradation in abandoned sloping fields in Aísa Valley, Central Pyrenees (Spain). Pirineos 137, 79-93. https://doi.org/10.3989/pirineos.1991.v137.196

Pardini, G., Gispert, M. 2005. Impact of land abandonment on water erosion in soils of the Eastern Iberian Peninsula. Agrochimica 50 (1-2),13-24.

Pausas, J.G. 1999. Response of plant functional types to changes in the fire regime in Mediterranean ecosystems: A simulation approach. Journal of Vegetation Science 10, 717-772. https://doi.org/10.2307/3237086

Pausas, J.G., Fernández-Muñoz, S. 2012. Fire regime changes in the Western Mediterranean Basin: from fuellimited to drought-driven fire regime. Climatic Change 110, 215-226. https://doi.org/10.1007/s10584011-0060-6 
Peco, B., Sánchez, A.M., Azcárate, F.M. 2006. Abandonment in grazing systems. Consequences for vegetation and soil. Agriculture, Ecosystems \& Environment $113 \quad$ (1-4), 284-294. https://doi.org/10.1016/j.agee.2005.09.017

Pedroli, B., Pinto-Correia, T., Cornish, P. 2006. Landscape -what's in in? Trends in European landscape science and priority themes for concerted research. Landscape Ecology 21, 421-430. https://doi.org/10.1007/s10980-005-5204-5

Peña-Angulo, D., Khorchani, M., Errea, P., Lasanta, T., Martínez-Arnáiz, M., Nadal-Romero, E. 2019. Factors explaining the diversity of land cover in abandoned fields in a Mediterranean mountain. Catena 181, 104064. https://doi.org/10.1016/j.catena.2019.05.010

Pereira, E., Queiroz, C., Pereira, H.M., Vicente, 1. 2005. Ecosystem services and human well-being: a participatory study in a mountain community in Portugal. Ecology and Society 10 (2), 14. https://doi.org/10.5751/ES01353-100214

Pérez, T., Díaz-Fierros, F. 1988. Resistencia del suelo y susceptibilidad a la compactación en terrenos de monte sometidos a pastoreo. Anales de Edafología y Agrobiología 47 (3-4), 547-560.

Pérez-Albert, Y. 1995. Implementación de un SIG para el estudio de las tierras de cultivo abandonadas en las montañas de Prades. En: Cambios regionales a finales del siglo XX. Asociación de Geógrafos Españoles - Universidad de Salamanca, 442-445 pp., Salamanca.

Pérez-Carazo, P. 2008. Santa María de Herce y su abadengo en la Edad Media. Universidad de La Rioja-Instituto de Estudios Riojanos, Logroño.

Pérez-Morales, A. 2008. Rentabilidad socioeconómica de los cultivos con riego localizado en la Región de Murcia. En: J.M. Gómez Espín, R. Martínez Medina (Coord.), Los espacios rurales españoles en el nuevo siglo: Actas XIV Coloquio de Geografía Rural, Murcia, pp. 181-198.

Perino, A., Pereira, H.M., Navarro, L.M., Fernández, N., Bullock, J.M., Ceausu, S., Cortés-Avizanda, A., Van Klint, R., Kuemmerle, T., Lomba, A., Pe'er, G., Plieninger, T., Rey-Benayas, J.M., Sandom, C.J., Svenning, J.C., Wheeler, H.C. 2019. Rewilding complex ecosystems. Science 364, https://doi.org/10.1126/science.aav5570

Pettorelli, N., Barlow, J., Stephens, P.A., Durant, S.M., Connor, B., Schulte to Buhne, H., Sandon, C.J., Wentworth, J., du Toit, J.T. 2017. Making rewilding fit for policy. Journal Applied Ecology 55 (3), 11141125. https://doi.org/10.1111/1365-2664.13082

Pineda, F.D., Nicolás, J.P., Ruiz, M., Peco, B., Bernáldez, F.G. 1981. Succession, diversité et niche écologique dans les pâturages du centre de la Peninsule Iberique. Vegetatio 47, 267-277. https://doi.org/10.1007/97894-009-7991-8_26

Pointereau, P., Coulon, F., Girard, P., Lambotte, M., Stuczynski, T., Sánchez Ortega, V., Del Río, A. 2008. Analysis of farmland abandonment and the extent and location of agricultural areas that are actually abandoned or are in risk to be abandoned. JRC Scientific and Technical Reports (EUR 23411). http://publicationsjrceceuropaeu/repository/handle/111111111/166

Poyatos, R., Latron, J., Llorens, P. 2003. Land use and land cover change after agricultural abandonment: The case of a Mediterranean Mountain area (Catalan Pre-Pyrenees). Mountain Research and Development 23 (4), 52-58. https://doi.org/10.1659/0276-4741(2003)023[0362:LUALCC]2.0.CO;2

Pueyo, Y., Beguería, S. 2007. Modelling the rate of secondary succession after farmland abandonment in a Mediterranean mountain area. Landscape and Urban Planning 83, 245-254. https://doi.org/10.1016/j.landurbplan.2007.04.008

Pugnaire, F.I., Luque, M.T., Armas, C., Gutiérrez, L. 2006. Colonization processes in semi-arid Mediterranean old-fields. Journal of Arid Environments 65 (4), 591-603. https://doi.org/10.1016/j.jaridenv.2005.10.002

Puigdefábregas, J. 2005. The role of vegetation patterns in structuring runoff and sediment fluxes in dryland. Earth Surface Processes and Landforms 30: 133-147. https://doi.org/10.1002/esp.1181

Puigdefábregas, J., Fillat, F. 1986. Ecological adaptation of traditional land-uses in the Spanish Pyrenees. Mountain Research and Development 6 (1), 63-72. https://doi.org/10.2307/3673341 
Ramankutty, N., Foley, J.A. 1999. Estimating historical changes in global land cover: Cropland from 1700 to 1992. Global Biogeochemical Cycles 13, 997-1027. https://doi.org/10.1029/1999GB900046

Regos, A., Dominguez, J., Gil-Tena, A., Brotons, L., Ninyerola, M., Pons, X. 2016. Rural abandoned landscapes and bird assemblages: winners and losers in the rewilding of a marginal mountain area (NW Spain). Regional Environmental Change 16 (1), 199-2121. https://doi.org/10.1007/s10113-014-0740-7

Reiné, R., Barrantes, O., Chocarro, C., Juárez, A., Broca, A., Maestro, M., Ferrer, C. 2014. Pyrenean meadows in Natura 2000 network: grass production and plant biodiversity conservation. Spanish Journal of Agricultural Research 12 (1), 61-77. https://doi.org/10.5424/sjar/2014121-4617

Rescia, A.J., Pons, A., Lomba, I., Esteban, C., Dover, J.W. 2008. Reformulating the social-ecological systems in a cultural rural mountain landscape in the Picos de Europa region (Northern Spain). Landscape and Urban Planning 88, 23-33. https://doi.org/10.1016/j.landurbplan.2008.08.001

Rey-Benayas, J.M., Galván, I., Carrascal, L.M. 2010. Differential effects of vegetation restoration in Mediterranean abandoned cropland by secondary succession and pine plantations on bird assemblages. Forest Ecology and Management 260, 87-95. https://doi.org/10.1016/j.foreco.2010.04.004

Rey Benayas, J.M., Martins, A., Nicolau, J.M., Schulz, J. 2007. Abandonment of agricultural land: an overview of drivers and consequences, CAB Reviews: Perspectives in Agriculture, Veterinary Science, Nutrition and Natural Resources 2, No. 57. https://doi.org/10.1079/PAVSNNR20072057

Rey-Benayas, J.M., Martínez-Baroja, L., Pérez-Camacho, L., Villar-Salvador, P., Holl, K.D. 2015. Predation and aridity slow down the spread of 21-year-old planted Woodland islets in restored Mediterranean farmland. New Forests 46, 841-853. https://doi.org/10.1007/s11056-015-9490-8

Rey-Benayas, J.M., Navarro, J., Espigares, T., Nicolau, J.M., Zabala, M.A. 2005. Effects of artificial shading and weed mowing in reforestation of Mediterranean abandoned cropland with contrasting Quercus species. Forest Ecology and Management 212, 302-314. https://doi.org/10.1016/j.foreco.2005.03.032

Riedel, J.L., Bernués, A., Casasús, I., 2013. Livestock grazing impacts on herbage and shrub dynamics in a Mediterranean Natural Park. Rangeland Ecology Management 66, 224-233. https://doi.org/10.2111/REM-D-11-00196.1

Riedel, J.L., Casasús, I., Bernués, A. 2007. Sheep farming intensification and utilization of natural resources in a Mediterranean pastoral agro-ecosystem. Livestock Science 111, 153-163. https://doi.org/10.1016/j.livsci.2006.12.013

Ries, J.B., Langer, M., Rehberg. C. 2000. Experimental investigations on water and wind erosion on abandoned fields and arable land in the central Ebro Basin, Aragon/Spain. Zeitschrift für Geomorphology 121, 91108.

Ries, J.B., Seeger, M., Marzolff, I. 1997. El Proyecto EPRODESER. Cambios de uso del suelo y morfodinámica en el Nordeste de España. Geographicalia 35, 205-225. https://doi.org/10.26754/ojs_geoph/geoph.1997351700

Robledano Aymerich, F., Zapata Pérez, V.M., Martínez López, V., García Meseguer, A.J., García Castellanos, F.A., Zamora López, A., Pérez Navarro, M.A. 2016. Indicadores de biodiversidad en campos abandonados: flora y fauna. En: A. Romero Díaz (Coord.) Abandono de cultivos en la Región de Murcia. Consecuencias Ecogeomorfológicas. Servicio de Publicaciones de la Universidad de Murcia, 111-137pp., Murcia.

Rodríguez Aizpeolea, J., Pérez Badía, R., Cerdà, A. 1991. Colonización vegetal y producción de escorrentía en bancales abandonados: Vall de Gallinera, Alacant. Cuaternario y Geomorfología 5, 119-129.

Rodríguez-Gutiérrez, F. 1989. La organización agraria de la montaña central asturiana. Consejería de Educación, Cultura y Deportes, Principado de Asturias, 636 pp., Oviedo.

Rodríguez-Martín, J.A., Álvaro-Fuentes, J., Gabriel, J.L., Gutiérrez, C., Nanos, N., Escuer, M., Ramos-Miras, J.J., Gil, C., Martin-Lammerding, D., Boluda, R. 2019. Soil organic carbon stock on the Majorca island: temporal change in agricultural soil over the last 10 years. Catena 181, 104087 https://doi.org/10.1016/j.catena.2019.104087 
Rodríguez-Merino, E., Errea, M.P., Lasanta, T. 1998. Valoración de los recursos pastorales de campos abandonados de Cameros Viejo (Sistema Ibérico riojano). Cuadernos de Investigación Geográfica 24, 69-87. https://doi.org/10.18172/cig.1027

Romero-Díaz, A. 2003. Influencia de la litología en las consecuencias del abandono de tierras de cultivo en medios mediterráneos semiáridos. Papeles de Geografía 38, 151-165.

Romero-Díaz, A. 2016. Estado de la cuestión de los estudios de abandono. En: A. Romero-Díaz (Coord.), Abandono de cultivos en la Región de Murcia. Consecuencias ecogeomorfológicas. Servicio de Publicaciones de la Universidad de Murcia, 19-39 pp., Murcia.

Romero-Díaz, A., Marín-Sanleandro, P., Sánchez-Soriano, A., Belmonte-Serrato, F., Faulkner, H. 2007. The causes of piping in a set of abandoned agricultural terraces in Southeast Spain. Catena 69, 282-293. https://doi.org/10.1016/j.catena.2006.07.008

Romero Díaz, A., Martínez Hernández, C., Belmonte Serrato, F. 2016. Procesos de erosión en áreas abandonadas de la Región de Murcia. En: A. Romero Díaz (Coord.), Abandono de cultivos en la Región de Murcia. Consecuencias Ecogeomorfológicas. Servicio de Publicaciones de la Universidad de Murcia, 85-110 pp., Murcia.

Romero Díaz, A., Ruiz Sinoga, J.D., Robledano-Aymerich, F., Brevik, E.C., Cerdà, A. 2017. Ecosystem responses to land abandonment in Western Mediterranean Mountains. Catena 149, 824-835. https://doi.org/10.1016/j.catena.2016.08.013

Romero-Martín, L., Ruiz-Flaño, P., Hernández-Calvento, L. 2004. Diagnóstico y calidad para la conservación de los espacios agrícolas abancalados. Propuesta metodológica para la cuenca del Guiniguada (Gran Canaria, Islas Canarias). Geographicalia 45, 113-127. https://doi.org/10.26754/ojs_geoph/geoph.2004451348

Rubio Balducci, P. 2019. Natural vegetation succession after land abandonment: a soil carbon comparison in the Central Spanish Pyrenees. Tesis-Master, Universidad de Amsterdam, 53 pp., Amsterdam.

Ruecker, G., Schad, P., Alcubilla, M.M., Ferrer, C. 1998. Natural regeneration of degraded soils and site changes on abandoned agricultural terraces in Mediterranean Spain. Land Degradation \& Development 9, 179188. https://doi.org/10.1002/(SICI)1099-145X(199803/04)9:2<179::AID-LDR276>3.0.CO;2-R

Ruiz-Flaño, P. 1993. Procesos de erosión en campos abandonados del Pirineo. Geoforma Ediciones: 191 pp., Logroño.

Ruiz-Flaño, P., García-Ruiz, J.M., Ortigosa, L. 1992. Geomorphological evolution of farmland abandonment fields. A case study in the Central Pyrenees. Catena 19, 301-308. https://doi.org/10.1016/03418162(92)90004-U

Ruiz-Flaño, P., Lasanta, T., Arnáez, J., Ortigosa, L., Oserín, M. 2010. El proceso de abandono del espacio agrícola en Cameros. En: T. Lasanta, J. Arnáez (Eds.), Gestión, usos el suelo y paisaje en Cameros. Sistema Ibérico, La Rioja. Universidad de La Rioja - Instituto de Estudios Riojanos, 109-126 pp., Logroño.

Ruiz-Sinoga, J.D., Martínez-Murillo, J.F. 2009. Hydrological response of abandoned agricultural soils along a climatological gradient on metamorphic parent material in southern Spain. Earth Surface Processes and Landforms 34, 2047-2056. https://doi.org/10.1002/esp.1890

Ruiz-Sinoga, J.D., Martínez-Murillo, J.F., Gabarrón-Galeote, M.A., García-Marín, R. 2011. The effects of soil moisture variability on the vegetation pattern in Mediterranean abandoned fields (Southern Spain). Catena 85, 1-11. https://doi.org/10.1016/j.catena.2010.11.004

Salaverri, L., Guitián, J., Munilla, I., Sobral, M. 2019. Bird richness decreases with the abandonment of agriculture in a rural region of SW Europe. Regional Environmental Change 19 (1), 245-250. https://doi.org/10.1007/s10113-018-1375-X

Sayadi, S., González-Roa, M.C., Calatrava-Requena, J. 2009. Public preferences for landscape features: The case of agricultural landscape in mountainous Mediterranean areas. Land Use Policy 26, 334-344. https://doi.org/10.1016/j.landusepol.2008.04.003

Sánchez Soriano, A. 2012. Procesos de erosión subsuperficiales (piping) en la Región de Murcia. Tesis Doctoral, Universidad de Murcia, Murcia. 
Santa Regina, I. 1995. Ciclos biogeoquímicos en bosques de la sierra de Béjar (Salamanca). Retorno de bioelementos por medio de agua de lluvia. Pirineos 145-146, 65-80. https://doi.org/10.3989/pirineos.1995.v145-146.147

Seeger, M., Beguería, S. 2003. La respuesta hidrológica en dos cuencas experimentales con diferentes usos del suelo en el Pirineo aragonés. En: I. Marzolff, J. Ries, J. de la Riva, M. Seeger (Eds.), El cambio en el uso del suelo y la degradación del territorio en España. Universität Frankfurt am Main y Universidad de Zaragoza: 203-221 pp., Zaragoza.

Segura, C., Jiménez, M.N., Nieto, O., Navarro, F.B., Fernández-Ordoño, E. 2006. Changes in soil organic carbon over 20 years after afforestation in semiarid SE Spain. Forest Ecology and Management 381, 268-278. https://doi.org/10.1016/j.foreco.2016.09.035

Serrano-Muela, P., Lana-Renault, N., Nadal-Romero, E., Regüés, D., Latron, J., Martí-Bono, C., García-Ruiz, J.M. 2008. Forest and their hydrological influence in Mediterranean mountains. The case of the Central Spanish Pyrenees. Mountain Research and Development 23 (3-4), 279-285. https://doi.org/10.1659/mrd.0876

Serrano-Muela, P., Regüés, D., Nadal-Romero, E., 2012. Trascolación y escorrentía cortical en un bosque de montaña media mediterránea. Un estudio reciente en el Pirineo central español. Cuaternario y Geomorfología 26 (1), 49-72.

Shakesby, R.A. 2011. Post-wildfire soil erosion in the Mediterranean: Review and future research directions. Earth-Science Reviews 105, 71-100. https://doi.org/10.1016/j.earscirev.2011.01.001

Solé-Benet, A., Lázaro, R., Domingo, F., Canton, Y., Puigdefábregas, J. 2010. Why most agricultural terraces in steep slopes in semiarid SE Spain remain well preserved since their abandonment 50 years ago? Pirineos 165, 215-235. https://doi.org/10.3989/Pirineos.2010.165011

Strijker, D. 2005. Marginal lands in Europe -causes of decline. Basic Applied Ecology 6, 99-106. https://doi.org/10.1016/j.baae.2005.01.001

Suárez-Seoane, S., Osborne, P.E., Baudry, J. 2002. Responses of birds of different biogeographic origins and habitat requirements to agricultural land abandonment in Northern Spain. Biological Conservation 105, 333-344. https://doi.org/10.1016/S0006-3207(01)00213-0

Tarazona, T., Santa Regina, I., Calvo, R. 1996. Interception, through fall and streamflow in two forest of the "Sierra de la Demanda" in the province of Burgos. Pirineos 147-148, 27-40. https://doi.org/10.3989/pirineos.1996.v147-148.135

Tárraga, R., Calvo, L., Taboada, A., García-Tejero, S., Marcos, E. 2009. Abandonment and management in Spanish dehesa systems: Effects on soil features and plant species richness and composition. Forest Ecology and Management 257, 731-738. https://doi.org/10.1016/j.foreco.2008.10.004

Tella, J.L., Forero, M.C., Hiraldo, F., Donázar, J.A. 1998. Conflicts between Lesser Kestrel conservation and European Agricultural Policies as identified by habitat use analysis. Conservation Biology 12 (3), 593604. https://doi.org/10.1046/j.1523-1739.1998.96288.x

Terres, J.M., Scacchiafichia, L.N., Wania, A., Ambar, M., Anguiano, E., Buckwell, A., Coppola, A., Gochtf, A., Källström, H.N., Pointereau, P., Strijker, D., Visek, L., Vranken, L., Zoben, A. 2015. Farmland abandonment in Europe: identification of drivers and indicators, and development of a composite indicator risk. Land Use Policy 49, 20-34. https://doi.org/10.1016/j.landusepol.2015.06.009

Tobarra González, M.A. 2002. Agua y plan hidrológico en la Región de Murcia. Papeles de Geografia 36, $185-$ 206.

Trigalet, S., Gabarrón-Galeote, M.A., Van Oost, K., van Wesemael, B. 2016. Changes in soil organic carbon pools along a chrono sequence of land abandonment in southern Spain. Geoderma 268, 14-21. https://doi.org/10.1016/j.geoderma.2016.01.014

Ustaoglu, E., Collier, M.J. 2018. Farmland abandonment in Europe: an overview of drivers, consequences, and assessment of the sustainability implications. Environmental Reviews 26 (4), 396-416. https://doi.org/10.1139/er-2018-0001 
Valdelvira, A., Balcells, E. 1986. La pardina de Esporret como unidad empresarial de las sierras prepirenaicas meridionales. Pirineos 128, 79-118.

Vallecillo, S., Brotons, L., Herrando, S. 2008. Assessing the response of open-habitat bird species to landscape changes in Mediterranean mosaics. Biodiversity Conservation 17, 103-119. https://doi.org/10.1007/s10531-007-9233-z

Van Leeuween. C.C.E., Cammeraat, E.L.H., de Vente, J., Boix-Fayos, C. 2019. The evolution of soil conservation policies targeting land abandonment and soil erosion in Spain: A review. Land Use Policy 83, 174-186. https://doi.org/10.1016/j.landusepol.2019.01.018

Vera, F., Romero, J. 1994. Impacto ambiental de la actividad agraria. Agricultura y Sociedad 71, 153-181.

Verdú, M., García-Fayos, P. 1996. Nucleation processes in a Mediterranean bird-dispersion plant. Functional Ecology 10, 275-280. https://doi.org/10.2307/2389853

Verdú, M, García-Fayos, P. 1998. Old-field colonization by Dapnhe gnidium: distribution and spatial dependence at different scales. Journal of Vegetation Science 9, 713-718. https://doi.org/10.2307/3237289

Vicente-Serrano, S., Beguería, S., Lasanta, T. 2006. Diversidad espacial de la actividad vegetal en campos abandonados del Pirineo Central español: análisis de los procesos de sucesión secundaria mediante imágenes Landsat (1984-2001). Pirineos 161, 54-84. https://doi.org/10.3989/pirineos.2006.v161.3

Vicente-Serrano, S.M., Lasanta, T., Cuadrat, J.M. 2005. Analysis of the spatial and temporal evolution of vegetation cover in the Spanish Central Pyrenees. The role of human management. Environmental Management 34 (6), 802-818. https://doi.org/10.1007/s00267-003-0022-5

Vila-Subirós, J., Ribas-Palom, A., Varga-Linde, D., Llausàs-Pascual, A. 2009. Medio siglo de cambios paisajísticos en la montaña mediterránea. Percepción y valoración social del paisaje en la alta Garrotxa (Girona). Pirineos 164, 69-92. https://doi.org/10.3989/pirineos.2009.v164.30

Violant i Simorra, R. 1949. El Pirineo español. Editorial Plus Ultra, 675 pp., Madrid.

Viviroli, D., Weingartner, R., Messerli, B. 2003. Assessing the hydrological significance of the World's mountains. Mountains Research and Development 23, 32-40. https://doi.org/10.1659/02764741(2003)023[0032:ATHSOT]2.0.CO;2

Zapata, V.M., Robledano Aymerich, F., Martínez López, V. 2016. Dinámica recolonizadora de la vegetación en campos abandonados de la Región de Murcia. En: A. Romero Díaz (Coord.), Abandono de cultivos en la Región de Murcia. Consecuencias Ecogeomorfológicas. Servicio de Publicaciones de la Universidad de Murcia, 139-159pp., Murcia.

Zornoza, R., Guerrero, C., Mataix-Solera, J., Srew, K.M., Arcenegui, V., Mataix-Beneyto, J. 2009. Changes in soil microbial community structure following the abandonment of agricultural terraces in mountain areas of Eastern Spain. Applied Soil Ecology 42, 315-323. https://doi.org/10.1016/j.apsoil.2009.05.011

Zozaya, E., Brotons, L., Saura, S. 2002. Recent fire history and connectivity patterns determine bird species distribution dynamics in landscape dominated by land abandonment. Landscape Ecology 27, 171-184. https://doi.org/10.1007/s10980-011-9695-y 